\title{
Identification and Quantification of Proteins from Preparative Partition Chromatography and Peptides from Organic Extraction of Fetal Versus Adult Bovine Serum using Nano-Spray-LC-ESI-MS/MS
}

\author{
by \\ Zhuo Zhen Chen \\ B.Sc., Ryerson University, 2017 \\ A thesis submitted to Ryerson University \\ in partial fulfillment of the requirements for the degree of \\ Master of Science \\ in the program of Molecular Science
}

Toronto, Ontario, Canada

(C) Zhuo Zhen Chen, 2019 


\section{AUTHOR'S DECLARATION FOR ELECTRONIC SUBMISSION OF A THESIS}

I hereby declare that I am the sole author of this thesis. This is a true copy of the thesis, including any required final revisions, as accepted by my examiners.

I authorize Ryerson University to lend this thesis to other institutions or individuals for the purpose of scholarly research

I further authorize Ryerson University to reproduce this thesis by photocopying or by other means, in total or in part, at the request of other institutions or individuals for the purpose of scholarly research.

I understand that my thesis may be made electronically available to the public. 


\title{
Identification and Quantification of Proteins from Preparative Partition Chromatography and Peptides from Organic Extraction of Fetal Versus Adult Bovine Serum using Nano-Spray-LC-ESI-MS/MS
}

\author{
Zhuo Zhen Chen \\ Master of Science, Molecular Science, Ryerson University, 2019
}

\begin{abstract}
Blood proteins communicate with many different cells, tissue and organs; perform key functions in the immune system and may be of particular biological complexity. One of the most widely used blood products in the laboratory is fetal bovine serum for cell culture. There are ethical and practical concerns regarding the use of fetal serum from animals and alternative serum-free replacements have been attempted using platelet lysates. Previous biochemical experiments have shown that FBS apparently contained factors such as alpha-feto protein (AFP) and insulin-like growth factors that may support the indefinite cell growth and division of certain cell lines. It is presumed that a set of as yet undefined growth factors transform cells growth resulting in rapid proliferation. Cultured Raw cells 264.7 in adult bovine serum multiplied slowly and differentiated into elongated cells with a dendritic shape, which died after the first few generations. On the contrary, in fetal bovine serum, cultured cells multiplied rapidly and formed many smaller cells with a rounded shape through many cell passages. Three independent batches of fetal bovine serum were tested on Raw cells 264.7 macrophages to confirm that they supported cell growth in culture compared to three independent batches of adult bovine serum. The intact proteins of each serum sample were separated by partition chromatography into 16 fractions with an increasing step gradient of salts over quaternary amine resin (proteomics). The endogenous peptides were precipitated with $90 \%$ of acetonitrile and extracted into 10 fractions
\end{abstract}


with a decreasing step gradient of acetonitrile in water (peptidomics). Trypsin digested intact proteins and endogenous peptides were then analyzed on a fresh C18 nano-HPLC column with random and independent sampling by LC-ESI-MS/MS. The fractionated mass spectra were identified with SEQUEST and X!TANDEM algorithms. Redundant use of MS/MS spectra were flirted out with the SQL Server system and the R statistical analysis system was used to perform Chi Square $\left(\mathrm{X}^{2}\right)$ analysis of frequency counts and ANOVA of the $\log _{10}$ precursor intensity results. Alpha-feto protein, fetal albumin, insulin, insulin like growth factors, platelet derived growth factors and proteins associated with HRAS/AKT growth pathway at the level of ligand, receptors, receptor associated enzyme and nucleic acid binding proteins including transcription factors were observed to be specifically enriched in fetal serum. 


\section{ACKNOWLEGMENTS}

I would like to thank my supervisor Dr. John G. Marshall for giving me this opportunity to take my first steps into scientific research and allowing me to work in his lab. Thank you for your patience, understanding, and seeing potential in me as a scientist. I would also like to thank my committee members, Dr. Gupta and Dr. Sabatinos, who have taken their time to help me and provide useful suggestions for this project. Last but not least, I would like to thank my family and friends; I would not have been able to come this far without your support and understanding. 


\section{TABLE OF CONTENTS}

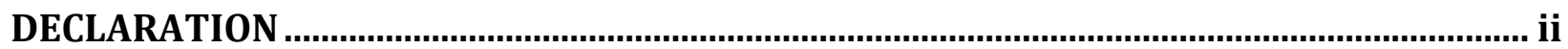

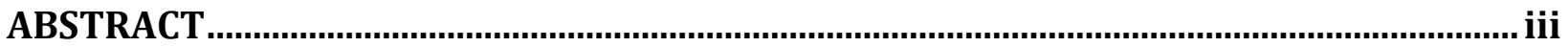

ACKNOWLEGMENTS

LIST OF SELECTED ABBREVIATIONS …..................................................................................

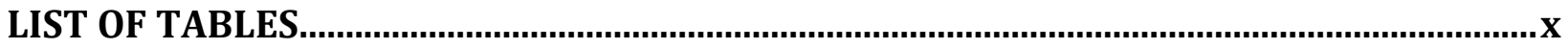

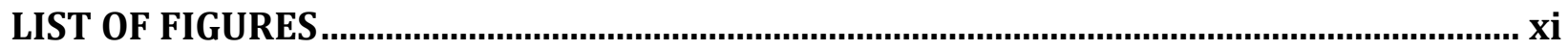

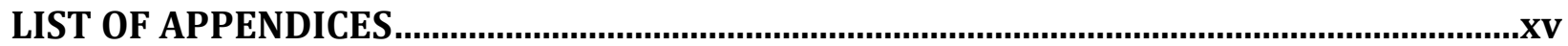

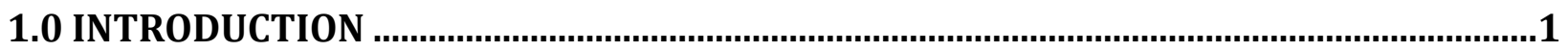

1.1.Blood Proteins and Proteomics …………………………………………………………….... 1

1.2.Adult Serum versus Fetal Serum ............................................................................................

1.2.1 Cell Growth in Adult and Fetal Serum.......................................................................... 3

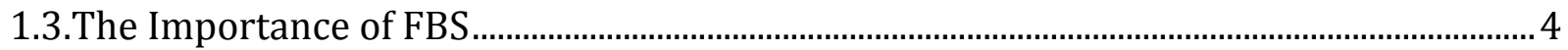

1.4.Comparison of Step-wise Proteins versus Peptide Fraction .................................................6

1.5.Mass Spectrometry and Tandem Mass Spectrometry .............................................................

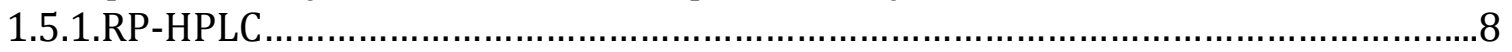

1.5.2.Nano-Spray-HPLC-ESI-MS/MS .....................................................................

1.6.Computation of Random and Independent Replicate Samples............................................

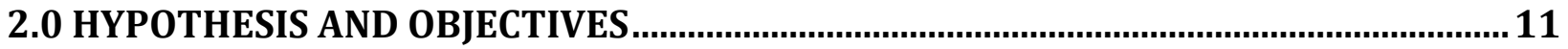

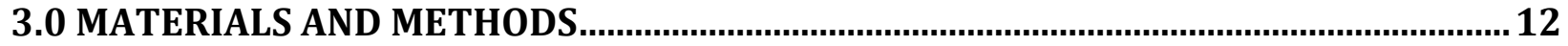

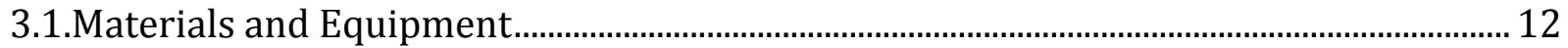

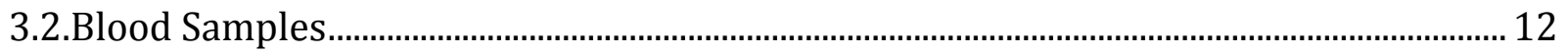

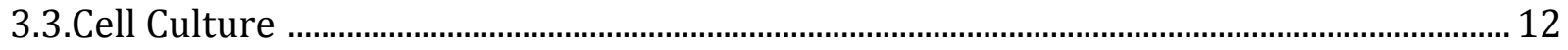

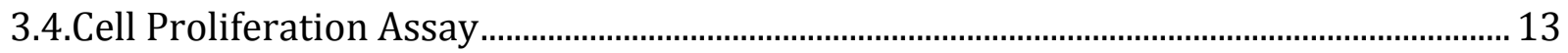

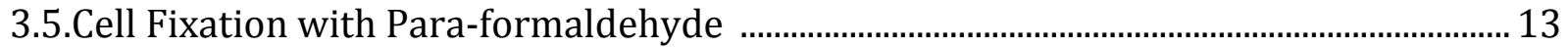

3.6.Cells Staining with Rhodamine Phalloidin............................................................................. 14

3.7.Salt Partition (Gravity) Chromatography Extraction of Proteins ..................................... 14

3.8.Trypsin Digestion of Intact Proteins …………………………………………………......15

3.9.0rganic Differential Extraction of Endogenous Peptides ................................................... 16

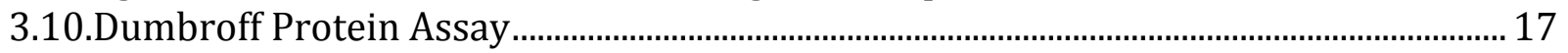

3.11.Protein Resolved by SDS-PAGE ............................................................................................. 18

3.12.C18 Column Packing........................................................................................................... 18

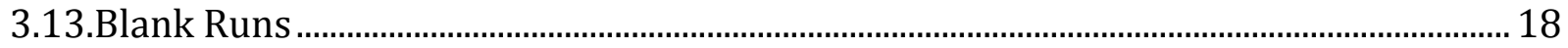


3.14.Sample Introduction into the MS Detector ………………............................................... 19

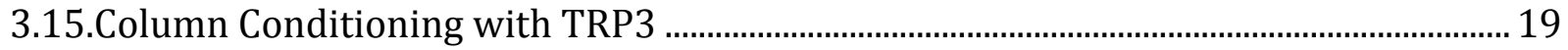

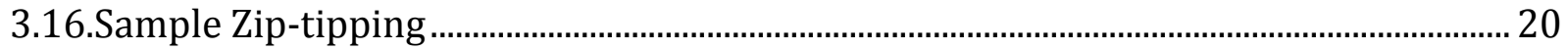

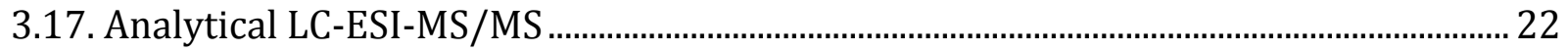

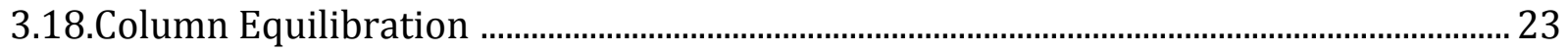

3.19.Correlation Analysis .......................................................................................................2 23

3.20.Data Sampling, Sorting, Transformation and Visualization .............................................. 24

4.0 RESULTS

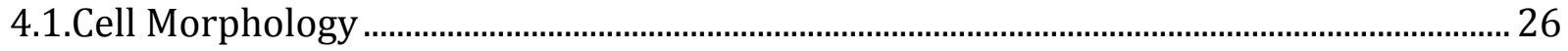

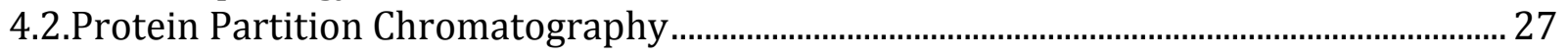

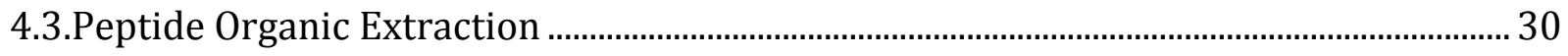

4.4.Normality and Variations across Treatments and Replicates............................................ 31

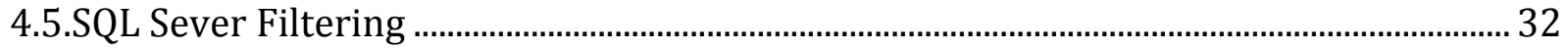

4.6.Peptides and Proteins Identification...................................................................................... 33

4.7.X!TANDEM and SEQUEST .................................................................................................. 36

4.8.X!TANDEM p-value and FDR Corrected q value ………………………………………...... 37

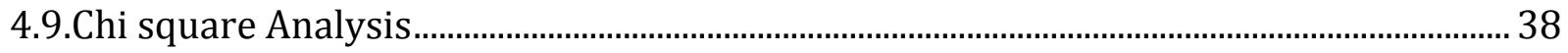

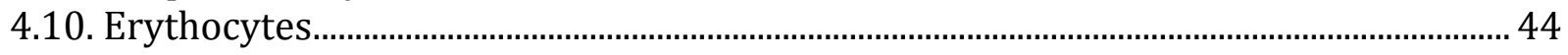

4.11.Granuocytes, Macrophages, Monocytes, Neutrophil, Platelets or rbcs .......................... 44

4.12.Hormones, Ligands, Growth Factors, Chemokines, Cytokines, Necrosis Factors and

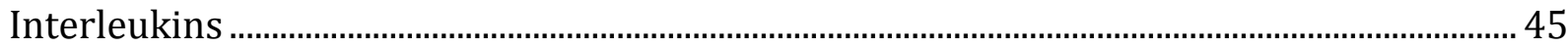

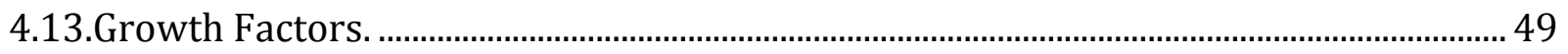

4.14.Pathway and Gene Ontology Analysis using the STRING Algorithm............................... 51

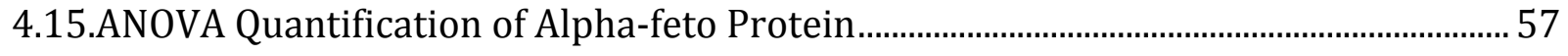

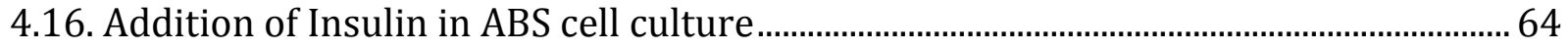

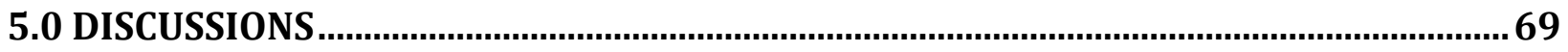

5.1.Agreement between Independent Methods ....……………………………………….....6

5.2.Release of Cellular Proteins from Blood Cells ………………………………………….... 70

5.3.Quaternary Amine Chromatography versus Organic Extraction ........................................ 71

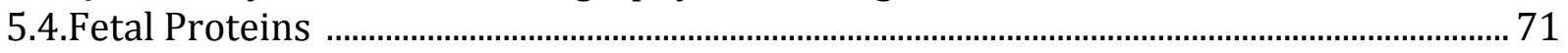

5.5.Ceullar and Multi Cellular Growth Pathways ........................................................................... 72

5.6.Potential Transforming Factors from Sera ……………………………………………... 73

5.7.Receptors and Receptor Signaling Associated Cellular and Nuclear Factors................... 74

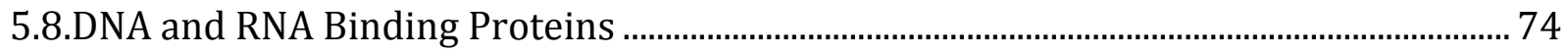

6.0 CONCLUSION

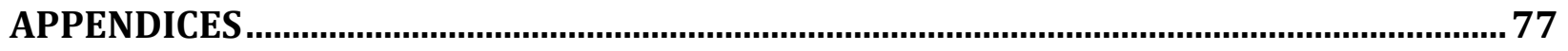

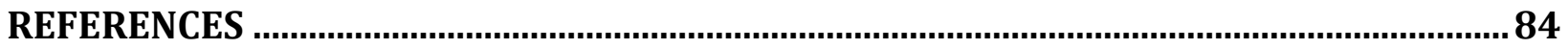




\section{LIST OF SELECTED ABBREVIATIONS}

ABS: adult bovine serum

ACN: acetonitrile

AFP: alpha-feto protein

BSA: bovine serum of albumin

CID: collision-induced dissociation

DMEM: dolbecco modified eagle's medium

DMSO: dimethyl sulfoxide

DTT: dithiothreitol

EDTA: ethylenediaminetetraacetic acid

FA: formic acid

FBS: fetal bovine serum

FGF: fibroblast growth factor

HAC: acetic acid

HSCs: haemopoietic stem cells

IgG: immunoglobulin

INS: insulin

LC-ESI-MS/MS: liquid chromatography -electrospray ionization - tandem mass spectrometry

MALDI-TOF: matrix-assisted laser desorption ionization -time of flight

$\mathrm{m} / \mathrm{z}$ : mass to charge ratio

NBCS: newborn calf serum

PBS: phosphate buffered saline 
PFA: para-formaldehyde

QA: quaternary amine

RBCs: red blood cells

RP -HPLC: reversed - phase high performance liquid chromatography

SDS-PAGE: sodium dodecyl sulfate -polyacrylamide gel electrophoresis

SQL Server: Structured Query Language

TGF: transforming growth factor

WBCs: white blood cells 


\section{LIST OF TABLES}

Table 1. The filtering of the MS/MS spectra and the resulting correlations to peptides to ensure that only the best hit was accepted. The total number of MS/MS spectra of greater than E4 counts collected in this study was 526,870 MS/MS spectra from organic extraction and $1,027,477$ from quaternary amine fractionation of proteins followed by digestion resulting in a total of $1,554,347 \mathrm{MS} / \mathrm{MS}$ spectra.

Table 2. Comparison of organic extraction of peptides versus separation of proteins over quaternary amine chromatography (See Fig.2). The redundant and distinct proteins and peptides and the overlap between treatments were computed in SQL Server.

Table 3. Proteins separation over the salt fractions versus endogenous peptide separation over organic water on the proteins and tryptic peptides identified (See Fig.2).

Table 4. Fetal serum specific proteins detected by fully tryptic peptides and fully tryptic phosphopeptides from X!TANDEM and/or SEQUEST or that show a Chi Square $(\chi 2)$ value of $\geq 60$.

Table 5. The proteins shown were identified by X!TANDEM with at least three independent peptide identifications and showed significant Chi Square values $(\geq 9)$ from both tryptic (TRYP) and phosphor-tryptic peptides.

Table 6. The growth factors that differ between fetal versus adult serum by Chi Square analysis of the tryptic (TRYP) and or serine, threonine or tyrosine phosphorylated tryptic peptides (STYP) identified by SEQUEST and X!TANDEM.

Table 7. The summary of STRING analysis of the fetal serum enriched proteins with respect to a random sampling of the human Genome for Gene Symbols showed the top 400 proteins with the most significant Chi Square ( $\chi 2$ ) value (See Fig.11). The Gene Symbols from unbiased Table IV and biased SQL Queries V were combined for analysis by the STRING algorithm that showed strong enrichment and protein-protein interactions in the fetal specific factors.

Table 8 . The mean and standard deviation of the $\log 10$ precursor intensity values for treatments between adult versus fetal serum. Alpha-feto protein was highly enriched in FBS over the partition chromatography extraction (See appendix Table 10).

Table 9. Peptide sequences specific to AFP. FLGDRDFNQLSSR, LGEYYLQNAFLVAYTK, QKPQITEEQLETVVADFSGLLEK, and KAPQLTSPELMALTR were examples of peptides that were specific to AFP but not albumin with enriched amounts (searched against BLAST) and found in fetal serum only. 


\section{LIST OF FIGURES}

Figure 1.1. 1. Plasma versus serum of Human/Bovine blood. Plasma is treated with anticoagulants and serum is treated after coagulation. Both plasma and serum do not contain WBCs, RBCs and platelets..........................................................................................................

Figure 3.7. 1. Demonstration of step-wise salt gradient extraction of proteins over a QA resin. A total number of 16 fractions were collected for each individual ABS/FBS sample.

Figure 3.8. 1. Demonstration of step-wise organic extraction of peptides with acetonitrile/water solvents. A total of 10 fractions were collected for each individual ABS/FBS sample.........17

Figure 3.15. 1. HPLC manual injection. Sample was introduced with a syringe and stayed in the sample loop when it was on LOAD. Solvents picked up samples from the sample loop and pushed it down to the column when it was on INJECT

Figure 3.16. 1. Demonstration of C18 sample zip-tipping. The C18 zip-tip was washed and desalted before collecting the samples for MS detection. ..........................................................22 
Figure 1. The effect of fetal versus adult serum on the morphology of RAW 264.7 murine macrophages cultured in DMEM plus 5\% bovine fetal or adult serum. The cells were stained with rhodamine pholloidin and the images were taken under a confocal microscope. Panel A: Cells grown in Adult bovine serum; B, Cells grown in Fetal bovine serum; C, the distribution of cell length in Adult (ABS) versus Fetal (FBS) serum. Ten cells were measured from 3 spots on 3 cover slips from 3 independent batches of fetal versus adult serum. The longest axis of the cell was measured.

Figure 2. Flowchart of the intact proteins and endogenous peptides isolation analysis steps. A: Steps of intact proteins by step-gradient salt extraction over a QA resin partition chromatography. B: Steps of endogenous peptides by step-wise acetonitrile water extraction.

Figure 3. The fractionation of FBS by a step gradient of $\mathrm{NaCl}$ in $20 \mathrm{mM}$ Tris $\mathrm{pH} 8.85$ buffer. Panels A: Dumbroff protein assay shows the protein potent in each sample fraction; Panel B: Tricine SDS-PAGE shows the selectivity between sample fractions. Lanes: 1, Molecular Weight Standard; 2, Flow-through; 3, Wash1; 4, Wash2; 5, 0mM NaCl; 6, 50mM NaCl; 7, $100 \mathrm{mM} ; 8,150 \mathrm{mM} ; 9,200 \mathrm{mM} ; 10,250 \mathrm{mM} ; 11,300 \mathrm{mM} ; 12,350 \mathrm{mM}$. 29

Figure 4. The sequential extraction of low molecular mass polypeptides from serum using a stepwise solublization in organic/water. Panels A: Dumbroff protein assay; Panel B: Tricine SDS-PAGE shows the selectivity between sample fractions. Lanes 1, Molecular Weight Standard; 2, 90\% acetonitrile supernatant; 3, 70\% ACN supernatant, 4, 60\% ACN supernatant; 5, 50\% ACN supernatant; 6, 40\% ACN supernatant; 7, 30\% ACN supernatant; $8,20 \%$ ACN supernatant; $9,10 \%$ ACN supernatant; $10,0 \%$ ACN supernatant. 30

Figure 5. The reproducibility of the fetal versus adult serum samples. Panels: A, the quantile Q-Q plot showing the normality of the $\log 10$ transformed intensity values; $\mathrm{B}$, the box plot showing the average $\log _{10}$ intensity and variation in $\log 10$ and $99 \%$ confidence interval is shown for the adult versus fetal serum replicates. (ID\# 1-12:ABS treatments; \#13-24: FBS treatments)

Figure 6. The total number of protein accessions and Gene symbols from the Bovine protein library that were correlated by the X!TANDEM and SEQUEST algorithms combined. Panels: A, redundant protein accessions (after filtration of the redundant MS/MS); B, best correlation per Gene symbol.

Figure 7. The protein accessions identified by the SEQUEST and X!TANDEM algorithms separately. Panels: A, Proteins identified using SEQUEST showed some 57,308 protein accessions; B, Proteins identified using X!TANDEM showed some 44,146 protein accessions.

Figure 8. The cumulative $\mathrm{p}$-value and FDR corrected q-value of the non-redundant peptides per gene symbol computed from the X!TANDEM results using the R statistical system. 
Figure 9. Quantile plots of the corrected difference in observation frequency (Delta) and Chi Square values of the fetal versus adult serum. The difference in observation frequency of fetal serum versus adult serum using the Quantile plot that tended to zero (see red line). Panels: A, Tryptic peptide corrected difference (delta) in observation frequency; B, tryptic peptide Chi Square $\chi 2 ; \mathrm{C}$, Tryptic and/or phosphor-tryptic peptides after the corrected difference (delta) in observation frequency; D, tryptic and/or STYP peptide Chi Square $\chi 2$.

Figure 10. The Fetal serum STRING network where Chi Square $\chi 2 \geq 15$ from fully tryptic peptides. The network shown is where fetal serum observations exceeded those of adult serum by tryptic peptide frequency difference with $\chi 2$ value greater than 15 at degrees of freedom of $1(\mathrm{p}<0.0001)$. 55

Figure 11. The STRING network shows the top 400 proteins with the most significant chi-square value in the fetal serum. Many AKT/HRAS proliferation pathways as well as AFP and Insulin like growth factors were observed.

Figure 12. Example MS/MS spectra from alpha feto protein that was specific to fetal serum from the X!TANDEM algorithm. Panels: A, the peptide DVLTIIEKPTGSK;, B, the peptide SYKENRELFINR; $C$, the peptide YIYEIAR.

Figure 13. AFP in fetal and adult bovine serum between treatments and replicates. Treatments and replicates from salt partition chromatography and organic extraction with and without the consideration of phosphorylation of AFP were shown here. Panels: A, the quantile Q-Q plot showing the normality of the log 10 transformed intensity values; $\mathrm{B}$, the box plot showing the average $\log 10$ intensity and variation in $\log 10$ for the adult versus fetal serum replicates.

Figure 14. Some peptides were found to be specific to AFP and highly observed in fetal serum. The four peptides shown above (Panels A, B, C, and D) were found to be unique to AFP but not Albumin, which were only found in fetal serum. These peptides from AFP were only observed from partition chromatography (See Table 8). Panels: A, the peptide KAPQLSPELMALTR; B, the peptide FLGDRDFNQLSSR; C, QKPQITEEQLETVVADFSGLLEK; D, the peptide LGEYYLQNAFLVAYTK

Figure 15. Example MS/MS spectra from high abundance insulin that was specific to fetal serum from X!TANDEM algorithm. Panels: A, the peptide EVEGPQVGALEKLAGGPPGAGGLEGPPQK; B, the peptide RGVSMGTPKLLR; C, the peptide PPPPGAATGGKGK 65

Figure 16. The variation in INS peptides in the fetal versus adult serum samples. Panels: A, the QQ plot showing the normality of the $\log 10$ transformed intensity values; B, all of the peptides from insulin (INS); $\mathrm{C}$, the peptide MGPGRAR from insulin. The box plot showing the average $\log 10$ intensity and variation in $\log 10$ and $99 \%$ confidence interval is shown for the adult versus fetal serum replicates ANOVA analysis show a significant effect of treatment and peptides both with a $\mathrm{p}$ value of $\sim 2 \mathrm{e}-16$ 66 
Figure 17. Raw cells cultured in 5\% ABS and stained with rhodamine phalloidin. The images were taken under a 20X magnification confocal microscope. Addition of $0 \mu \mathrm{g}, 0.2 \mu \mathrm{g}, 2 \mu \mathrm{g}$, and $20 \mu \mathrm{g}$ of insulin to Raw cell 264.7 in ABS cell culture showed different cell morphologies. Different amounts of INS were compared to the control (no addition of INS), where $2 \mu \mathrm{g}$ of INS gave the similar results to FBS, $0.2 \mu \mathrm{g}$ of INS did not seem to have any results to the cell and $20 \mu \mathrm{g}$ of INS seemed to be saturated.

Figure 18. ANOAVA analysis shows the means of cell length between the levels of insulin addition to the ABS cell culture. Ten cells were measured from 3 spots of each treatment. The longest axis of the cell was measured. 


\section{LIST OF APPENDICES}

Table A.1. Experimental treatment table. The data of all QA column extracions and organic extractions from ABS and FBS as well as data of all blank runs and column conditioning were collected by the Tandem Mass Spectrometry, and computed in the SQL server..........77

Table A.2. Precursor intensity of INS in $\log _{10}$ between treatments of ABS and FBS. 78

Figure B.1. The effect on the morphology of RAW cell 264.7 murine macrophages cultured in DMEM plus 5\% ABS and stained with rhodamine phallodin. The cells were cultured in three independent batches of $\mathrm{ABS}$ and observed to have dendritic shapes under a $63 \mathrm{X}$ magnification confocal microscope. Panels: A1, 3 different individual experiments from ABS batch 1; A2, 3 different individual experiments from ABS batch 2; A3, 3 different individual experiments from $\mathrm{ABS}$ batch 3 .

Figure B.2. The effect on the morphology of RAW cell 264.7 murine macrophages cultured in DMEM plus 5\% FBS and stained with rhodamine phallodin. The cells were cultured in three independent batches of FBS and observed to have rounded shapes under a $63 \mathrm{X}$ magnification confocal microscope. Panels: F1, 3 different individual experiments from FBS batch 1; F2, 3 different individual experiments from FBS batch 2; F3, 3 different individual experiments from FBS batch 3

Figure B.3. The RAW cells cultured in the ABS/FBS were fixed with para-formaldehyde and stained with rhodamine phalloidin. The images were taken under a 20X magnification confocal microscope. Panels: A, cells grown in fetal serum that divided rapidly and piled onto each other; B, cells grown in adult serum that divided slowly and often died.

Figure B.4. Base-peak chromatograms of ABS sample collected over QA resin partition chromatography with $225 \mathrm{mM} \mathrm{NaCl}$ in tricine eluting buffer between 3 individual replicates.

Figure B.5. Base-peak chromatograms of ABS sample collected over $40 \%$ acetonitrile organic extraction between 3 individual replicates. 


\subsection{INTRODUCTION}

\subsection{Blood Proteins and Proteomics}

Proteomics is the study of proteins and peptides' primary structure and quantification [1]. The proteome, which refers to all the possible proteins encoded by the genome, is neither as static nor as uniform as the genome [2]. The blood may contain the most diverse set of proteins since they communicate between all of the organs, tissues and cells. Blood is also a most significant source of therapeutic proteins, transfusion products and is commonly used for diagnostic testing [3]. Blood proteins serve many different functions such as lipid and hormone transporters, binding proteins and may regulate the function of the immune system. Similar blood proteins were observed in serum and plasma [4]. Serum is prepared after coagulation of blood cells by fibrin cleavage and polymerization. Plasma results when blood is collected with anti-coagulants such as EDTA and the cells are removed by low speed centrifugation without the activation of coagulation cascade [5]. The most effective separation for the selective purification of intact blood proteins prior to identification was partition chromatography which identified more proteins than electrophoresis [3]. The identification of proteins resolved by chromatography from tryptic peptides can be performed using electrospray ionization [6] and the peptide fragmentation spectra [7] from a linear quadrupole ion trap [8]. 


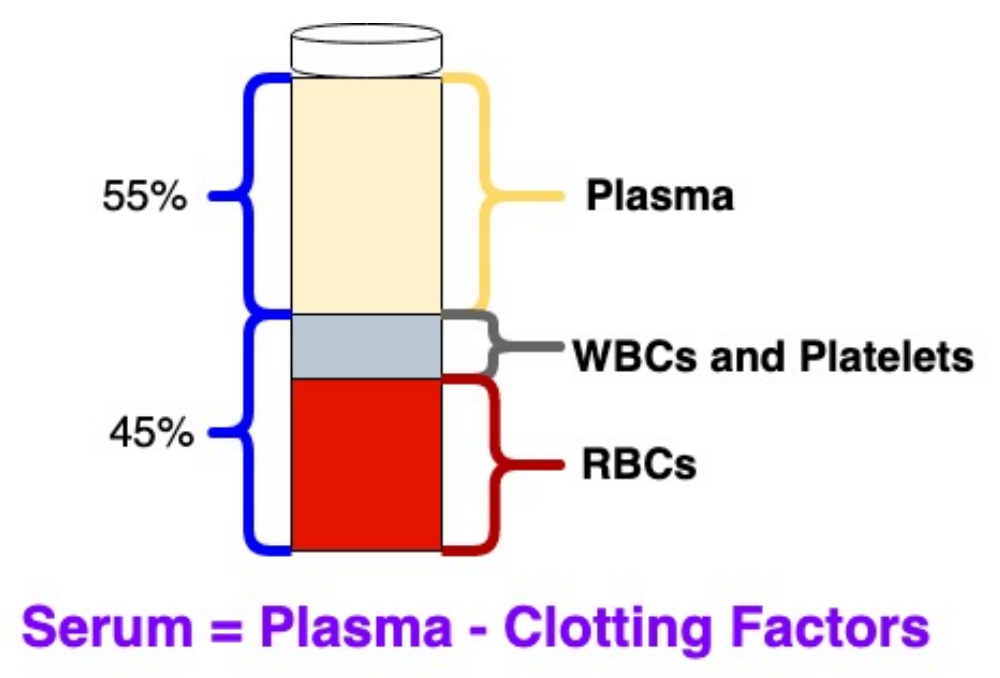

Figure 1.1. 1. Plasma versus serum of Human/Bovine blood. Plasma is treated with anticoagulants and serum is treated after coagulation. Both plasma and serum do not contain WBCs, RBCs and platelets.

\subsection{Adult Serum vs. Fetal Serum}

Fetal serum is an essential supplementation of basal culture media for cell growth and proliferation [9]. Many animal cells can grow in a fetal serum-containing media such as Eagle's medium, while certain cell types require specific protein growth factors that are not present in serum [10]. The most widely used sera are from adult or fetal bovine origin [9], and the most widely used product manufactured from bovine blood is bovine serum for cell culture [11]. Bovine serum is the liquid fraction of clotted blood that contains a large number of nutritional factors as well as small molecules like amino acids, sugars, lipids, pyruvate and hormones that can increase cell growth [5].

Fetal serum is a mixture of thousands of protein factors needed for proliferation of cells in culture [10]. One of the major blood proteins is serum albumin, which accounts for 55\% of blood proteins. Albumin is an important contributor to maintaining the osmotic pressure of plasma to 
assist in the lipids and steroid hormones transportations [9]. Bovine serum of albumin (BSA) is the major component of the bovine serum, that together with transferrin is known to enhance growth in cultured cells [5]. Studies have shown that different serum constituents have distinct effects on cell cultures. Insulin alone, nerve growth factor, epidermal growth factor, insulin-like growth factor, fibroblast growth factor (FGF), platelet-derived growth factor, and transforming growth factor (TGF) [12-14] were found to increase proliferation but were inferior to effect of fetal serum [15] indicating there are as yet unknown growth factors in fetal serum. Thus, it is important to analyze the biological properties of adult bovine serum in comparison with fetal bovine serum for cell culture [11]. In general, FBS is an extremely complex mixture of a large number constituents, including both low and high molecular weight biomolecules with different growth-promoting and growth-regulating activities [9]. Previous studies showed that fetal serum contains more growth factors and has low immunoglobulin (IgG) content as well as lower levels of complements than adult serum (complement can interfere with immunoassays since they contain the undesired effect of lysing cells in culture). In addition, FBS provides essential compounds, such as hormones, binding and attachment factors that promote cell growth and maintain cellular activities $[5,16]$.

\subsubsection{Cell Growth in Adult and Fetal Serum}

Within the tissues of intact animals, most cells tightly contact and interact specifically with other cells via various cellular junctions. In addition, the cells can contact the extracellular matrix, which a complex network that fills the gaps between cells with secreted proteins and carbohydrates. The extracellular matrix helps cells bind in tissue together while providing a lattice through which cells can move during early stage of animal differentiation. Most cultured 
animal cells may require a surface to grow on in vivo when interacting with one another in an extracellular matrix surrounding. Many cell types can adhere to and grow on glass as they secret collagen and bind to the culture surface and function as a bridge between the cells [10]. For instance, the RAW 264.7 mouse macrophage was used in this experiment, which is a monocyte white blood cell that can differentiate into macrophage and adhere to the glass [17].

Cultured cells are useful models for studying cell growth and differentiation. When cells are removed from an embryo or an adult animal the adherent primary cells line may grow spontaneously in culture for a limited time before growth stops. Primary cultures may eventually die after many passages, even when provided with fetal serum [10]. For the past decades, FBS has been preferred for culturing cells over other bovine sera since it contains higher levels of nutrients, adhesion proteins and growth factors that promote cell growth [11], [18], [19]. Moreover, significantly lower levels of antibodies that reduce the risks posed by cross-reaction of antibodies in cell culture were found in FBS [11], [20].

\subsection{The Importance of FBS}

The variability of FBS results in the presence of unpredictable amounts of different bioactive components, including immunoglobulin, transcription factors and growth factors, which highly influence cell behavior [18]. Although there are several controversies about using animal serum in culture systems, the alternative use of other products for cell growth was not widely popularized. Most laboratories use FBS despite the high price and limited supply. The most common concern about FBS alternatives is the lack of solid evidence indicating that they exhibit equal performance as FBS. Studies have demonstrated that most cell lines were maintained in 
FBS-containing serum while adult serum products have less effect on cell growth and proliferation. More importantly, the number of generations that certain cell lines had been cultured or whether these FBS alternatives serum would support long-term cell growth is still not known [21].

It remains possible that serum from different species may exhibit different effects on cell behavior in cultures [16]. These sera contain proteins that can adhere onto the material surface, which play crucial roles in subsequent cell behavior, including adhesion, spreading, and proliferation [22]. Some studies have shown that cells cultured in FBS exhibited a constrained morphology and did not extend as well as in adult bovine serum [21]. Cells in fetal serum tend to remain circular and spherical, which act like stem cells [16].

Fetal serum contains factors that can promote changes in gene expression [23], [24] and permit the indefinite culture of certain cell lines such as RAW 264.7 murine macrophages [25]. All of the factors in fetal serum that permit indefinite cell growth have yet to be determined [26]-[28]. Fetal serum or platelet lysates have also been shown to expand clonal cell lines and may have therapeutic applications towards human health [29]. There have been significant efforts to create cell growth media that contains the types of growth factors contained in natural serum for use in cell culture experiments [13]. There have been several attempts to compare fetal serum to adult serum from umbilical chords or other approaches [30]. The peptides and proteins specific to fetal serum may have therapeutic and basic biochemical importance [31]. The technology of identifying peptides from proteins using LC-ESI-MS/MS has been successfully applied to many cell and tissue types [32]-[35]. In this study, the application of LC-ESI-MS/MS to fetal versus 
adult bovine serum was compared using partition chromatography of intact proteins and organic extraction of endogenous peptides.

\subsection{Comparison of Step-wise Proteins versus Peptide Fraction}

Pure substances can be measured with great sensitivity and log linearity using a mass spectrometer, and pre-fraction of proteins by chromatography shows even greater sensitivity results compared to crude serum. The use of partition chromatography of intact protein chains prior to digestion permitted the identification of the major blood proteins from tryptic peptides [3]. The analysis of serum or plasma by LC-ESI-MS/MS [36] requires that each sample must be partitioned into many fractions [37], [38], so that each enriched in a sub set of proteins or polypeptides prior to subsequent to nano-LC-ESI-MS/MS in order to achieve sufficient sensitivity to detect the many proteins that may be in pico-molar or lower concentrations [3], [39]. A comparison of intact proteins over many chromatography resins showed that quaternary amine resin identified the largest number of soluble proteins from intact serum proteins [39]. The use of quaternary amine ion exchange fractionation prior to digestion was effective for examining proteins released from cancer cells lines cultured in artificial media [37], [40]. A comparison of endogenous peptides purified using ultrafilters, ion exchange chromatography, C18, size exclusion chromatography and organic extraction showed that steps wise organic fractionation provided the best results [41], [42]. High signal to noise ratio of blood peptides is dependent on sample preparation to enrich certain proteins or peptides in each of the many subfractions, relieve competition and suppression of ionization, and thus achieve sensitivity [3], [38], [39]. 


\subsection{Mass Spectrometry and Tandem Mass Spectrometry}

Mass spectrometer (MS) is an ideal tool to quantify and identify the protein and complexes of blood in which abundant peptides may be detected with high intensity[39]. MS is also an analytical approach that is used to fractionate a complex mixture into fragments, measure its mass-to-charge ratio of ions [43]. The capacity of a MS to detect proteins at low concentrations in blood is critical to the discovery of new biomarkers of disease [39]. Furthermore, mass spectrometry is a diagnostic and cancer biomarker discovery tool; research has been done on discovering biomarkers for different types of cancers with this technology including ovarian, prostate, breast, bladder, renal etc [44]-[46].

A Tandem Mass Spectrometer (MS/MS) involves multiple steps of MS selection with fragmentation occurring in between the stages. In the first stage of a Tandem Mass Spectrometer, ions are formed in the ion source and then separated by mass to charge ratio (MS1-"Parent m/z") [43], [47]. Ions of a particular m/z, also known as precursor ions, are selected where CID (Collision-Induced Dissociation) process creates the fragment ions are separated and detected in the second stage of MS (MS2 or MS/MS- "Fragment m/z") [48]. Thus, precursor and product ions are both characterized independently by their $\mathrm{m} / \mathrm{z}$ [49]. A single stage mass analysis allows for the identification of analytes of interest at which atmospheric pressure ionization produces mass spectra that can provide information of the molecular mass of the analytes. A two-stage mass (MS/MS) analysis allows for even more accurate compound identification, which it monitors how a parent ion fragments when exposed to an additional stage of ionization [50]. This is a very popular, reliable and well-established method of protein identification. Ion intensity is a measure of each $\mathrm{m} / \mathrm{z}$ values in MS and then MS/MS fragments, which indicates how strong the 
signal is to the detector [47]. Using MS/MS analysis, it is easier to quantify and identify target analytes in complex maxtices such us plants, animal tissues, soil, or human plasma [43], [47].

Mass Spectrometry has become invaluable to a broad range of fields and applications. For instance, mass spectrometry can be applied to proteomic studies, to determine protein's primary structure, function, folding and interactions [51]. MS can also identify peptides from the precursor and fragment masses and thus can be used to monitor enzyme reactions, chemical modifications and protein digestion [51], [52]. Furthermore, mass spectrometry can also be used for drug discovery, to determine significant structures of drugs and metabolites. Last but not least, mass spectrometry has a broad range of applications in genomic, environmental, geological, and forensic science studies. It has been suggested that MS can achieve much higher diagnostic sensitivity and specificity in comparison to the classical cancer biomarkers [44], [53].

\subsubsection{RP-HPLC}

Reversed-phase HPLC has also become an essential tool in the separation of proteins and peptides and it is able to separate peptides of nearly identical structure. Also, RP-HPLC is widely used in the biochemistry industry to characterize protein therapeutic products. The sensitivity of detection is a driving factor to develop HPLC columns of smaller diameter and for new types of stationary phases. The instrumental components of a HPLC are pumps, connecting tubing, an injection valve, and a detector. The pumping systems provide flow rates in the $\mu \mathrm{L} / \mathrm{min}$ to $\mathrm{nL} / \mathrm{min}$ range. There are usually two different solvents in the pumping systems, which are the aqueous buffer and the organic buffer. A reversed-phased chromatographic column is the most widely used separation technique for proteomic research. It is based on the interaction between a polar 
hydrophilic mobile phase and the sample with a hydrophobic stationary phase [36]. HPLC is capable of carefully controlling the polarity via a gradient of the two solvents in order to further increase the selectivity of proteins that elute off the column [54].

\subsubsection{Nano-Spray-HPLC-ESI-MS/MS}

Mass spectrometry can be coupled with gas chromatography (GC) or high-pressure [55] liquid chromatography (HPLC) for identification and quantification of relatively small molecules. Nano-Spray ionization was the specific MS technique used in this project. A small volume $(2 \mu \mathrm{L})$ of the mobile phase containing the sample can be ionized and scanned at a time. Ionization occurs via an application of high voltage to the mobile phase and the ions are separated by an electromagnetic field generated in the MS [56]: lighter ions are deflected much more readily than heavier ones, as well as their charge are altered their direction of movement. This allows the MS to measure the $\mathrm{m} / \mathrm{z}$. The resulting ions can be detected based on this whereas the signal can be converted into a spectrum (chromatogram) [57].

\subsection{Computation of Random and Independent Replicate Samples}

Mathematical and statistical analysis of the many treatments, samples, replicates and fractions results in hundreds or thousands of LC-ESI-MS/MS runs and requires a robust computation and statistical strategy [46], [58]. The statistical validity of MS/MS correlation from the ion trap has been established for standards and human plasma [59]-[61] by multiple methods in agreement [37], [62]-[64]. Random and independent sampling of tryptic peptides from step-wise fractionation followed by LC-ESI-MS/MS [60] is a time and manual labor intensive approach that is sensitive, direct, and rests on few assumptions [37], [38]. Analysis of many experimental 
treatments and controls with independent replicates samples [4], [46], [58] each fractioned into many sub-samples, requires large computing power to re-assemble the sub-fractions together, and organize and analyze the results across treatments [38], [65]. Extensive computation is required to match MS/MS spectra to peptide sequences using the X!TANDEM [28] and SEQUEST [66] algorithms and these results must be stored together with and related to the raw LC-ESI-MS/MS data in a SQL Sever database for statistical analysis. The large amount of mass spectra raw data and correlation results may be stored and related in SQL Server [67] for analysis by a generic statistical algorithm like those found in the $\mathrm{R}$ statistical system to summarize the results and compute error rates [65]. The combination of 64 bit SQL Server together with generic computation software such as the $\mathrm{R}$ package permits the use of a classical random and independent sampling of experimental treatments, and controls for subsequent analysis [65]. Here the peptides and proteins of bovine fetal serum were compared to adult serum by differential solubility in organic solvent versus quaternary amine chromatography prior to digestion to provide the identity and quantification of the factors unique to fetal serum. The combination of step wise preparative separation prior to analytical separation of the resulting peptides by nano LC-ESI-MS/MS with a linear ion trap was shown to be much more sensitive than the use of one step fractionation and micro electrospray, and has apparently detect many cellular proteins in plasma [4], [46]. 


\subsection{HYPOTHESIS AND OBJECTIVES}

The hypothesis of this study is that there was a difference in the proteins and peptides of FBS versus $\mathrm{ABS}$ that transform cell growth. The aim and objective was to observe the cell morphology and to compare the proteins and peptides in the FBS with ABS by random and independent sampling using the organic differential extraction and the step-wise salt extraction for partition chromatography over a quaternary amine resin. The proteins and peptides collected were then analyzed by a LC-ESI-MS/MS with a linear ion trap to enumerate and quantify the differences in peptide observation frequency by the Chi Square test or precursor intensity by ANOVA and the proteins observed to be specific to fetal serum may be subsequently assayed for their effect on cellular proliferation. 


\subsection{MATERIALS AND METHODS}

\subsection{Materials and Equipment}

The model of MS used was the LTQ Tune Plus Finnigan Linear Ion Trap from Thermo Electron Corporation (Waltham, MA, USA). HPLC used was Agilent Technologies 1260 Infinity and 1200 Series. Ceramic QA resin was from BioRad. C18 ZipTips were obtained from Millipore (Bedford, MA). C18 HPLC resin (Zorbax 300 SB-C18 5-micron, 300 Angstrom) was from Agilent. HPLC grade solvents were obtained from Caledon Laboratories (Georgetown, Ontario, Canada). All other salts and reagents were obtained from Sigma-Aldrich-Fluka (St Louis, MO) except where indicated.

\subsection{Blood Samples}

FBS and ABS were supplied from Cell Grow, Sigma-Aldrich (Canada), Gibco by life technologies (New Zealand), MP Biomedical (MP, USA), Rocky Mountain Biologicals (USA), and Thermo Fisher. Blood samples were drawn into sera tubes. The samples were thawed, aliquot and re-frozen once before being used and discarded as described.

\subsection{Cell Culture}

Most cell lines can be grown using DMEM culture media with 5\% Fetal Bovine Serum [68]. All media, blood samples, supplement and reagents were sterilized prior to cell culture.

Micropipettors, pipette tips, micro cover glasses, and cell culture flasks/plates were autoclaved in order to create an aseptic environment. A volume of $25 \mathrm{~mL}$ was added to a 500mL DMEM (5\% serum). $0.5 \mathrm{~mL}$ of raw cells 264.7 (white blood cells) were diluted with $3 \mathrm{~mL} 5 \%$ FBS in a cell 
culture flask and incubated in a humidified atmosphere of $5 \% \mathrm{CO}_{2}$ at $37^{\circ} \mathrm{C}$ until confluence reached (the confluence of cells was observed under a light microscope). Media was changed after the first four hours since the raw cells contained DMSO when it was frozen down in the liquid nitrogen. Cells were passaged and scraped when they became $80 \%$ confluent (1:2 split in 1 to 2 days) [69].

\subsection{Cell Proliferation Assay}

The ability to culture cells under very low cell density is a stringent criterion of the quality of culture sera. Many experiments require growing cells at low density so that individual colonies can develop [21]. To compare the effects of each serum on cell growth, three independent controls of FBS and three independent treatments of ABS from different sources assay were performed and observed. Cells were seeded in 6-well plates with maximum $2 \mathrm{~mL}$ of $5 \%(\mathrm{v} / \mathrm{v})$ FBS and 5\% (v/v) ABS in DMEM respectively. They were cultured in the incubator at $37^{\circ} \mathrm{C}$ and sampled (passaged) every 48 hours. The rate of cell growth was measured by looking at the confluence of the cells under a light microscope and the data was recorded [11], [69].

\subsection{Cell Fixation with Para-formaldehyde}

Raw 264.7 Monocytic white blood cells can differentiate into macrophages, which adhere to cover slips [70]. 5\% FBS or 5\% ABS in media was removed from each well (cells were first cultured in FBS), and each cover slip with cells adhered to it was washed 3 times with $2 \mathrm{~mL} 1 \mathrm{X}$ PBS solution. The 6-well cell culture plate was shake on a rocker plate for 30 minutes. $2 \mathrm{~mL}$ of

$2 \%$ Para-formaldehyde was added to each well in order to fix the cells. The cell culture plate was allowed to stay in Para-formaldehyde for no more than 2 hours (or $0.1 \%$ PFA overnight). The 
Para-formaldehyde was removed and the cells were washed 3 times with $2 \mathrm{~mL} 1$ x PBS [69], [71].

\subsection{Cell Staining with Rhodamine Phalloidin}

Cells used to measure length and shapes were quenched in $1 \mathrm{X}$ PBS with 10mM glycine for 15 minutes. Then the cells were stored in the $4^{\circ} \mathrm{C}$ refrigerator for microscopic analysis. For cells that were used to stain with rhodamine phallodin, the cells were first permeabilized with $0.1 \%$ Triton $\mathrm{X}-100$ in $1 \mathrm{X}$ PBS (used to dissolve the cell membranes). $2 \mathrm{~mL}$ of $1 / 1000$ dilution phalloidin in 1X PBS was added to the 6-well plate with fixed cells and stained for 30 minutes on a rocker plate [72]. The cells were then washed with 3 portions of $2 \mathrm{~mL} 1 \mathrm{X}$ PBS. The cover slip that had the fixed cells on it was dried by holding the edge of it with a tweezers on a Kim-wipe and rotating the edge of the cover slip so that it could get dry faster. The cover slip was mounted onto a glass slide with Dako (mountant). It was dried and stored in the $-20^{\circ} \mathrm{C}$ freezer for microscopic imaging.

\subsection{Salt Partition (Gravity) Chromatography Extraction of Proteins:}

The preparative gravity chromatography was performed by adding $100 \mu \mathrm{L}$ scale columns in $3 \mathrm{~mL}$ plastic transfer pipettes stoppered with glass wool. The tops of the plastic transfer pipettes were cut off with scissors in order to form an upper reservoir. The stoppered pipettes were placed within $15 \mathrm{~mL}$ disposable falcon tubes to strike the column with the loading buffer. A $200 \mu \mathrm{L}$ volume of $50 \%$ slurry of quaternary amine (QA) resin was added to the top of the transfer pipette column and allowed to settle to the glass wool at the bottom by gravity. The column was then drained and equilibrated with $20 \mathrm{mM}$ Tricine $1 x \mathrm{PBS}$ loading buffer. A $25 \mu \mathrm{L}$ volume of serum 
was diluted in $200 \mu \mathrm{L}$ of $20 \mathrm{mM}$ Tricine $1 \times$ PBS solution and then added to the column. Additional PBS loading buffer was added in order to bind the column and wash off excess sample. A flowthrough elution (proteins that do not bind to the column) was collected into a $1.5 \mathrm{~mL}$ eppendorf tube. The column was then loaded with a sequential gradient of salts $(\mathrm{NaCl})$. All protein separations were performed by gravity-drip chromatography, and each protein fraction eluted was collected into a $1.5 \mathrm{~mL}$ eppendorf tube. A column volume of $100-200 \mu \mathrm{L}$ can be run by gravity alone without the aid of frit or centrifugation. Given a binding capacity of $50 \mathrm{mg} / \mathrm{mL}$, such a column could bind up to $5 \mathrm{mg}$ of protein, which is more than sufficient for SDS-PAGE and HPLC-MS/MS [3], [39].

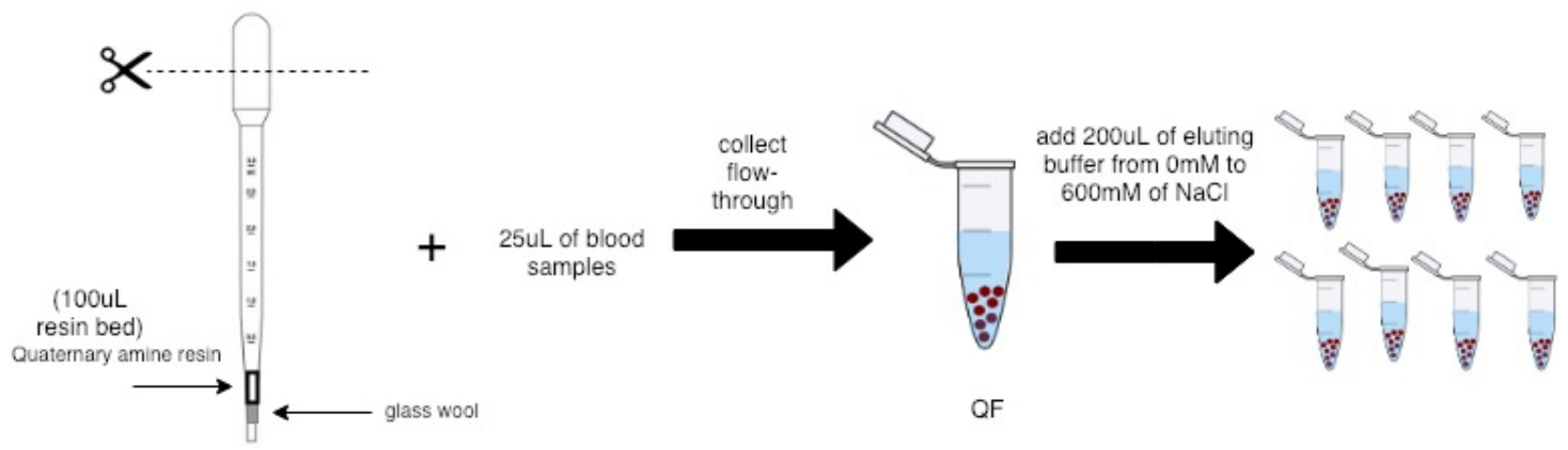

Figure 3.7. 1. Demonstration of step-wise salt gradient extraction of proteins over a $Q A$ resin. A total number of 16 fractions were collected for each individual ABS/FBS sample.

\subsection{Trypsin Digestion of Intact Proteins}

A $6 \mathrm{M}$ urea digestion buffer was prepared by dissolving $36.036 \mathrm{~g}$ urea in a $100 \mathrm{~mL}$ bottle with $50 \%$ ACN and $500 \mathrm{mM}$ Tris- $\mathrm{HCl} \mathrm{pH} 8.8$ (10X stock). $90 \mu \mathrm{L}$ of previously collected samples by the QA resin chromatography was mixed with $10 \mu \mathrm{L}$ of the $10 \mathrm{X}$ digestion buffer (Now the final digestion buffer is $1 \mathrm{X})$. A $25 \mu \mathrm{g}$ of trypsin was dissolved and mixed in $50 \mu \mathrm{L} 1 \%$ acetic acid (HAC) on ice $(0.5 \mathrm{mg} / \mathrm{mL}) .1 \mu \mathrm{L}$ of dissolved trypsin was added to each sample $(100 \mu \mathrm{L}$ mixture 
of samples and digestion buffer). The samples were then incubated at $37^{\circ} \mathrm{C}$ overnight (12 hours incubation). $1 \mu \mathrm{L}$ of $200 \mathrm{mM}$ fresh DTT was added to each sample ( $2 \mathrm{mM}$ in each sample). The samples were then heated at $50^{\circ} \mathrm{C}$ for 5 minutes, another $1 \mu \mathrm{L}$ of trypsin was added and incubated for 2 hours at $37 \cdot \mathrm{C}$. The samples were quenched with $5 \%$ formic acid and freeze-dried for the MS analysis [73].

\subsection{Organic Differential Extraction of Endogenous Peptides}

The sample preparation was carried out by an organic differential extraction where $1800 \mu \mathrm{L}$ of $100 \%$ acetonitrile was added to the $200 \mu \mathrm{L}$ of FBS/ABS in the biological cleanroom. Disposable plastic $1.5 \mathrm{~mL}$ sample tubes and plastic pipette tips were used to handle samples. FBS/ABS samples precipitation followed by the selective extraction of the pellet using a step gradient to achieve selectivity across sub-fractions and thus greater sensitivity. Sample mixture was vortexed (mixed) for 10 seconds, then centrifuged for 5 minute at 12,000 RCF. The supernatant (aqueous portion) was collected and the organic precipitate (pellet) that contains a much larger total amount of endogenous polypeptides was manually sequentially re-suspended in increasingly polar solvent (water content) of 70,60, 50, 40, 30, 20, 10, $0 \%$ of acetonitrile, followed by water with $5 \%$ formic acid. After re-suspending the pellet in each organic solvent/water mixture, samples were centrifuged at 12,000 RCF for 5 minutes and the supernatant was collected. All samples were transferred to a fresh tube, dried in the rotary evaporator for 4 hours and kept at $-80^{\circ} \mathrm{C}$ in aliquots for future uses [4], [46]. 


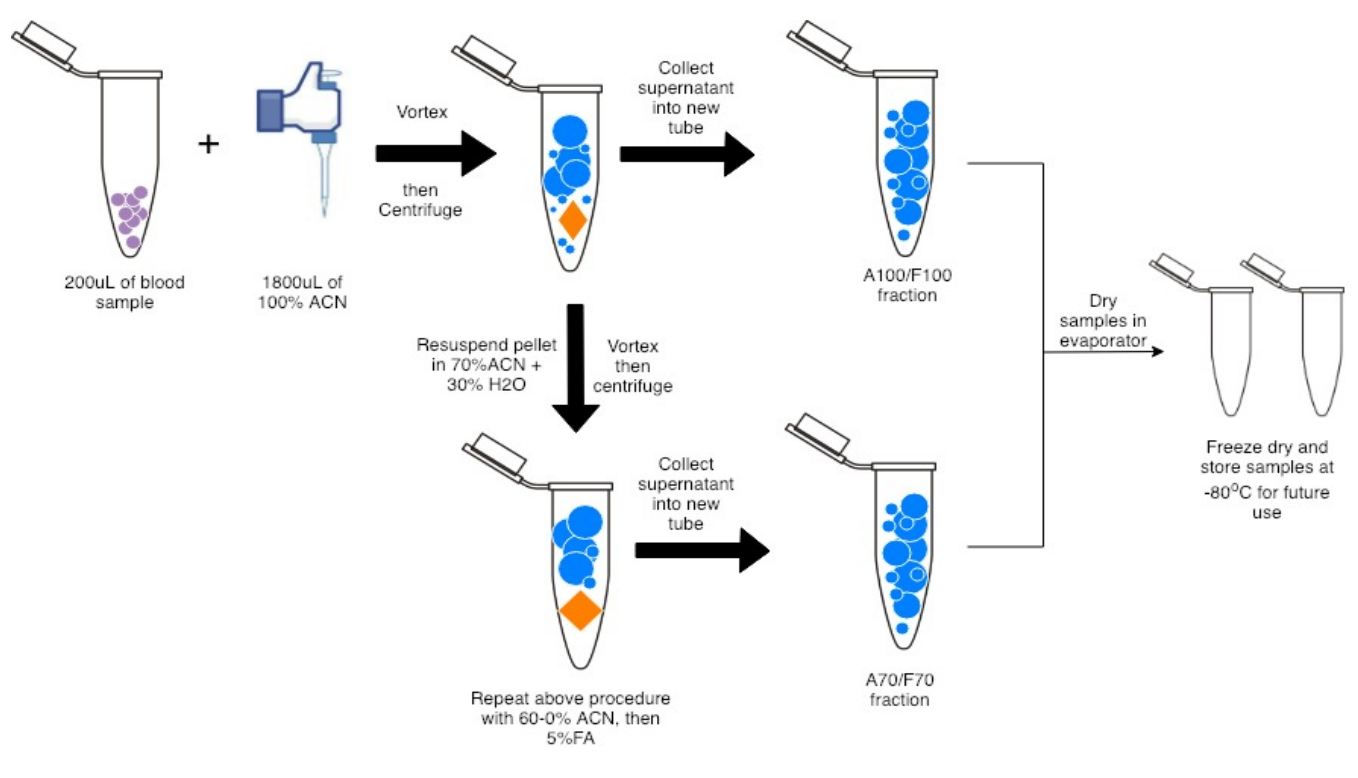

Figure 3.8. 1. Demonstration of step-wise organic extraction of peptides with acetonitrile/water solvents. A total of $\mathbf{1 0}$ fractions were collected for each individual ABS/FBS sample.

\subsection{Dumbroff Protein Assay}

The concentration of proteins in each fraction was determined by dot blotting method of Dumbroff on a Whatman number 1 filter paper alongside BSA standards (range from 0.0mg/mL to $5.0 \mathrm{mg} / \mathrm{mL}$ ). The proteins were mixed in a 1:1 ratio with $2 X$ SDS sample loading buffer, and $2 \mu \mathrm{L}$ of volume was dotted on Whatman number 1 filter paper along with BSA standards at the bottom in the same detergent buffer before drying. The dot-blot was rinsed in methanol and then stained with CBBR in water, methanol and acetic acid. It was allowed to stain for 15 minutes. The blots were de-stained in water, methanol and acetic acid. The Dumbroff method has an advantage prior to SDS-PAGE: the sample content can be measured in detergent and then directly loaded on the gel [3], [39]. 


\subsection{Protein Resolved by SDS-PAGE:}

Tricine-SDS-PAGE was used to resolve the protein fractions for the comparison selectivity [3], [39]. The protein fractions in 1:1 2X SDS were resolved on polyacrylamide gels. Polyacrylamide gels with $9 \%$ monomer resolving gels with Tris- $\mathrm{HCl} \mathrm{pH} 8.8$ and $4 \%$ monomer stacking gels with Tris- $\mathrm{HCl} \mathrm{pH} 6.8$ were run in tricine anode and cathode buffers. Protein fractions were resolved and compared by SDS-PAGE alongside protein molecular weight standards [74]. The gels were then stained with CBBR in methanol and acetic acid [39].

\subsection{C18 Column Packing}

A C18 reversed phase HPLC column was packed with a column guard. For every sample, the C18 resin solvent was prepared by mixing a C18 Zorbax 5 micron 300 Angstrom with chloroform. C18 packing was performed with a high-pressure liquid chromatography (HPLC) pump set at $100 \%$ acetonitrile in $0.1 \%$ of acetic acid (100\% organic buffer) over a $15 \mathrm{~cm}$

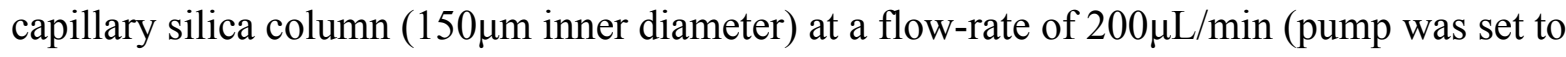
normal mode -range from $20-200 \mu \mathrm{L} / \mathrm{min}$ ). In this case, the column guard was filled with $2 / 3$ of the mixture (Zorbax and chloroform) and attached to the pump. The C18 resin migrated down to the column by high-pressure pump. If the pressure of the pump went above 200 bars, the pump had to be stopped and the flow rate was set to $0 \mu \mathrm{L} / \mathrm{min}$. Once the entire silica column was fully packed, it was sealed and dated and the resin type (C18) was labeled.

\subsection{Blank Runs}

A blank run was where there was no samples injected to the column and it was recorded on a chromatogram over a 30 -minute gradient from $5 \%$ to $65 \%$ of acetonitrile using Nano-LC-ESI- 
MS/MS. Each new packed column was washed at least 3 times with both water and acetonitrile and recorded as a blank on a chromatogram. The blanks were run in order to wash off the contaminants of the column before column conditioning and sample injections to the mass spectrometer. After the blank run was finished, the column was then equilibrated by flushing the C18 column with a high organic buffer of 50\% acetonitrile for 20 minutes, and then 5\% acetonitrile for 10 minute.

\subsection{Sample Introduction into the MS Detector}

The samples were introduced from a syringe into the loop via a Rhodynne injector before injecting onto the analytical column, and then into the LC flow using a divert valve that enters the MS detector [50]. 20 $\mu \mathrm{L}$ mixture of protein sample and 5\%FA were introduced each time.

\subsection{Column Conditioning with TRP3}

The purpose of column conditioning was to coat the C18 column with a digested TRP3 protein. A TRP3 standard was used to confirm the sensitivity and mass accuracy of the system, which made of $5 \mu \mathrm{L}$ of each three non-human proteins (rabbit muscle glycogen phosphorylase B, yeast alcohol dehydrogenase, and bovine cytochrome c-like-protein) in $1485 \mu \mathrm{L}$ of $1 \%$ of acetic acid. The mass spectrometer was cleaned and calibrated. The HPLC pump was set to $50 \%$ acetonitrile for 20 minutes and then $5 \%$ acetonitrile for 10 minutes manually in order to clean the column. The column conditioning was performed by the TRP 3 peptides coated onto the C18 reverse phase column in a 120-minute tune method. A sample injection valve was used for HPLC transferring sample from a syringe to a sample loop. The sample loop was connected via a change in valve configuration, to a high-pressure mobile phase stream, which carried the sample 
into the column. A $20 \mu \mathrm{L}$ of TRP3 was introduced using a syringe into the sample loop via a port on the injection valve on LOAD. The sample injector was then switched to INJECT and the column was attached to the mass spectrometer ion trap source. The HPLC pump was then set to $50 \%$ acetonitrile and sample injector was switched to LOAD when the first TRP3 peak appeared on the chromatogram. A second TRP3 peak appeared at 50\% acetonitrile. This procedure was repeated three times until a total of six peaks were collected [4], [46], [60].

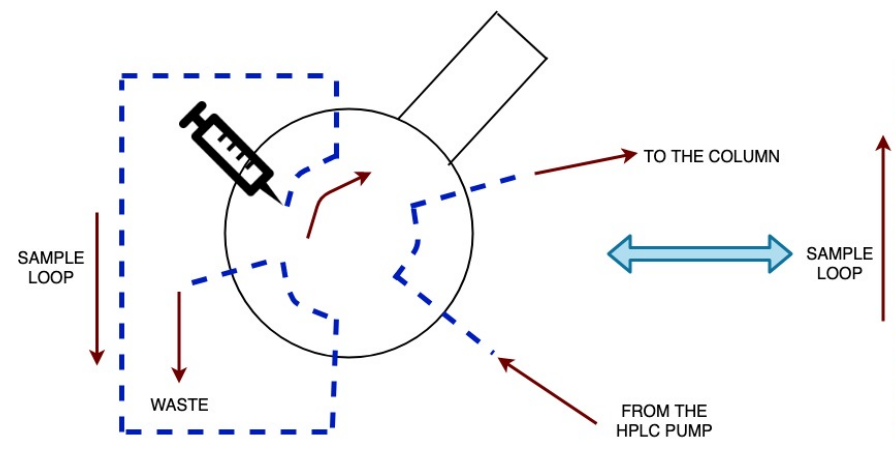

LOAD

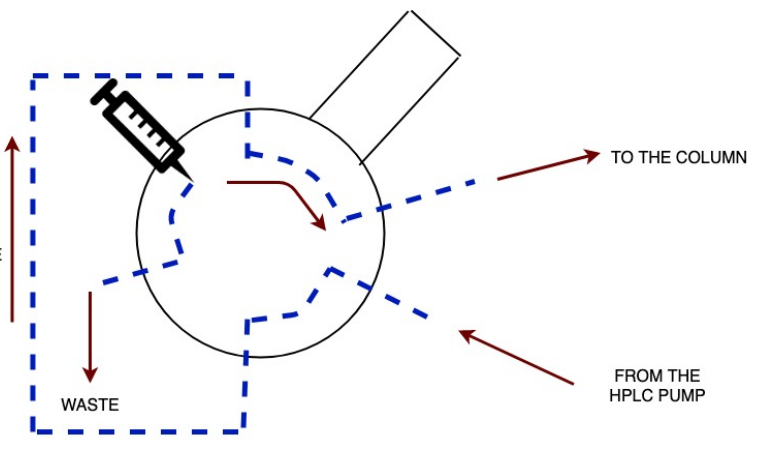

INJECT

Figure 3.15. 1. HPLC manual injection. Sample was introduced with a syringe and stayed in the sample loop when it was on LOAD. Solvents picked up samples from the sample loop and pushed it down to the column when it was on INJECT.

\subsection{Sample Zip-tipping}

Each of the previously extracted protein fractions was re-suspended by adding $200 \mu \mathrm{L}$ of $5 \%$ formic acid and vortexed to mix well. Sample was then zip-tipped in 65\% acetonitrile (organic solvent) and 5\% formic acid (aqueous solvent). 5 volumes of $1 \mathrm{~mL}$ solutions were prepared in 5 eppendorf tubes labeled as "B1 A1 S A2 B2", where B was 65\% acetonitrile organic solvent, A was $5 \%$ formic acid, and $\mathrm{S}$ was the extracted protein fraction. The organic solvent was used to concentrate and precipitate the peptides from the sample onto the resin pipette tip, whereas the 
aqueous solvent was used to wash off other compounds from the environment and desalt. A P20 micropipettor was set to $20 \mu \mathrm{L}$, and a $\mathrm{C} 18$ reversed phase pipette zip-tip was placed on the pipettor. $20 \mu \mathrm{L}$ of B1 solution was pipetted slowly and aspirated to avoid introducing air into the packing materials and to maximize binding (the $\mathrm{C} 18$ resin could not be dried out once it was hydrated). The solution was then slowly expelled back into the tube. The solution was pipetted and expelled 10 times into the same tube. The buffer A was the wash solution; $20 \mu \mathrm{L}$ of A1 solution was aspirated and expelled back into the tube for 5 times. The pipette tip was clean and placed to the sample tube. $20 \mu \mathrm{L}$ of the sample solution was aspirated and expelled back into the eppendorf tube for 20 times. $20 \mu \mathrm{L}$ of A2 solution was aspirated one time only, and then the solution was expelled into a waste container. At last, $2 \mu \mathrm{L}$ aliquot of B2 solution was aspirated (the $2 \mu \mathrm{L}$ mark was indicated on the pipette tip) and expelled into a new eppendorf tube. The micropipettor was set to $18 \mu \mathrm{L}$, and then $18 \mu \mathrm{L}$ of $5 \%$ formic acid was added to the tube with the $2 \mu \mathrm{L}$ buffer B solution. The zip-tipped protein sample was kept in ice [4], [46]. 


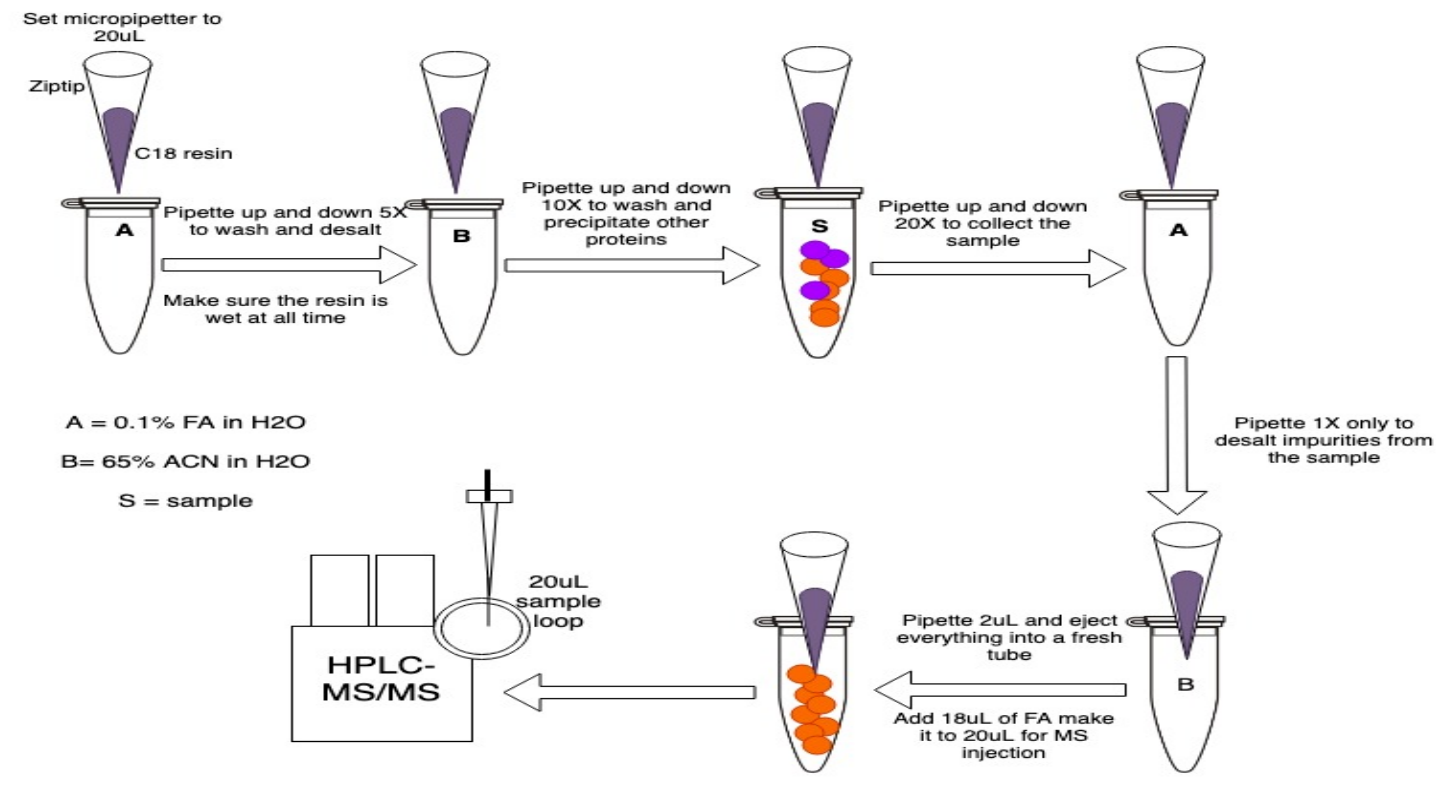

Figure 3.16. 1. Demonstration of C18 sample zip-tipping. The C18 zip-tip was washed and desalted before collecting the samples for MS detection.

\subsection{Analytical LC-ESI-MS/MS}

All preparative peptides were collected by zip-tipping prior to injections as described above. Fractionated proteins were resolved by $\mathrm{C} 18$ reversed phase chromatography $(150 \mu \mathrm{m} \mathrm{ID,} 15 \mathrm{~cm}$ column). The sample was analyzed over an 85 minutes gradient sequence, which started at $5 \%$, ramped to $12 \%$ and then increased to $65 \%$ for 5 minutes, decreased to $50 \%$ for 15 minutes then declined to a final proportion of $5 \%$ of acetonitrile at a flow rate of $5 \mu \mathrm{L} / \mathrm{min}$ with an Agilent 1200 series capillary pump via an emitter needle Nano-spray into an ion trap. The MS/MS data chromatograms were searched against a library of proteins, cDNAs, and genomic DNA using SEQUEST or X!TANDEM algorithms [3]. 


\subsection{Column Equilibration}

The column was equilibrated to the initial aqueous/organic solvents composition before performing another analysis. The purpose of the equilibration was to wash off all the previous peptides that stuck to the column. A column equilibration was performed by flushing the C18 column with a high organic buffer $(50 \% \mathrm{ACN})$ for 20 minutes. The alternative column equilibration was to make the first run a blank run before the real analysis [39], [41].

\subsection{Correlation Analysis}

In this study $1,554,347$ precursor ions from fetal versus adult MS/MS spectra were recorded by nano-LC-ESI-MS/MS. Correlation analysis of ion trap data was performed with X!TANDEM [7] and SEQUEST [66] algorithms to match tandem mass spectra to peptide sequences from a library of 209,111 bovine proteins that differ by at least one amino acid from RIKEN, IMAGE, RefSeq, NCBI, Swiss Prot, TrEMBLE, ENSEMBL, UNIPROT and UNIPARC along with available Gene Symbols, all previous accession numbers, description fields and any other available annotation that was rendered non-redundant by protein sequence in SQL Server last assembled in 2015 [38], [60]. Endogenous peptides with precursors greater than 10,000 (E4) arbitrary counts were fit as fully tryptic peptides and/or tryptic phosphor-peptides on separate servers for each algorithm and the results combined, and compared in SQL Server/R. The $\mathrm{X}$ !TANDEM default ion trap data settings of $\pm 3 \mathrm{~m} / \mathrm{z}$ from precursors peptides considered from 300 to $2000 \mathrm{~m} / \mathrm{z}$ with a tolerance of $0.5 \mathrm{Da}$ error in the fragments were used [7], [37], [39], [63], [64], [75]. The best fit peptide of the MS/MS spectra to fully tryptic and/or tryptic phospho peptides at charge states of +2 versus +3 were accepted with additional acetylation, or oxidation of methionine and with possible loss of water or ammonia. The resulting accession numbers, 
actual and estimated masses, correlated peptide sequences, peptide and protein scores, resulting protein sequences and other associated data were captured and assembled together in an SQL Server relational database [65].

\subsection{Data Sampling, Sorting, Transformation and Visualization}

The linear quadrupole ion trap provided the precursor ion intensity values and the peptide fragment MS/MS spectra that were correlated to specific tryptic peptide of STYP

phosphopeptides by the X!TANDEM and SEQUEST algorithms. The MS and MS/MS spectra together with the results of the X!TANDEM and SEQUEST algorithms were parsed into a SQL Server database and redundant fits of MS/MS spectra were filtered to the best fit and the observation frequency was corrected on the basis of total MS/MS spectra before statistical and graphical analysis with the generic $\mathrm{R}$ data system [37], [62], [65], [76], [77]. The peptide to protein correlation counts for each gene symbol were compared for fetal versus adult serum using the Chi Square test using equation \#1:

i)

$$
\frac{\left[(\text { Fetal }- \text { Adult })^{\wedge} 2\right]}{\text { Adult }+1}
$$

EQN\#1

The precursor intensity data for MS/MS spectra were $\log _{10}$ transformed, tested for normality and analyzed across institution/study and diseases versus controls by means, standard errors and ANOVA [37], [62], [77]. The entirely independent analysis of the precursor intensity using the rigorous ANOVA with Tukey Kramer HSD test versus multiple controls was achieved using a 64-bit R server. 


\subsection{RESULTS}

There was $\sim 99 \%$ agreement on the proteins independently identified by peptidomics versus proteomics. Exogenous tryptic peptide sequences showed low levels of overlap with endogenous peptide sequences (23\%). Both sets of independent peptide sequences mapped to the same group of protein accessions (99\%), which was an unambiguous and clear demonstration that LC-ESIMS/MS with a sensitive ion trap shows low error rates of peptide and protein identification. LCESI-MS/MS of blood with a simple quadrupole ion trap was a sensitive and reliable technology that permits the accurate identification and relative quantification of observation frequency or precursor intensity from tens of thousands of blood proteins by random and independent sampling. It appears that the combination of step wise fractionation of serum proteins over disposable quaternary amine resin prior to tryptic digestion, or organic extraction of endogenous peptides, and LC-ESI-MS/MS will provide a sensitive and direct method to compare the expression of proteins over different physiological states such as fetal versus adult serum. Many proteins associated with cell growth pathways and DNA or RNA binding factors were observed to differ between the fetal versus adult blood. The analysis of the results by STRING [78] has reinforced the previous conclusion from human serum that blood contains a large number of cellular proteins that apparently exist as protein complexes in circulation and at least some of these must come from blood cells. 


\subsection{Cell morphology}

The cells grown in fetal serum divided rapidly forming small spherical cells that frequently forms spherical foci organized into a globe of cells that extended vertically upwards piled onto each other. In contrast, cells cultured in adult serum frequency formed a monolayer of elongated rhomboids with dendritic extensions that divided slowly and often died after a few passages.

Staining with rhodamine phalliodin showed changes in the morphology of the cells (see Appendix). Cells cultured in FBS that formed in rounded symmetrical shape was measured to be average 10 microns in length while cells cultured in ABS with dendritic shape was measured to be average 40 microns in length. One-way ANOVA analysis showed statistically significant measurement of the cell lengths between adult versus fetal serum (Fig. 1)(see Appendix for more cell images).
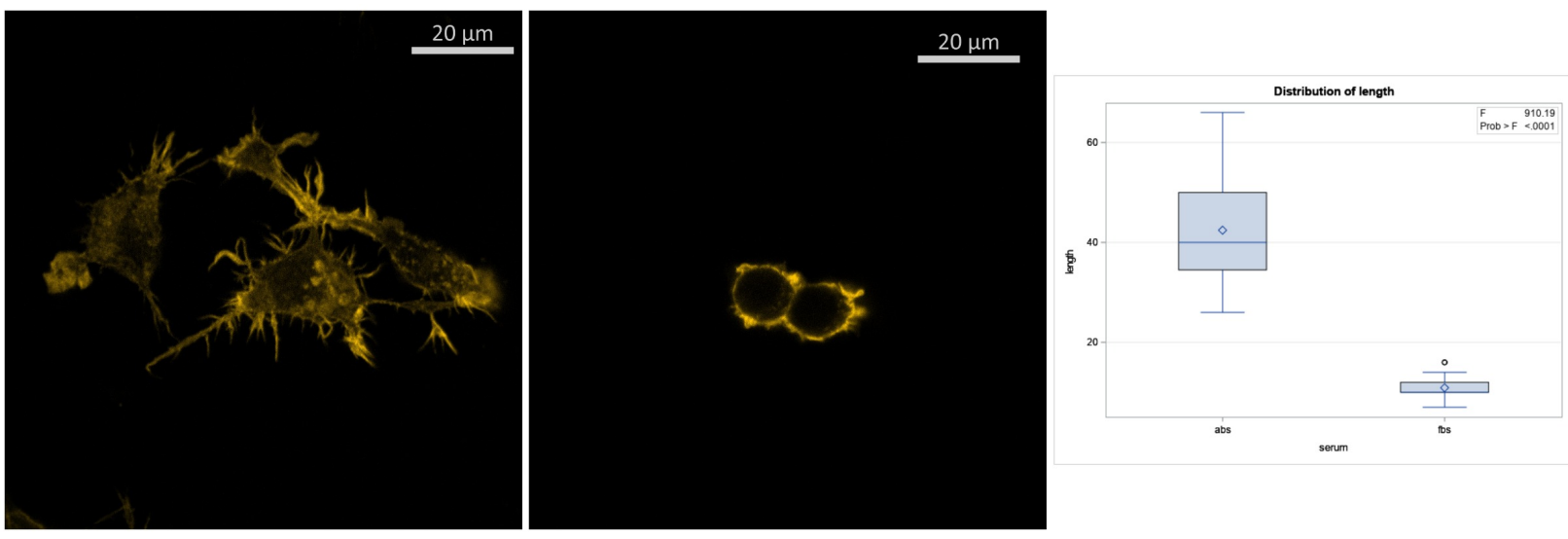

A

B

C

Figure 1. The effect of fetal versus adult serum on the morphology of RAW 264.7 murine macrophages cultured in DMEM plus 5\% bovine fetal or adult serum. The cells were stained with rhodamine pholloidin and the images were taken under a confocal microscope. Panel A: Cells grown in Adult bovine serum; B, Cells grown in Fetal bovine serum; C, the distribution of cell length in Adult (ABS) versus Fetal (FBS) serum. Ten cells were measured from 3 spots on 3 cover slips from 3 independent batches of fetal versus adult serum. The longest axis of the cell was measured. 
One-way ANOVA Statistical Test on the means between the cell lengths of ABS versus FBS:

Estimated Std. Error t value $\operatorname{Pr}(>|t|)$

(Intercept) $\quad 46.0438 \quad 2.145821 .457<2 \mathrm{e}-16 * * *$

Slide $\quad-1.1375 \quad 0.6852 \quad-1.660 \quad 0.0989$.

$\begin{array}{lllll}\text { Replicate } & -\mathbf{0 . 7 7 9 2} & \mathbf{0 . 6 8 5 2} & \mathbf{- 1 . 1 3 7} & \mathbf{0 . 2 5 7 2}\end{array}$

Treatment[T.FBS] $-31.5375 \quad 1.0409-30.299<2 \mathrm{e}-16 * * *$

Signif. codes: 0 ***' $0.0011^{\prime * *} 0.011^{\prime * \prime} 0.05$ '.' $0.11^{\prime}{ }^{\prime} 1$

Residual standard error: 6.583 on 156 degrees of freedom

Multiple R-squared: $0.8552, \quad$ Adjusted R-squared: 0.8524

F-statistic: 307.1 on 3 and $156 \mathrm{DF}$, p-value: $<2.2 \mathrm{e}-16$

\subsection{Protein partition chromatography}

The proteins of ABS and FBS were separated over ceramic quaternary amine resin [37], [39] and the fractions tested for protein content by the Dumbroff method [79] prior to resolving the proteins by tricine SDS-PAGE that showed selectivity over the course of the salt step gradient (Fig. 2A \&3). 
A

Proteins

$25 \mu 1$ Sera

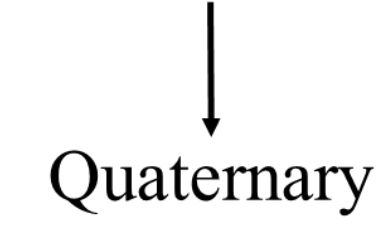

Step Wise $\mathrm{NaCl}$

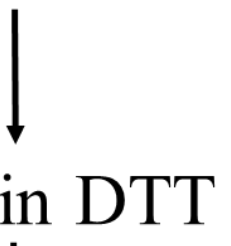

Trypsin DTT

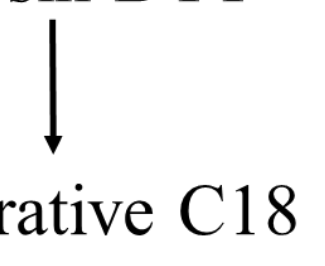

Preparative C18

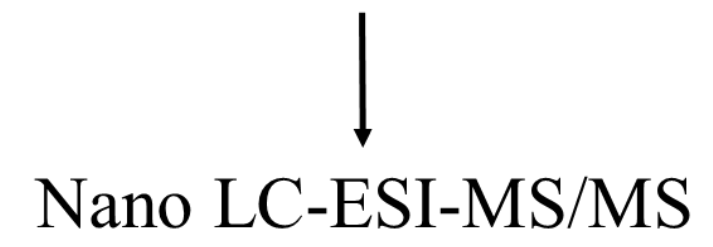

B

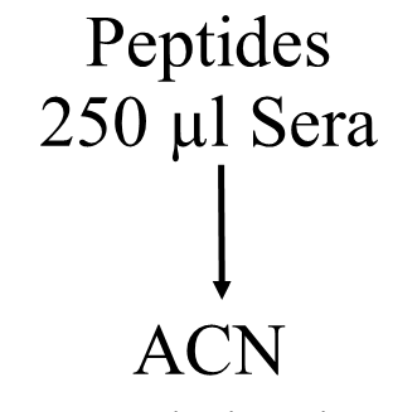

Precipitation

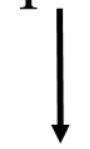

Step Wise H2O
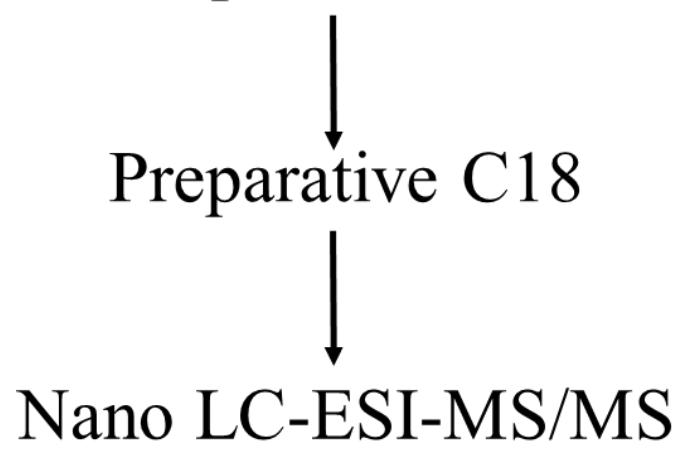

Figure 2. Flowchart of the intact proteins and endogenous peptides isolation analysis steps. A: Steps of intact proteins by step-gradient salt extraction over a QA resin partition chromatography. B: Steps of endogenous peptides by step-wise acetonitrile water extraction. 
A
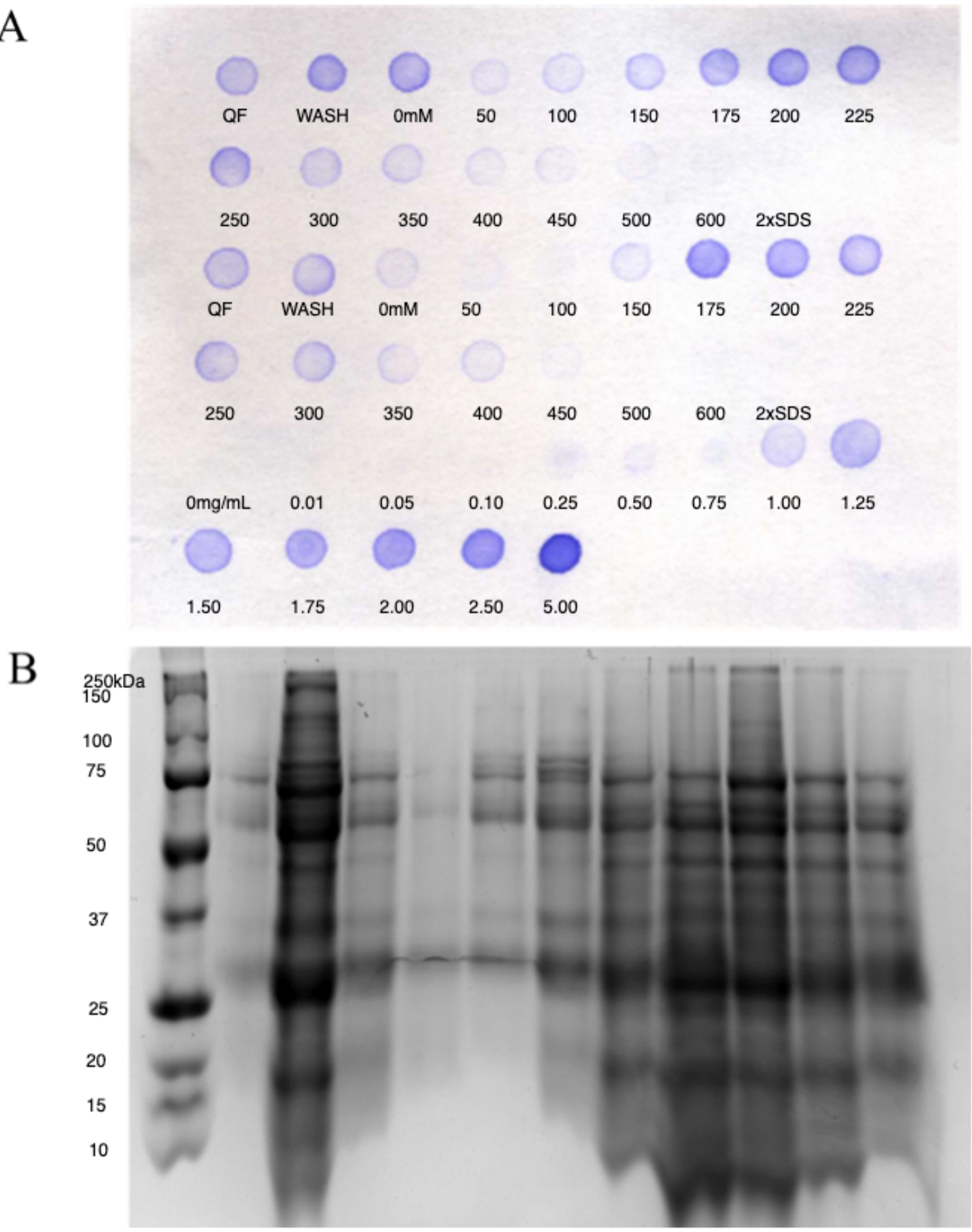

Figure 3. The fractionation of $\mathrm{FBS}$ by a step gradient of $\mathrm{NaCl}$ in $20 \mathrm{mM}$ Tris $\mathrm{pH} 8.85$ buffer. Panels A: Dumbroff protein assay shows the protein potent in each sample fraction; Panel B: Tricine SDS-PAGE shows the selectivity between sample fractions. Lanes: 1, Molecular Weight Standard; 2, Flow-through; 3, Wash1; 4, Wash2; 5, 0mM $\mathrm{NaCl} ; 6,50 \mathrm{mM} \mathrm{NaCl} ; 7,100 \mathrm{mM} ; 8,150 \mathrm{mM} ; 9,200 \mathrm{mM} ; 10,250 \mathrm{mM} ; 11,300 \mathrm{mM} ; 12$, $350 \mathrm{mM}$. 


\subsection{Peptide organic extraction}

The organic precipitate of endogenous peptides from ABS and FBS were separated by a water acetonitrile step gradient and differential centrifugation, tested for protein content by the Dumbroff method before resolving the polypeptides on tricine SDS-PAGE that showed selectivity for low molecular mass polypeptides (Fig. 2B \&4).

A

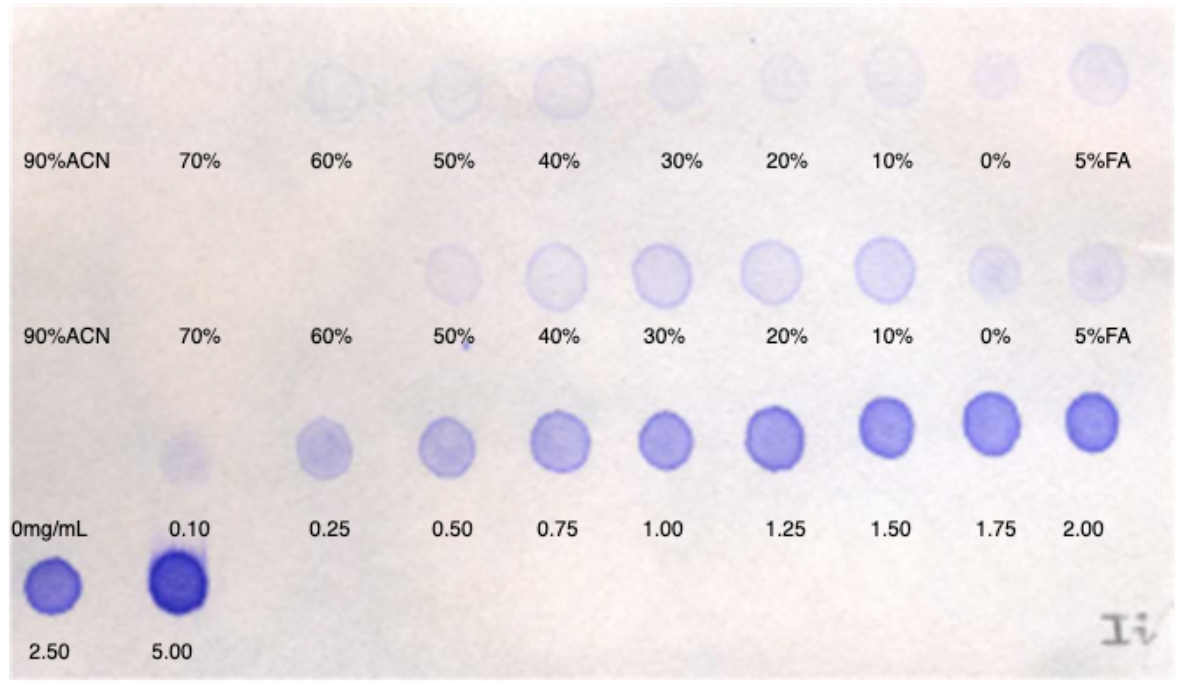

B

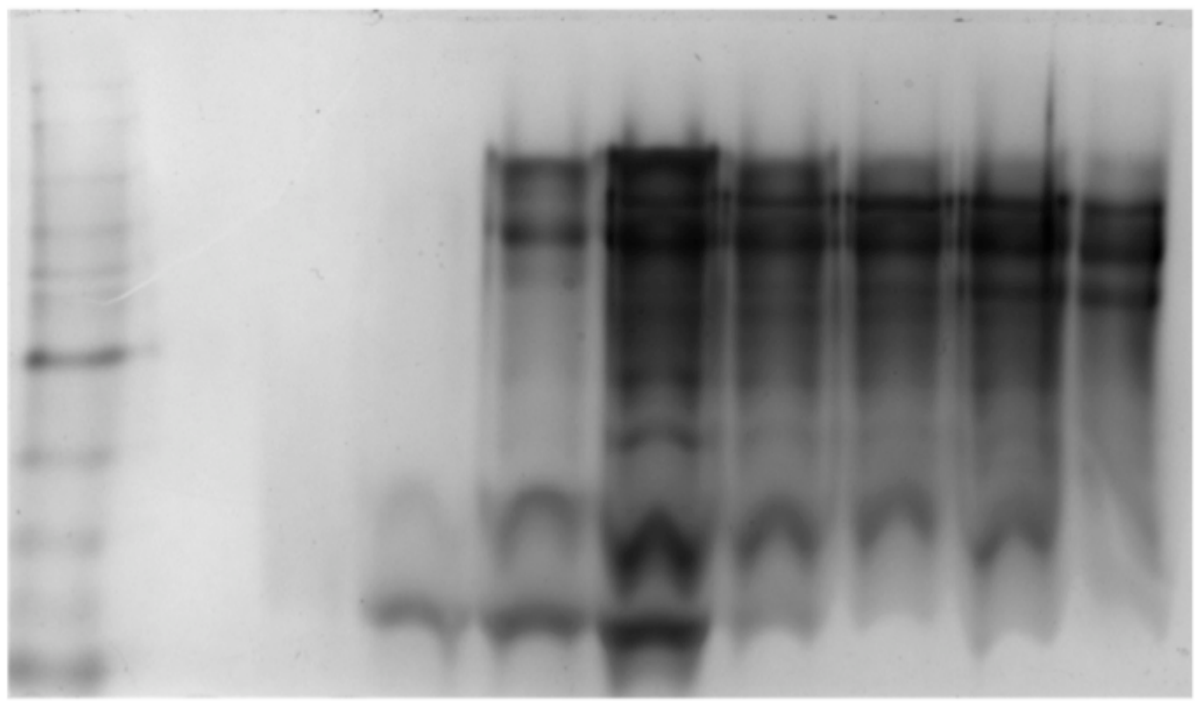

Figure 4. The sequential extraction of low molecular mass polypeptides from serum using a step-wise solublization in organic/water. Panels A: Dumbroff protein assay; Panel B: Tricine SDS-PAGE shows the selectivity between sample fractions. Lanes 1, Molecular Weight Standard; $2,90 \%$ acetonitrile supernatant; $3,70 \%$ ACN supernatant, $4,60 \% \mathrm{ACN}$ 
supernatant; 5, 50\% ACN supernatant; 6, 40\% ACN supernatant; 7, 30\% ACN supernatant; 8, 20\% ACN supernatant; 9, 10\% ACN supernatant; 10, 0\% ACN supernatant.

\subsection{Normality and variation across treatments and replicates}

The $\log _{10}$ precursor intensity values from all treatments and replicates together approached a linear and Gaussian distribution (Fig. 5A). The average results of the 6 experiments (2 treatments $\mathrm{x} 3$ replicates) were comparable in terms of the intensity of the precursor peptides obtained with and without the consideration of phosphorylation (Fig. 5B).

A

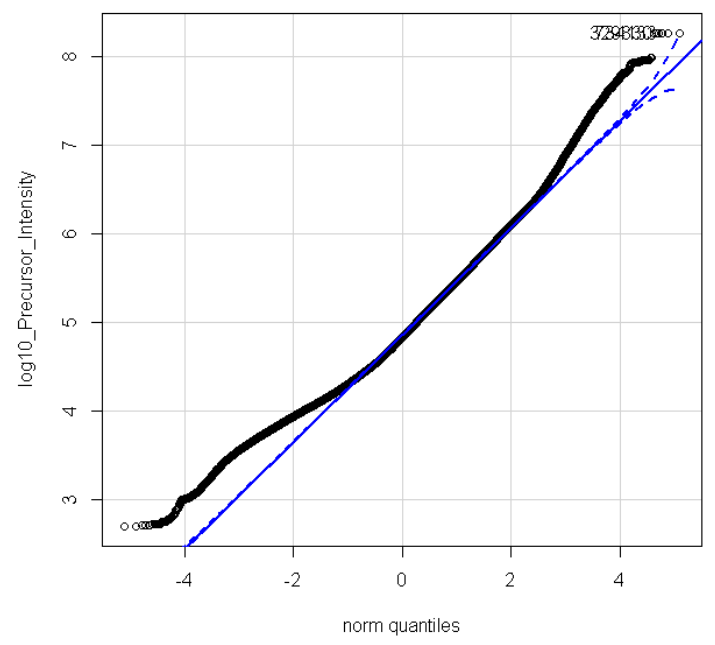

B

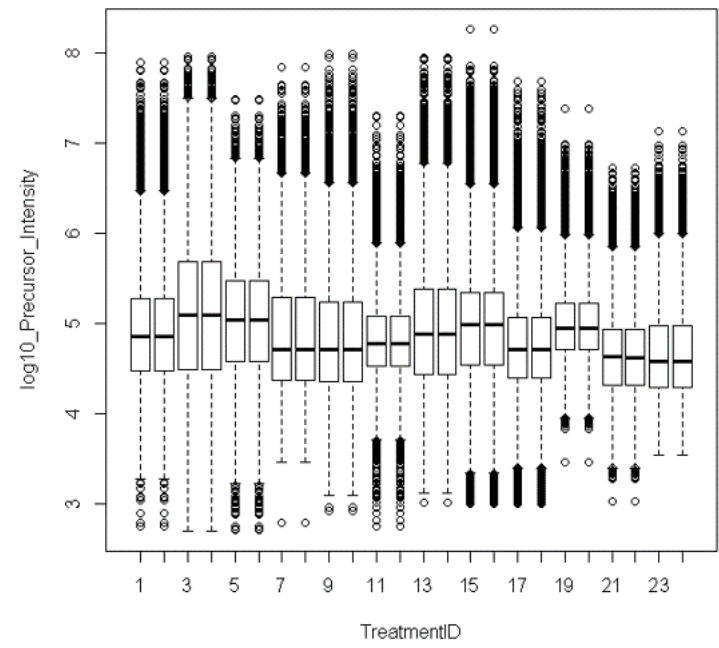

Figure 5. The reproducibility of the fetal versus adult serum samples. Panels: $A$, the quantile Q-Q plot showing the normality of the log10 transformed intensity values; $B$, the box plot showing the average $\log _{10}$ intensity and variation in $\log 10$ and $99 \%$ confidence interval is shown for the adult versus fetal serum replicates. (ID\# 1-12:ABS treatments; \#13-24: FBS treatments) 


\subsection{SQL Server Filtering}

The pool of tryptic peptides from proteins and endogenous tryptic (TRYP) peptides and/or tryptic phosphor-peptides (STYP) were randomly and independently sampled without replacement by liquid chromatography, nano-electrospray ionization and tandem mass spectrometry (LC-ESI-MS/MS) [60] from FBS versus ABS. The raw correlations from precursors $\geq$ E4 intensity counts were filtered to retain only the best fit by charge state and peptide sequence in SQL Server to entirely avoid re-use of the same MS/MS spectra. The LCESI-MS/MS of adult serum resulted in 1,553,347 MS/MS spectra that spectra resulting in 61,152 best fit correlations tryptic by the X!TANDEM (Table 1).

Table 1. The filtering of the MS/MS spectra and the resulting correlations to peptides to ensure that only the best hit was accepted. The total number of MS/MS spectra of greater than $\mathrm{E} 4$ counts collected in this study was $526,870 \mathrm{MS} / \mathrm{MS}$ spectra from organic extraction and 1,027,477 from quaternary amine fractionation of proteins followed by digestion resulting in a total of $1,554,347 \mathrm{MS} / \mathrm{MS}$ spectra.

\begin{tabular}{|c|c|c|c|c|c|c|c|}
\hline & \multicolumn{2}{|l|}{ Redundant MS/MS } & \multirow[b]{2}{*}{ Redundant MS/MS Spectra } & \multirow[b]{2}{*}{ Distinct MS/MS Spectra } & \multirow[b]{2}{*}{ Protein Identifications } & \multirow[b]{2}{*}{ Distinct Protein Identifications } & \multirow[b]{2}{*}{ Distinct Peptide Identifications } \\
\hline & PSTY Mod & Total Spectra Count & & & & & \\
\hline TRYP & 0 & 2616468 & 36560334 & 2353004 & 36560334 & 204332 & 2777338 \\
\hline \multirow[t]{9}{*}{ TRYP-PSTY } & 1 & 2616468 & 36297856 & 2351922 & 36297856 & 201220 & 2598348 \\
\hline & & & & & & & \\
\hline & Best Hit Spectra & & & & & & \\
\hline & & Total Spectra Count & Redundant MS/MS Spectra & Distinct MS/MS Spectra & Protein Identifications & Distinct Protein Identifications & Distinct Peptide Identifications \\
\hline & No Mods & 2616468 & 7782701 & 2353004 & 7782701 & 179653 & 1063402 \\
\hline & PSTY & 2616468 & 7730807 & 2351922 & 7730807 & 176176 & 1040077 \\
\hline & TOTAL & 5232936 & & & & & \\
\hline & Best Hit by Engine & isPSTYMOD & Redundant MS/MS Spectra & Distinct MS/MS Spectra & Protein Identifications & Distinct Protein Identifications & Distinct Peptide Identifications \\
\hline & SearchEngineID & & & & & & \\
\hline XITANDEM & 2 & 0 & 383535 & 127250 & 383535 & 57308 & 61152 \\
\hline XITANDEM & 2 & 1 & 342083 & 116827 & 342083 & 44146 & 57435 \\
\hline SEQUEST & 9 & 0 & 7399166 & 2344666 & 7399166 & 178895 & 1021440 \\
\hline SEQUEST & 9 & 1 & 7388724 & 2345002 & 7388724 & 176133 & 998966 \\
\hline
\end{tabular}




\subsection{Peptide and protein identification}

Organic extraction identified a set of 58,200 proteins compared to 59,799 proteins identified from protein separation over salt partition chromatography. A set of 142,197 peptides was only found in organic extraction compared to a set of 348,543 peptides found only in salt partition chromatography showed a $99 \%$ confidence on the protein identity between ABS versus FBS (Table 2). The optimal organic solvent composition was from 40 to $60 \%$ of ACN while the optimal salt elution was from 100 to $175 \mathrm{mM} \mathrm{NaCl}$ (Table 3). The average results of the 6 experiments were comparable in terms of the intensity of the precursor peptides obtained (Fig.5). The filtered results were then analyzed by the generic $\mathrm{R}$ statistical system that showed more than 55,000 protein accession and more than 20,000 proteins gene symbols were detected by the sum of the X!TANDEM and SEQUEST results with at least 5 peptides (Fig. 6).

Table 2. Comparison of organic extraction of peptides versus separation of proteins over quaternary amine chromatography (See Fig.2). The redundant and distinct proteins and peptides and the overlap between treatments were computed in SQL Server.

\begin{tabular}{|c|c|c|c|c|c|}
\hline Total Distinct Proteins & Organic Distinct Proteins & Salt Distinct Proteins & Common Distinct Proteins & Found Only in Organic & Found Only in Salt \\
\hline 60233 & 58200 & 59799 & 57766 & 434 & 2033 \\
\hline Total Distinct peptides & Organic Distinct peptides & Salt Distinct peptides & Common Distinct Peptides & Found only in Organic & Found Only in Salt \\
\hline 573640 & 225097 & 431443 & 82900 & 142197 & 348543 \\
\hline
\end{tabular}


Table 3. Proteins separation over the salt fractions versus endogenous peptide separation over organic water on the proteins and tryptic peptides identified (See Fig.2).

\begin{tabular}{|c|c|c|c|c|}
\hline \multicolumn{5}{|l|}{ Peptides } \\
\hline FractionNumber & Concentration (\%) & Redundant Protein & \multicolumn{2}{|c|}{ Distinct Protein Distinct Peptide } \\
\hline & $0 \% A c N$ & 223397 & 44397 & 48853 \\
\hline & $5 \% \mathrm{AcN}$ & 249899 & 46250 & 55977 \\
\hline 3 & $10 \% A c N$ & 250107 & 45728 & 53953 \\
\hline & $20 \% A c N$ & 236723 & 44892 & 49899 \\
\hline & $30 \% A c N$ & 249846 & 46750 & 58077 \\
\hline & $40 \% A c N$ & 263797 & 48017 & 63652 \\
\hline & $50 \% A c N$ & 271287 & 47568 & 62042 \\
\hline & $60 \% A c N$ & 266640 & 47248 & 62155 \\
\hline & $70 \% A c N$ & 278624 & 46975 & 59369 \\
\hline \multirow[b]{3}{*}{ Proteins } & \multirow[t]{2}{*}{$90 \% \mathrm{AcN}$} & \multirow[t]{2}{*}{274823} & 46150 & 54845 \\
\hline & & & 463975 & 568822 \\
\hline & \multicolumn{4}{|c|}{ Proteins } \\
\hline FractionNumber & Concentration (mM) & Redundant Protein & Distinct Protein & Distinct Peptide \\
\hline \multicolumn{2}{|c|}{$10 \mathrm{mM}$} & 430748 & 51459 & 87107 \\
\hline \multicolumn{2}{|c|}{$250 \mathrm{mM}$} & 393872 & 50332 & 79094 \\
\hline \multicolumn{2}{|c|}{$3100 \mathrm{mM}$} & 517203 & 52308 & 91084 \\
\hline \multicolumn{2}{|r|}{$4150 \mathrm{mM}$} & 478902 & 52205 & 93276 \\
\hline \multicolumn{2}{|r|}{$5175 \mathrm{mM}$} & 530335 & 53440 & 109606 \\
\hline \multicolumn{2}{|r|}{$6200 \mathrm{mM}$} & 379348 & 50820 & 83834 \\
\hline \multicolumn{2}{|r|}{$7225 \mathrm{mM}$} & 324976 & 50150 & 78085 \\
\hline \multicolumn{2}{|c|}{$8250 \mathrm{mM}$} & 278455 & 48049 & 64995 \\
\hline \multicolumn{2}{|r|}{$9300 \mathrm{mM}$} & 382052 & 50746 & 81509 \\
\hline \multicolumn{2}{|c|}{$10350 \mathrm{mM}$} & 351982 & 49386 & 73052 \\
\hline \multicolumn{2}{|c|}{$11400 \mathrm{mM}$} & 326096 & 48878 & 69684 \\
\hline \multicolumn{2}{|c|}{$12450 \mathrm{mM}$} & 261822 & 46261 & 57871 \\
\hline \multicolumn{2}{|c|}{$13500 \mathrm{mM}$} & 404293 & 50257 & 79141 \\
\hline \multicolumn{2}{|c|}{$14600 \mathrm{mM}$} & 322479 & 48271 & 67073 \\
\hline \multicolumn{2}{|c|}{15 BdDigest } & 211181 & 43258 & 46105 \\
\hline \multirow[t]{2}{*}{$16 \mathrm{C}$} & QF & 399748 & 50099 & 77835 \\
\hline & & & 795919 & 1239351 \\
\hline
\end{tabular}


A

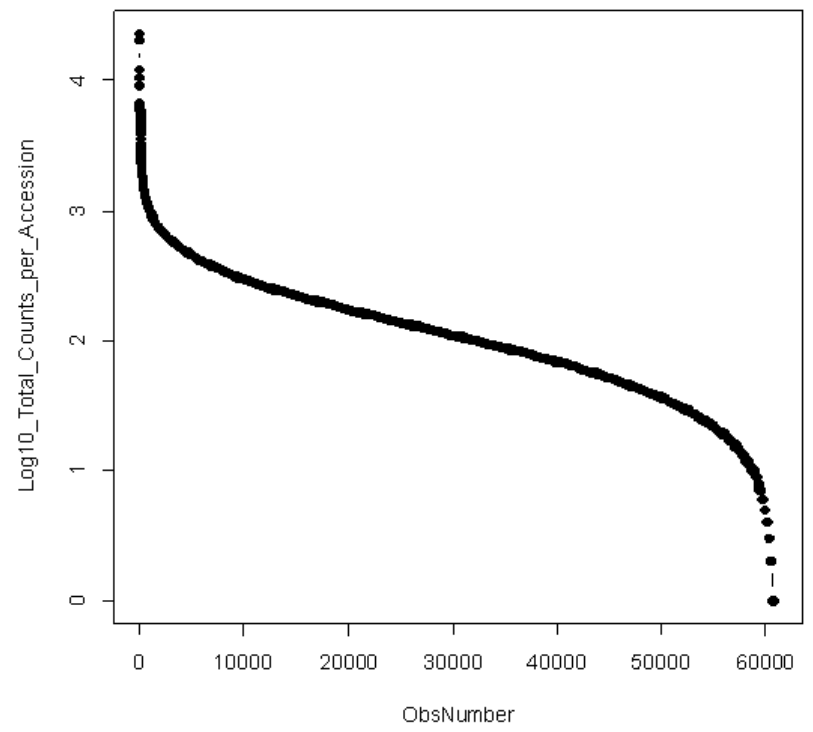

B

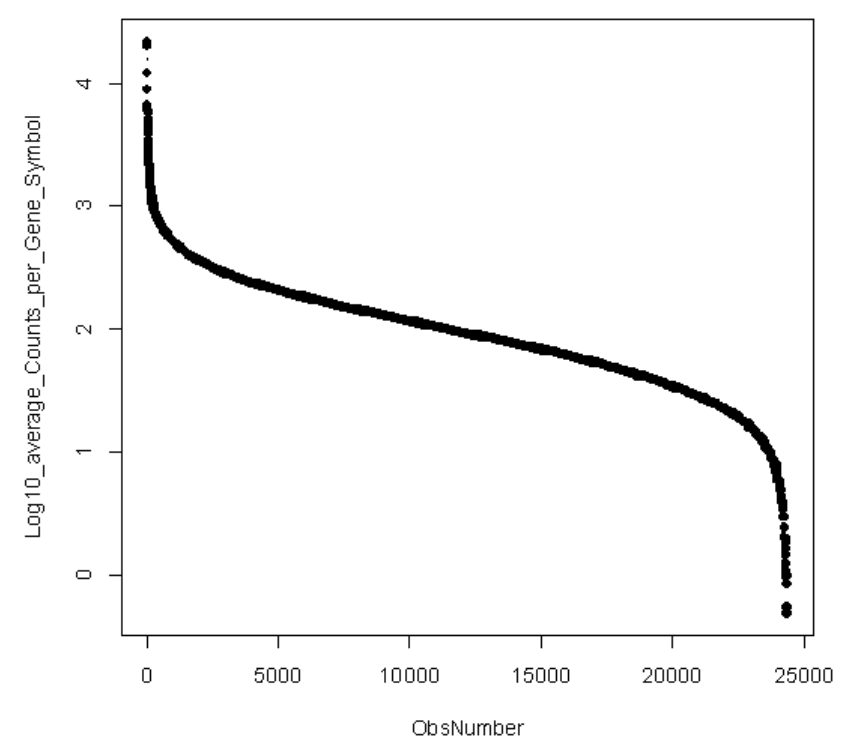

Figure 6. The total number of protein accessions and Gene symbols from the Bovine protein library that were correlated by the X!TANDEM and SEQUEST algorithms combined. Panels: A, redundant protein accessions (after filtration of the redundant MS/MS); B, best correlation per Gene symbol. 


\subsection{X!TANDEM versus SEQUEST}

The SEQUEST algorithm identified some 58,000 proteins with at least 5 peptides and X!TANDEM identified identified some 12,000 protein gene symbols with multiple peptides

(Fig. 7). X!TANDEM was used to identified the proteins by gene symbols whereas SEQUEST was used to count the relative abundance per protein accession.
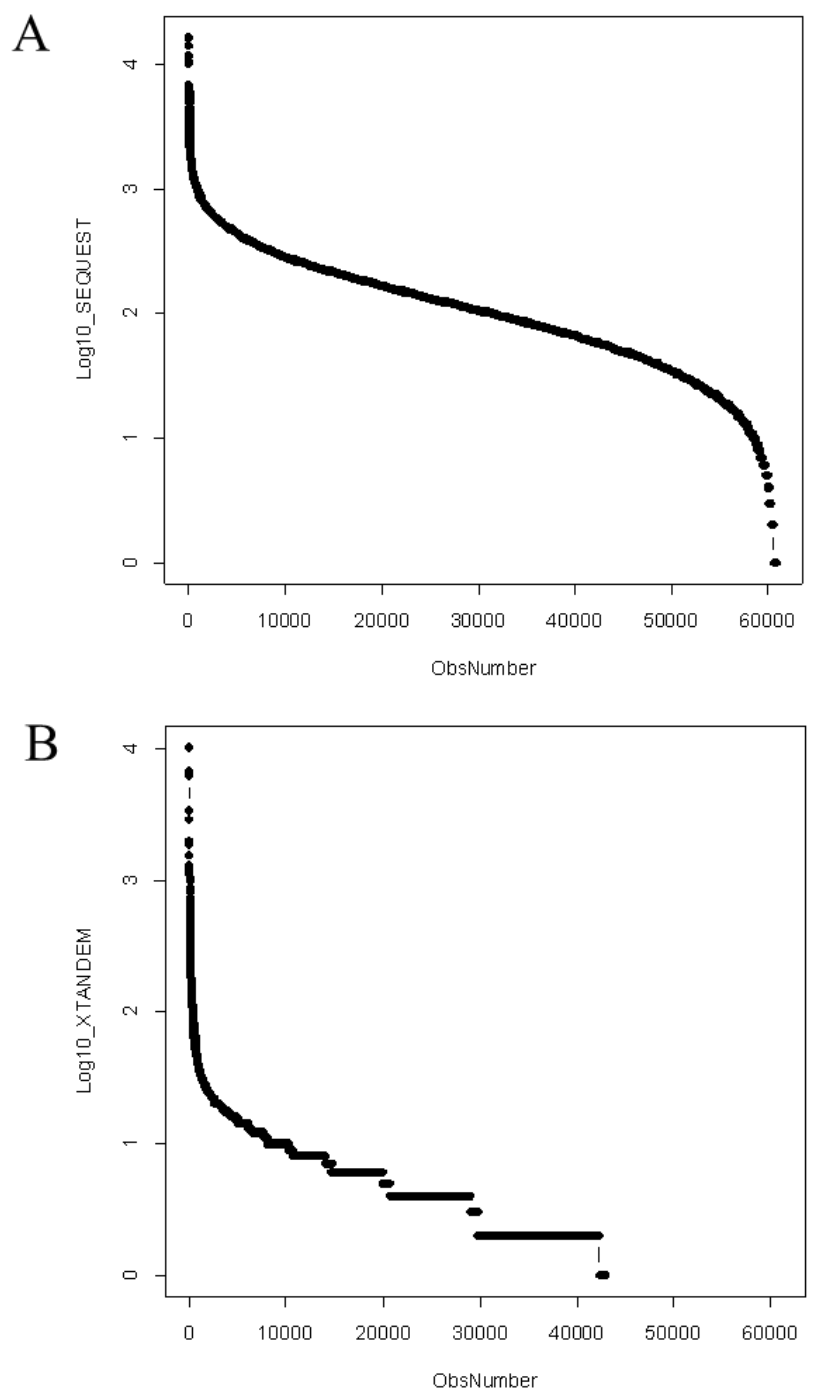

Figure 7. The protein accessions identified by the SEQUEST and X!TANDEM algorithms separately. Panels: A, Proteins identified using SEQUEST showed some 57,308 protein accessions; B, Proteins identified using X!TANDEM showed some 44,146 protein accessions. 


\subsection{X!TANDEM p-value and FDR corrected $q$-value}

Computation of cumulative p-values and FDR corrected q-values for each gene symbol by the method of Benjamini and Hochberg [55] that showed some 12,000 proteins had a q-value of 0.01 or less (Fig. 8).

$$
\begin{array}{cc}
-1 & \text { FDR_q_value } \\
-2 & \text { Sum_p_Value }
\end{array}
$$

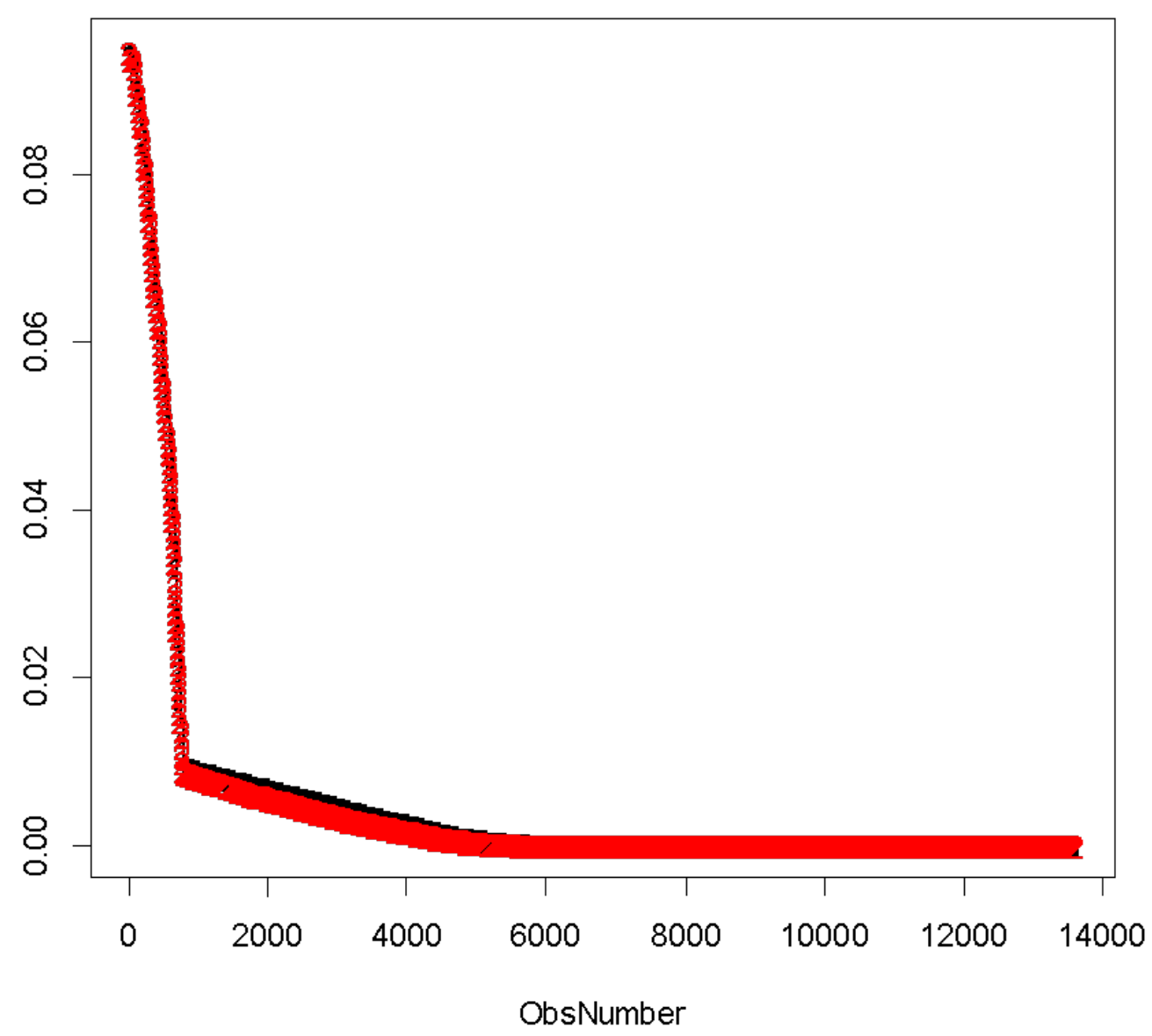

Figure 8. The cumulative p-value and FDR corrected q-value of the non-redundant peptides per gene symbol computed from the X!TANDEM results using the $R$ statistical system. 


\subsection{Chi Square analysis}

Unbiased Chi Square analysis of fetal proteins that showed $\chi 2$ values greater that $60(\mathrm{DF}=1)$ compared to adult serum after correcting observation frequency by the number of MS/MS spectra collected (Table 4). The observed frequency difference plot passed through the 0 point (no difference in observed frequency) at the 0 quantile point (mean of difference distribution) clearly indicating the observation frequency values were proportionally corrected prior to Chi Square comparison. Proteins that showed highly significant increases in observation frequency in the fetal serum included alpha-fetoprotein that is known to be expressed in the fetal liver. Other proteins raised in the fetal serum included, alpha-2-HS-glycoprotein precursor, serpin peptidase inhibitor clade A, fetuin B, gamma globin, inter-alpha-trypsin inhibitor heavy chain $\mathrm{H} 3$, collagen and calcium-binding EGF domain- protein, pyruvate carboxylase, adenylate kinase, hemoglobin subunit beta, kallikrein K, thrombospondin 4 and many others. The Chi Square analysis showed some proteins with $\chi 2$ values that were apparently far too large $(\chi 2 \geq 60, p<0.0001, D F=1)$ to all have resulted from random sampling error (Fig. 9). 
Table 4. Fetal serum specific proteins detected by fully tryptic peptides and fully tryptic phosphopeptides from X!TANDEM and/or SEQUEST or that show a Chi Square $\left(\chi^{2}\right)$ value of $\geq 60$.

\begin{tabular}{|c|c|c|c|c|c|c|}
\hline $\begin{array}{r}\text { Total } \\
\text { Protein } \\
\text { Identifica } \\
\text { tion } \\
\text { Count }\end{array}$ & GeneSymbol & DescriptionFasta & GoFunction & GoProcess & TANDEM & PD_MSF \\
\hline 13062 & AHSG & \multicolumn{3}{|c|}{ Alpha-2-HS-glycoprotein } & 7364 & 5698 \\
\hline 6313 & SERPINA1 & \multicolumn{3}{|c|}{ Alpha-1-antiproteinase } & 3602 & 2711 \\
\hline 1256 & FETUB & Fetuin-B & & & 575 & 681 \\
\hline 1603 & ITIH3 & \multicolumn{3}{|c|}{ inter-alpha-trypsin inhibitor heavy chain $\mathrm{H} 3$ isofo } & 738 & 865 \\
\hline 1714 & ITIH3 & \multicolumn{3}{|c|}{ Inter-alpha-trypsin inhibitor heavy chain $\mathrm{H} 3$} & 774 & 940 \\
\hline 1673 & ITIH3 & \multicolumn{3}{|c|}{ inter-alpha (globulin) inhibitor $\mathrm{H} 3$} & 758 & 915 \\
\hline 2472 & AFP & \multicolumn{3}{|l|}{ Alpha-fetoprotein } & 1222 & 1250 \\
\hline 6646 & LOC104974567 & \multicolumn{3}{|c|}{ translation initiation factor IF-2-like } & 4 & 6642 \\
\hline 6731 & PDCD4 & \multicolumn{3}{|c|}{ programmed cell death protein 4} & 2 & 6729 \\
\hline 433 & RRAGB & \multicolumn{3}{|c|}{ ras-related GTP-binding protein B } & 6 & 427 \\
\hline 10513 & DGAT1 & \multicolumn{3}{|c|}{ Truncated diacylglycerol acyltransferase 1 (Fragment) } & 6 & 10507 \\
\hline 5829 & SH2B1 & \multicolumn{3}{|l|}{ SH2B1 (Fragment) } & 6 & 5823 \\
\hline 5841 & SH2B1 & \multicolumn{3}{|l|}{ SH2B1 (Fragment) } & 8 & 5833 \\
\hline 2625 & & \multicolumn{3}{|c|}{ Uncharacterized protein KIAA2012 homolog } & 9 & 2616 \\
\hline 2625 & KIAA2012 & \multicolumn{3}{|c|}{ Uncharacterized protein KIAA2012 homolog } & 9 & 2616 \\
\hline 5913 & SH2B1 & \multicolumn{3}{|c|}{ SH2B adapter protein 1} & 12 & 5901 \\
\hline 5914 & SH2B1 & \multicolumn{3}{|c|}{$\mathrm{SH} 2 \mathrm{~B}$ adapter protein 1 isoform $\mathrm{X} 4$} & 14 & 5900 \\
\hline 5922 & SH2B1 & \multicolumn{3}{|c|}{ SH2B adapter protein 1 isoform X3 } & 12 & 5910 \\
\hline 5933 & SH2B1 & \multicolumn{3}{|c|}{$\mathrm{SH} 2 \mathrm{~B}$ adapter protein 1 isoform $\mathrm{X} 2$} & 12 & 5921 \\
\hline 2836 & SPRY4 & \multicolumn{3}{|c|}{ protein sprouty homolog 4 isoform X1 } & 14 & 2822 \\
\hline 429 & RRAGB & \multicolumn{3}{|c|}{ ras-related GTP-binding protein B isoform X1 } & 6 & 423 \\
\hline 434 & RRAGB & \multicolumn{3}{|c|}{ Uncharacterized protein } & 6 & 428 \\
\hline 5216 & KIRREL3 & \multicolumn{3}{|c|}{ Uncharacterized protein } & 0 & 5216 \\
\hline 5223 & KIRREL3 & \multicolumn{3}{|c|}{ kin of IRRE-like protein 3 precursor } & 0 & 5223 \\
\hline 3615 & FBLL1 & \multicolumn{3}{|c|}{ Uncharacterized protein } & 125 & 3490 \\
\hline 6016 & CCDC9 & \multicolumn{3}{|c|}{ coiled-coil domain-containing protein 9 isoform $\mathrm{X} 1$} & 20 & 5996 \\
\hline 6012 & CCDC9 & \multicolumn{3}{|c|}{ coiled-coil domain-containing protein 9} & 20 & 5992 \\
\hline 6417 & RBMX & \multicolumn{3}{|c|}{ RNA-binding motif protein, $\mathrm{X}$ chromosome } & 33 & 6384 \\
\hline 5805 & NFATC2IP & \multicolumn{3}{|c|}{ NFATC2-interacting protein } & 18 & 5787 \\
\hline 6172 & GAR1 & $\mathrm{H} / \mathrm{ACA}$ ribonucle & otein complex & nit 1 & 30 & 6142 \\
\hline 1493 & IL13RA1 & Uncharacterized $\mathrm{p}$ & & & 0 & 1493 \\
\hline 5850 & SFPQ & splicing factor, pr & e- and glutami & & 34 & 5816 \\
\hline 5724 & HMX1 & homeobox protein & MX1 & & 20 & 5704 \\
\hline 2991 & L2HGDH & L-2-hydroxygluta & dehydrogenas & tochondrial & 0 & 2991 \\
\hline
\end{tabular}




\begin{tabular}{|c|c|c|c|c|}
\hline 5733 & HMX1 & Uncharacterized protein & 18 & 5715 \\
\hline 5825 & SFPQ & splicing factor, proline- and glutamine-rich isofo & 28 & 5797 \\
\hline 540 & GNPTG & $\mathrm{N}$-acetylglucosamine-1-phosphotransferase subunit $\mathrm{g}$ & 12 & 528 \\
\hline 6021 & BRWD3 & Uncharacterized protein & 10 & 6011 \\
\hline 589 & GNPTG & $\mathrm{N}$-acetylglucosamine-1-phosphotransferase subunit g & 18 & 571 \\
\hline 597 & GNPTG & $\mathrm{N}$-acetylglucosamine-1-phosphotransferase subunit g & 18 & 579 \\
\hline 414 & FGA & Fibrinogen alpha chain & 159 & 255 \\
\hline 6115 & BRWD3 & bromodomain and WD repeat-containing protein 3 iso & 10 & 6105 \\
\hline 6115 & BRWD3 & bromodomain and WD repeat-containing protein 3 iso & 10 & 6105 \\
\hline 412 & FGA & Fibrinogen alpha chain & 159 & 253 \\
\hline 4396 & ADGRV1 & Uncharacterized protein & 26 & 4370 \\
\hline 4548 & PLA2G2A & phospholipase A2, group IIA (platelets, synovial f & 4 & 4544 \\
\hline 4545 & PLA2G2A & Phospholipase A2, membrane associated & 4 & 4541 \\
\hline 262 & LOC101902853 & homeobox protein ESX1-like & 0 & 262 \\
\hline 4549 & LOC 100125947 & uncharacterized protein LOC100125947 precursor & 4 & 4545 \\
\hline 4459 & ADGRV1 & G-protein coupled receptor 98 & 26 & 4433 \\
\hline 6132 & CTR9 & Uncharacterized protein & 28 & 6104 \\
\hline 6148 & CTR9 & RNA polymerase-associated protein CTR9 homolog & 26 & 6122 \\
\hline 3191 & MORF4L1 & mortality factor 4-like protein 1 isoform X1 & 2 & 3189 \\
\hline 3174 & MORF4L1 & mortality factor 4-like protein 1 isoform X3 & 2 & 3172 \\
\hline 558 & FGA & fibrinogen alpha chain isoform $\mathrm{X} 1$ & 163 & 395 \\
\hline 2162 & NXNL2 & nucleoredoxin-like protein 2 isoform $\mathrm{X} 1$ & 4 & 2158 \\
\hline 3102 & & & 8 & 3094 \\
\hline 2581 & H2AFX & histone H2A.x & 6 & 2575 \\
\hline 596 & LOC 100138633 & $\mathrm{~N}$-acetylglucosamine-1-phosphotransferase subunit g & 8 & 588 \\
\hline 3081 & MORF4L1 & Uncharacterized protein & 2 & 3079 \\
\hline 2062 & NXNL2 & nucleoredoxin-like protein 2 isoform $\mathrm{X} 2$ & 4 & 2058 \\
\hline 3139 & & Hemoglobin fetal subunit beta & 1671 & 1468 \\
\hline 1651 & ETFA & Electron transfer flavoprotein subunit alpha, mito & 2 & 1649 \\
\hline 1652 & ETFA & Electron transfer flavoprotein subunit alpha, mito & 2 & 1650 \\
\hline 348 & PRDM11 & Uncharacterized protein & 213 & 135 \\
\hline 382 & & fibrinogen A-alpha chain & 152 & 230 \\
\hline 1216 & ZRSR2 & U2 small nuclear ribonucleoprotein auxiliary facto & 8 & 1208 \\
\hline 1234 & ZRSR2 & Uncharacterized protein & 8 & 1226 \\
\hline 2121 & PPP1R12B & Uncharacterized protein & 10 & 2111 \\
\hline 258 & LOC787241 & Uncharacterized protein & 0 & 258 \\
\hline 122 & SUSD4 & sushi domain-containing protein 4 isoform $\mathrm{X} 1$ & 0 & 122 \\
\hline 122 & SUSD4 & Uncharacterized protein & 0 & 122 \\
\hline 338 & HSPB8 & Heat shock protein beta- 8 & 2 & 336 \\
\hline 1592 & NFKBIL1 & NF-kappa-B inhibitor-like protein 1 isoform X1 & 10 & 1582 \\
\hline 1947 & EME2 & Uncharacterized protein & 4 & 1943 \\
\hline 6439 & ITIH2 & Inter-alpha-trypsin inhibitor heavy chain $\mathrm{H} 2$ & 3303 & 3136 \\
\hline 6242 & ITIH2 & inter-alpha-trypsin inhibitor heavy chain $\mathrm{H} 2$ precu & 3256 & 2986 \\
\hline
\end{tabular}




\begin{tabular}{|c|c|c|c|c|c|}
\hline 1605 & NFKBIL1 & \multicolumn{2}{|c|}{ NF-kappa-B inhibitor-like protein 1} & 16 & 1589 \\
\hline 1700 & & \multicolumn{2}{|c|}{ Uncharacterized protein } & 931 & 769 \\
\hline 2239 & & \multicolumn{2}{|c|}{ Uncharacterized protein } & 6 & 2233 \\
\hline 396 & LUM & Lumican & & 168 & 228 \\
\hline 1477 & BDKRB1 & \multicolumn{2}{|c|}{ B1 bradykinin receptor } & 2 & 1475 \\
\hline 1476 & & \multicolumn{2}{|c|}{ Bradykinin B1 receptor (Fragment) } & 2 & 1474 \\
\hline 441 & LOC 101902766 & \multicolumn{2}{|c|}{ vegetative cell wall protein gp1-like } & 0 & 441 \\
\hline 2310 & AKT1 & \multicolumn{2}{|c|}{ RAC-alpha serine/threonine-protein kinase } & 8 & 2302 \\
\hline 2270 & METTL25 & \multicolumn{2}{|c|}{ methyltransferase like 25} & 4 & 2266 \\
\hline 195 & ACOT6 & \multicolumn{2}{|c|}{ putative acyl-coenzyme A thioesterase 6 isoform X2 } & 128 & 67 \\
\hline 235 & BAG4 & \multicolumn{2}{|c|}{ BAG family molecular chaperone regulator 4} & 0 & 235 \\
\hline 553 & FBLN1 & \multicolumn{2}{|c|}{ fibulin-1 precursor } & 86 & 467 \\
\hline 554 & FBLN1 & Fibulin-1 & & 86 & 468 \\
\hline 643 & & \multicolumn{2}{|c|}{ Uncharacterized protein } & 0 & 643 \\
\hline 1085 & TTLL10 & \multicolumn{2}{|c|}{ Uncharacterized protein } & 2 & 1083 \\
\hline 605 & TMEM143 & \multicolumn{2}{|c|}{ Transmembrane protein 143} & 4 & 601 \\
\hline 1475 & $\mathrm{CCDC} 124$ & \multicolumn{2}{|c|}{ Coiled-coil domain-containing protein 124} & 0 & 1475 \\
\hline 2856 & & & & 1495 & 1361 \\
\hline 375 & MCAT & \multicolumn{2}{|c|}{ MCAT protein (Fragment) } & 203 & 172 \\
\hline 586 & $\mathrm{IK}$ & \multicolumn{2}{|c|}{ protein Red } & 218 & 368 \\
\hline 613 & TMEM143 & \multicolumn{2}{|c|}{ transmembrane protein 143 isoform $\mathrm{X} 5$} & 4 & 609 \\
\hline 604 & FLJ10922 & \multicolumn{2}{|c|}{ hypothetical protein LOC55260 } & 4 & 600 \\
\hline 605 & TMEM143 & \multicolumn{2}{|c|}{ transmembrane protein 143 isoform X3 } & 4 & 601 \\
\hline 747 & & \multicolumn{2}{|c|}{ Uncharacterized protein C11orf71 homolog } & 2 & 745 \\
\hline 615 & TMEM143 & \multicolumn{2}{|c|}{ transmembrane protein 143 isoform X2 } & 4 & 611 \\
\hline 1276 & KEAP1 & \multicolumn{2}{|c|}{ kelch-like ECH-associated protein 1} & 2 & 1274 \\
\hline 613 & TMEM143 & \multicolumn{2}{|c|}{ transmembrane protein 143 isoform $\mathrm{X} 4$} & 4 & 609 \\
\hline 1252 & KEAP1 & \multicolumn{2}{|c|}{ Kelch-like ECH-associated protein 1 (Fragment) } & 4 & 1248 \\
\hline 1435 & MRVI1 & protein $\mathrm{MF}$ & $\mathrm{m} \mathrm{X} 1$ & 10 & 1425 \\
\hline 1435 & MRVI1 & protein $\mathrm{MF}$ & $\mathrm{m} \mathrm{a}$ & 10 & 1425 \\
\hline 615 & TMEM143 & transmemb & in 143 isoform X1 & 4 & 611 \\
\hline 839 & TMEM114 & transmemb & in 114 isoform X1 & 10 & 829 \\
\hline 1437 & MRVI1 & Protein MI & & 8 & 1429 \\
\hline 1145 & TTLL10 & inactive po & e TTLL10 isoform X2 & 4 & 1141 \\
\hline 3222 & LEO1 & RNA poly & ociated protein LEO1 isoform $\mathrm{X} 3$ & 2 & 3220 \\
\hline 2161 & & Uncharact & & 1170 & 991 \\
\hline 218 & FUT2 & galactoside & -fucosyltransferase 2 isoform & 0 & 218 \\
\hline 438 & LGMN & Legumain & & 7 & 431 \\
\hline 814 & TMEM114 & transmemb & in 114 & 6 & 808 \\
\hline 1142 & TTLL10 & inactive po & e TTLL10 isoform X1 & 10 & 1132 \\
\hline 1867 & GRK5 & G protein- & eptor kinase 5 & 14 & 1853 \\
\hline 439 & LGMN & legumain $\mathrm{i}$ & & 8 & 431 \\
\hline 123 & SUSD4 & sushi dome & ing protein 4 & 0 & 123 \\
\hline
\end{tabular}




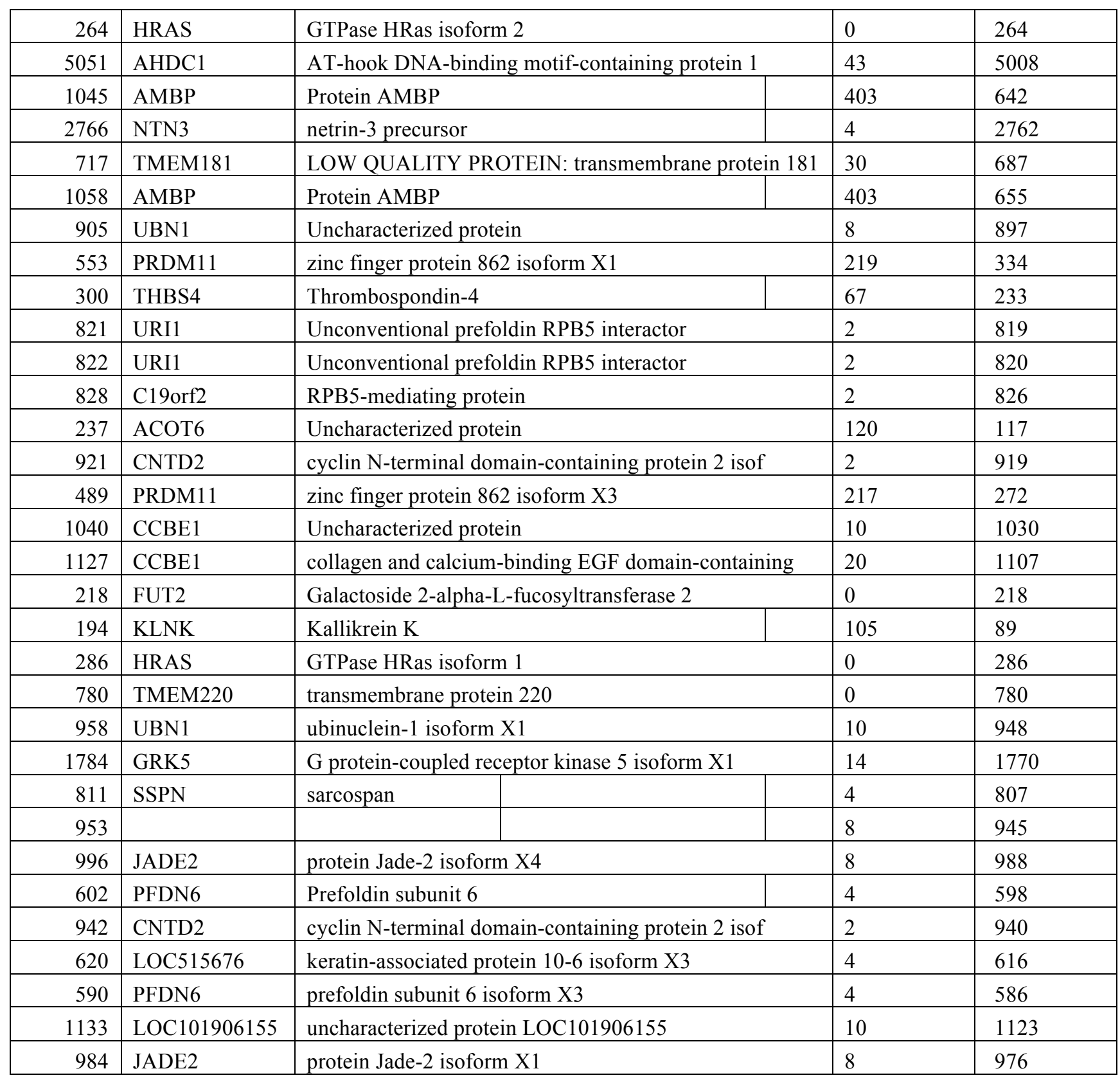


A

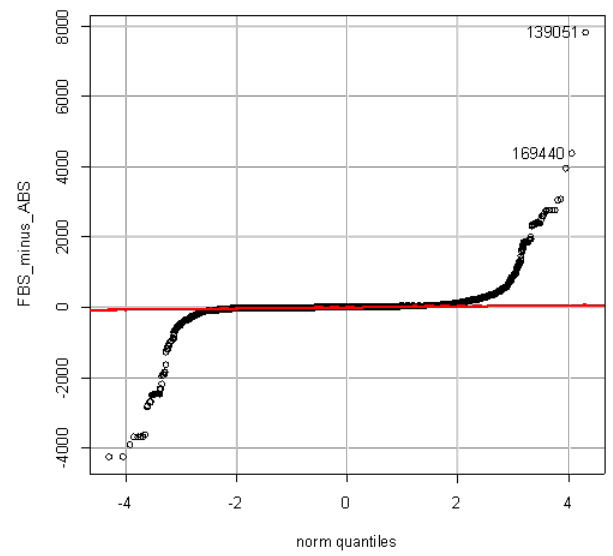

B

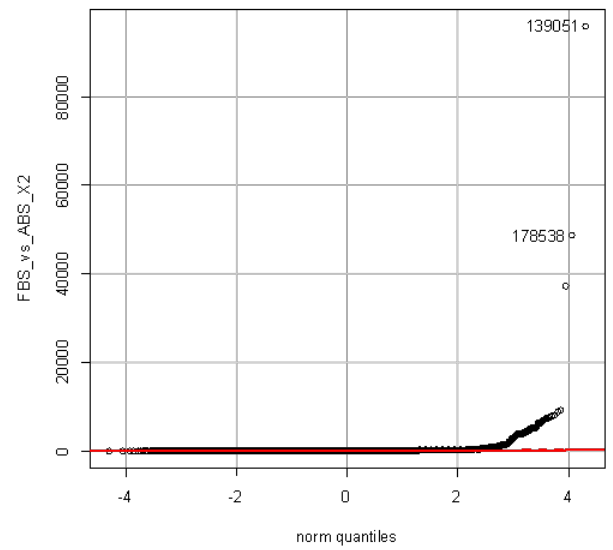

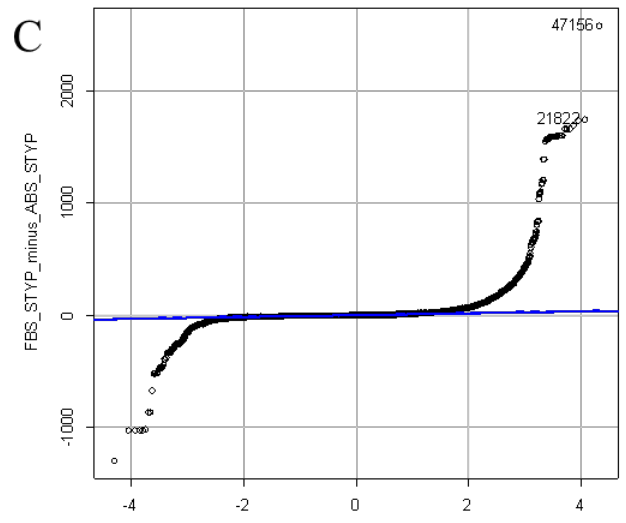

norm quartiles

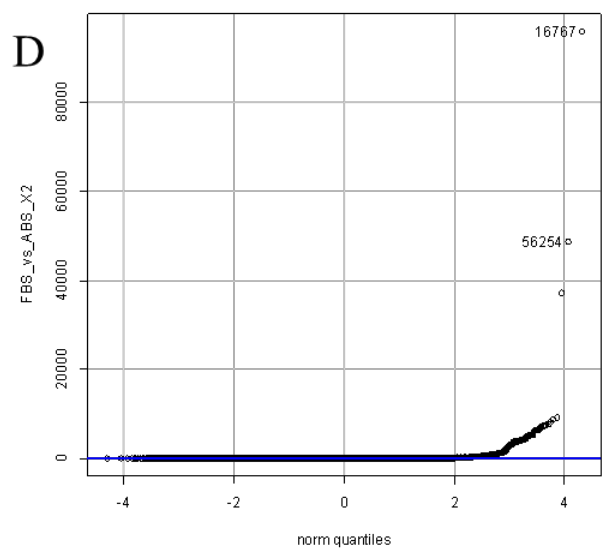

Figure 9. Quantile plots of the corrected difference in observation frequency (Delta) and Chi Square values of the fetal versus adult serum. The difference in observation frequency of fetal serum versus adult serum using the Quantile plot that tended to zero (see red line). Panels: A, Tryptic peptide corrected difference (delta) in observation frequency; $B$, tryptic peptide Chi Square $\chi 2$; C, Tryptic and/or phosphor-tryptic peptides after the corrected difference (delta) in observation frequency; D, tryptic and/or STYP peptide Chi Square $\chi 2$. 


\subsection{Erythrocytes}

Hemoglobin fetal subunit beta, Hemoglobin subunit beta that were observed in the fetal versus adult serum thousands of times in close proportions, similar to the ratio of sampled MS/MS spectra from fetal versus adult serum but few other known red blood cells proteins were observed. Some, but not all proteins annotated from erythrocyte or red blood cells were observed in the fetal and/or adults serum.

\subsection{Granulocytes, macrophages, monocytes, neutrophils, platelets or rbcs}

It remains possible that the cellular proteins observed in serum were released from white blood cells during sample collection. However only a small minority of all known macrophage, granulocyte, neutrophil, monocyte proteins were observed in plasma by X!TANDEM that typically showed little trend to differences between fetal and adult plasma. For example, macrophage receptor MARCO isoform, macrophage scavenger receptors macrophagestimulating protein receptor, natural resistance-associated macrophage protein, macrophage colony-stimulating factor, macrophage mannose receptor, phospholipase A2, group IIA and other were observed in serum. Similarly, a small subset of all known granulocyte, neutrophil, monocyte or mast cell proteins were observed in plasma. Specific platelet associated proteins including platelet glycoprotein IV (CD36) or platelet endothelial cell adhesion molecule isoform, platelet glycoprotein Ib alpha chain, Platelet-derived growth factor D isoform X1, Plateletactivating factor receptor, platelet-activating factor receptor isoform X1 and platelet factor 4 (PF4) were observed in fetal serum, however most of the known platelet associated proteins were not strongly detected. 


\subsection{Hormones, ligands, growth factors, chemokines cytokines, necrosis factors and interleukins}

A biased search was performed for tryptic and/or phosphor-peptides from factors identified by X!TANDEM and counted with SEQUEST in fetal versus adult serum that might play regulatory roles in signal reception, gene expression related to cell growth and development that resulted in a set of gene symbols showed Chi Square $(\chi 2)$ values of $\geq 9$. The SQL Server database was queried for peptides and/or phosphor-peptides for ligands, receptors, growth factors, cytokines, chemokines, interleukins, and necrosis factors along with their receptors, kinases, phosphatases, g-proteins, cyclases, phosphodiesterases, transcription factors, nucleic acid binding proteins identified by X!TANDEM that showed greater frequency in fetal serum (Table 5). Growth or regulatory hormones that showed increased observation frequency in fetal serum included parathyroid hormone/parathyroid hormone-related peptide receptor, hormone-sensitive lipaselike, Lutropin-choriogonadotropic hormone receptor, parathyroid hormone 2 receptor precursor, thyrotropin-releasing hormone, thyrotropin-releasing hormone receptor, glycoprotein hormone beta-5, steroid hormone receptor ERR1, anti-Muellerian hormone type-2 receptor precursor. Platelet associated molecules that were enriched in fetal serum by Chi Square analysis included Platelet factor 4, platelet endothelial cell adhesion molecule, platelet-derived growth factor C, platelet glycoprotein 4, Platelet-derived growth factor receptor-like detected by X!TANDEM and SEQUEST but some other platelet derived growth factors were only detected by SEQUEST. Multiple growth factors and associated receptors or binding proteins showed greater observation frequency in fetal serum including macrophage colony-stimulating factor 1 , multiple epidermal growth factor-like domains, lens epithelium-derived growth factor, transforming growth factor beta-2, pro-epidermal growth factor, Insulin-like growth factor-binding protein, latent- 
transforming growth factor beta-binding protein, Insulin-like growth factor-binding protein, hepatoma-derived growth factor-related protein 3, fibroblast growth factor 7 precursor, Fibroblast growth factor receptor, Fibroblast growth factor, Fibroblast growth factor 18, insulinlike growth factor II isoform X, Connective tissue growth factor and others. C-X-C motif chemokine 6, C-X-C chemokine receptor type 4, C-C motif chemokine 21 precursor, Chemokine (C-C motif) ligand 21, C-C motif chemokine 8, cardiotrophin-like cytokine factor 1, cytokine receptor-like factor 1 isoform $\mathrm{X} 1$, Complement $\mathrm{C} 1 \mathrm{q}$ and tumor necrosis factor-related protein, Tumor necrosis factor alpha-induced protein 8-like, tumor necrosis factor (ligand) superfamily members. Interleukins or associated factors were observed including toll/interleukin-1 receptor domain-containing adaptor protein (TIRAP), pro-interleukin-16 isoform X1 (IL16), interleukin17D (IL17), interleukin 8 receptor alpha (CXCR1), interleukin-27 subunit alpha precursor (IL27) and interleukin-18 receptor accessory protein (IL18RAP). Additional factors that were observed included nuclear receptor corepressor 2 isoform X2, cytokine receptor-like factor 1 isoform X1, Atrial natriuretic peptide receptor 2, scavenger receptor class A member 3, ALK tyrosine kinase receptor and others. Specific examples of fetal specific proteins include G-protein coupled receptor 98, Leucine-rich repeat-containing G-protein-coupled receptor, G-protein-signaling modulator 1, adhesion G-protein coupled receptor G7, serine/threonine-protein phosphatase 2B catalytic, receptor-type tyrosine-protein phosphatase mu, ectonucleotide pyrophosphatase/phosphodiesterase, Protein phosphatase 2, G protein-coupled receptor kinase 5, adenylate kinase 8, Serine/threonine-protein kinase 33, Mitogen-activated protein kinase 13, RNA-binding motif protein, AT-hook DNA-binding motif-containing protein, transcription factor 15, doublesex- and mab-3-related transcription factor, transcriptional enhancer factor TEF3, pre-B-cell leukemia transcription factor 2, chromodomain-helicase-DNA-binding protein 1, 
zinc finger protein 862 and others. The zinc finger and BTB domain-containing protein 20 and many nuclear receptors including ROR-alpha were observed in both fetal and adult serum. Many proteins that were enriched by counting tryptic peptides showed even greater observation frequency in fetal serum when phosphorylation was taken into account, for example alpha feta protein (AFP). 
Table 5. The proteins shown were identified by X!TANDEM with at least three independent peptide identifications and showed significant Chi Square values ( $\geq 9)$ from both tryptic (TRYP) and phosphor-tryptic peptides.

\begin{tabular}{|c|c|c|c|c|c|}
\hline \multicolumn{2}{|c|}{ GeneSymb DescriptionFasta } & \multirow{2}{*}{$\begin{array}{r}\text { Fetal_TRYP_X2 } \\
5348.602116\end{array}$} & \multirow{2}{*}{$\begin{array}{r}\text { Fetal_TRYP_Delta } \\
1113.946\end{array}$} & \multirow{2}{*}{$\begin{array}{r}\text { Fetal_STYP_X2 } \\
1556.325992\end{array}$} & \multirow{2}{*}{$\begin{array}{r}\text { Fetal_STYP_Delta } \\
449.8026\end{array}$} \\
\hline AFP & Alpha-fetoprotein & & & & \\
\hline NULL & Hemoglobin fetal subunit beta & 854.2719438 & 676.044 & 176.7079574 & 272.4286 \\
\hline PDGFC & platelet-derived growth factor $\mathrm{C}$ isoform $\mathrm{X} 2$ & 12.3596 & 11.66 & 0.636712967 & 3.8268 \\
\hline FGF13 & fibroblast growth factor 13 isoform $\mathrm{X} 2$ & 9.058456333 & 10.426 & 2.512436338 & 4.7552 \\
\hline TNF & Tumor necrosis factor & 17.34245633 & 14.426 & 1.982581813 & 2.4388 \\
\hline HDGFRP3 & hepatoma-derived growth factor-related protein 3 & 25.42848711 & 15.128 & 0.217444516 & 1.4746 \\
\hline INS & insulin isoform X1 & 22.74426021 & 20.788 & 44.60723627 & 34.7044 \\
\hline NULL & Insulin (Fragment) & 24.265008 & 8.532 & 12.80995681 & 7.1582 \\
\hline ADGRL3 & Adhesion G protein-coupled receptor L3 & 9.326156108 & 18.576 & 9.950830602 & -15.4538 \\
\hline ADGRV1 & G-protein coupled receptor 98 & 1112.372984 & 626.632 & 2195.764741 & 1061.3328 \\
\hline ADORA3 & adenosine receptor $\mathrm{A} 3$ isoform 2 precursor & 28.86375625 & 21.49 & 55.10568452 & 23.4746 \\
\hline ADRA2B & Alpha-2B adrenergic receptor (Fragment) & 19.21192467 & 28.406 & 67.9008967 & 64.8834 \\
\hline ALK & ALK tyrosine kinase receptor & 55.88393086 & 67.28 & 13.32430466 & -33.851 \\
\hline CRLF1 & cytokine receptor-like factor 1 isoform X1 & 31.61250625 & 22.49 & 41.1135674 & 27.9492 \\
\hline GPR68 & ovarian cancer G-protein coupled receptor 1 isoform X1 & 33.4643805 & 16.362 & 15.35385856 & 11.7552 \\
\hline GPR84 & G-protein coupled receptor 84 isoform X1 & 19.4724135 & 21.618 & 29.74095992 & 33.6178 \\
\hline GRID1 & glutamate receptor ionotropic, delta- 1 & 71.7184188 & 70.854 & 314.3117279 & 189.2922 \\
\hline GRIN3B & glutamate receptor ionotropic, NMDA 3B isoform X1 & 194.6561805 & 118.386 & 10.33909278 & 23.4088 \\
\hline GRK4 & G protein-coupled receptor kinase 4 isoform X13 & 32.68163462 & 29.15 & 17.17261096 & 31.2864 \\
\hline GRK5 & G protein-coupled receptor kinase 5 & 373.5386091 & 215.218 & 495.8210284 & 340.6202 \\
\hline NPR2 & Atrial natriuretic peptide receptor 2 & 24.68672653 & 27.214 & 57.73592009 & 48.0566 \\
\hline NULL & Ig-like receptor A3 & 12.3596 & 11.66 & 85.10406817 & 22.597 \\
\hline OR10C1 & olfactory receptor $10 \mathrm{C} 1$ & 62.13958017 & 38.618 & 162.6927626 & 69.8626 \\
\hline PRLR & Prolactin receptor (Fragment) & 47.71521424 & 40.278 & 9.557999923 & 14.8268 \\
\hline SCARA3 & scavenger receptor class A member 3 & 26.52385225 & 54.26 & 366.8439746 & 311.2022 \\
\hline TRPM3 & LOW QUALITY PROTEIN: transient receptor potential cation chan & 20.1097216 & 41.344 & 69.6317658 & 85.0982 \\
\hline TRPM7 & transient receptor potential cation channel subfamily $\mathrm{M}$ member & 16.2294087 & 48.006 & 25.73137734 & 56.4862 \\
\hline LGR4 & Leucine-rich repeat-containing G-protein-coupled receptor 4 & 36.60403776 & 35.278 & 16.09956841 & 34.5162 \\
\hline ARAF & serine/threonine-protein kinase A-Raf & 14.6906317 & 19.916 & 9.134377013 & 15.7044 \\
\hline ARHGAP22 & rho GTPase-activating protein 22 isoform X6 & 33.83385306 & 60.728 & 66.80683781 & 115.88 \\
\hline BAZ1B & tyrosine-protein kinase BAZ1B isoform X1 & 13.58472512 & 42.346 & 38.24375118 & 72.119 \\
\hline CHKB & choline/ethanolamine kinase isoform $\mathrm{X} 2$ & 77.8075236 & 27.894 & 21.0356952 & 27.8984 \\
\hline DYRK1B & dual specificity tyrosine-phosphorylation-regulated kinase $1 \mathrm{~B}$ iso & 15.45208278 & 18.852 & 39.50967953 & 43.0924 \\
\hline ENPP1 & ectonucleotide pyrophosphatase/phosphodiesterase family men & 46.70131284 & 29.788 & 28.42717701 & 27.7044 \\
\hline ERMARD & endoplasmic reticulum membrane-associated RNA degradation F & 14.83352337 & 16.788 & 13.15999009 & -22.9434 \\
\hline GUK1 & guanylate kinase isoform X6 & 36.51382044 & 18.128 & 20.94301009 & -28.9434 \\
\hline INPP5」 & phosphatidylinositol 4,5-bisphosphate 5-phosphatase A isoform : & 17.52325008 & 29.002 & 13.86270096 & 18.985 \\
\hline IRS2 & LOW QUALITY PROTEIN: insulin receptor substrate 2 & 12.34738713 & 16.852 & 29.67798006 & 21.791 \\
\hline JAK2 & Tyrosine-protein kinase & 16.37276166 & 33.854 & 54.48583008 & 70.0266 \\
\hline LOC10713: & Guanylate cyclase & 34.60903153 & 24.256 & 71.9202806 & 41.5462 \\
\hline LOC10713: & hormone-sensitive lipase-like & 17.51585506 & 17.256 & 10.46691381 & 18.3014 \\
\hline LRRK2 & leucine-rich repeat serine/threonine-protein kinase 2 isoform X1 & 231.156482 & 169.984 & 207.2239401 & 180.9458 \\
\hline MAP3К13 & Mitogen-activated protein kinase kinase kinase 13 & 124.2969135 & 54.618 & 9.821326633 & -18.5404 \\
\hline MAP3K5 & mitogen-activated protein kinase kinase kinase 5 & 17.8233082 & 32.428 & 13.33753 & -31.2032 \\
\hline MARS & methionine--tRNA ligase, cytoplasmic isoform X2 & 22.86991506 & 38.258 & 162.9276714 & 104.4804 \\
\hline MYLK3 & myosin light chain kinase 3 isoform $\mathrm{X} 1$ & 13.03970312 & 25.534 & 18.77508114 & -32.7136 \\
\hline NULL & guanylate cyclase & 43.62402689 & 28.022 & 84.90731635 & 46.985 \\
\hline PLK5 & inactive serine/threonine-protein kinase PLK5 isoform X1 & 64.47198084 & 76.174 & 94.94012583 & 111.522 \\
\hline RALGAPA1 & ral GTPase-activating protein subunit alpha- 1 isoform X6 & 15.97455031 & 41.728 & 15.64689987 & 33.7968 \\
\hline SRPK1 & LOW QUALITY PROTEIN: SRSF protein kinase 1 & 13.14351607 & 27.13 & 17.51624315 & 43.6952 \\
\hline STK33 & serine/threonine-protein kinase 33 isoform X3 & 161.9011727 & 94.364 & 242.5024154 & 123.6028 \\
\hline STK33 & serine/threonine-protein kinase 33 isoform X1 & 179.512809 & 99.364 & 229.140802 & 122.0416 \\
\hline TTBK2 & tau-tubulin kinase 2 & 56.72732498 & 54.832 & 23.59860779 & 30.3372 \\
\hline UPP1 & uridine phosphorylase 1 isoform $\mathrm{X} 1$ & 9.058456333 & 10.426 & 12.3853946 & 14.5104 \\
\hline LOC529501 & aryl hydrocarbon receptor repressor & 13.916126 & 13.958 & 41.9056751 & 25.0716 \\
\hline
\end{tabular}




\subsection{Growth factors}

It has been previously demonstrated that fetal plasma contains insulin, insulin like growth factors and other transforming growth factors [80]. Multiple growth factors and associated receptors or binding proteins showed greater observation frequency in fetal serum including macrophage colony-stimulating factor 1 , multiple epidermal growth factor-like domains, lens epitheliumderived growth factor, transforming growth factor beta-2, pro-epidermal growth factor, Insulinlike growth factor-binding protein, latent-transforming growth factor beta-binding protein, Insulin-like growth factor-binding protein, hepatoma-derived growth factor-related protein 3, fibroblast growth factor 7 precursor, Fibroblast growth factor receptor, Fibroblast growth factor, Fibroblast growth factor 18, insulin-like growth factor II isoform X, connective tissue growth factor and others (Table 6). 
Table 6. The growth factors that differ between fetal versus adult serum by Chi Square analysis of the tryptic (TRYP) and or serine, threonine or tyrosine phosphorylated tryptic peptides (STYP) identified by SEQUEST and X!TANDEM.

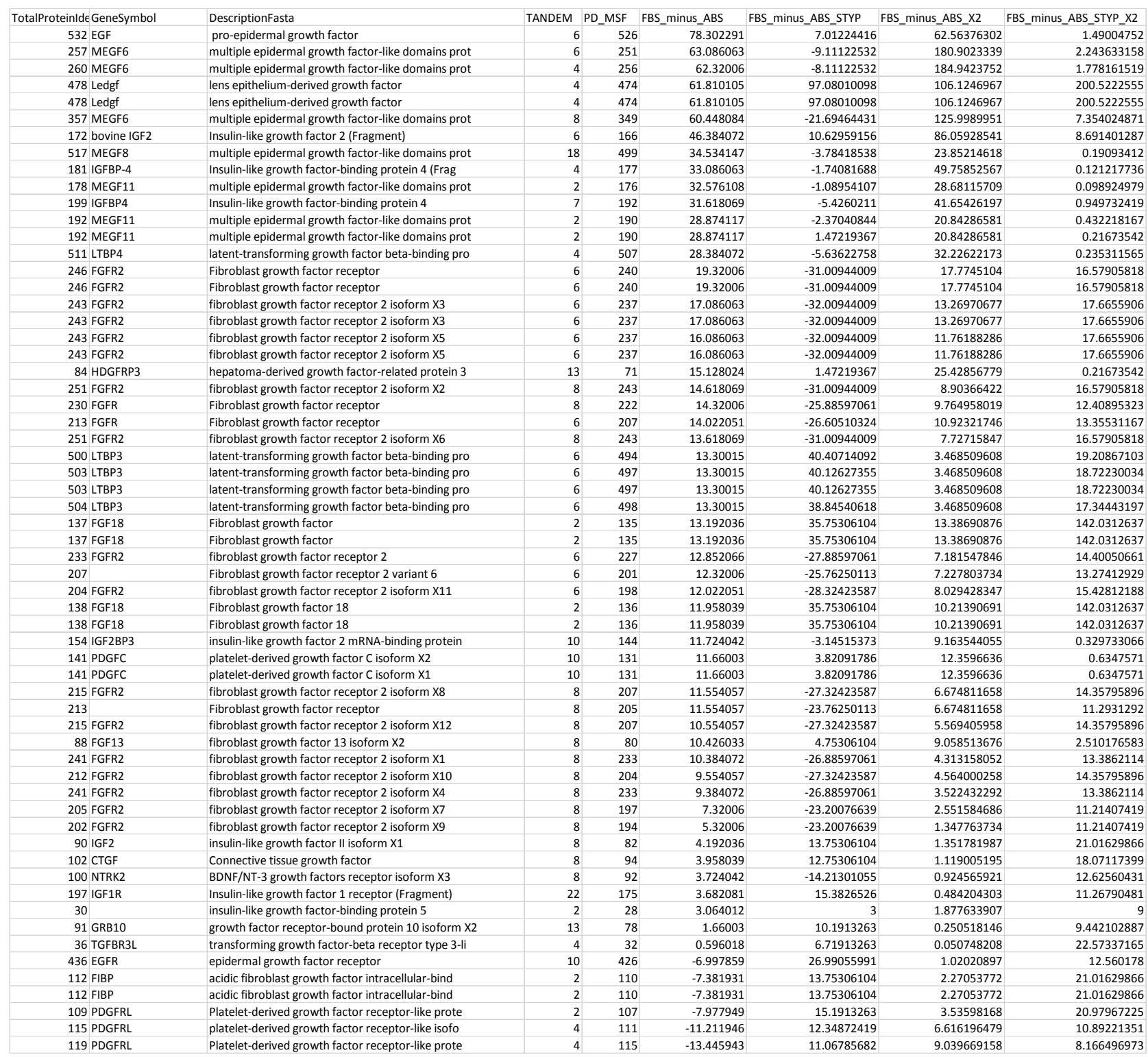




\subsection{Pathway and gene ontology analysis using the STRING algorithm}

Many tryptic peptides (TYRP) and/or phospho-tryptic peptides (STYP) from growth or regulatory pathways were identified by both X!TANDEM and SEQUEST showed greater observation frequency by Chi Square in fetal compared to adult serum (Fig. 10). In a computationally independent method, the fetal proteins that showed a higher observation frequency from both tryptic and phosphorylated tryptic peptides were analyzed by the STRING protein-protein interaction network. The STRING analysis showed a significant $p$-value that so many previously established protein-protein interactions were just randomly sampled from the genome (Fig. 10\&11). The distribution of the cellular locations, molecular functions, and biological processes (Table 7) were significant with respect to the category distribution of the human genome. The proteins that were observed to differ between the fetal and adult serum by unbiased Chi Square analysis were organized at least in part around the PI3K, AKT, HRAS growth and proliferation pathways [81] that may include hormones and ligands, receptors, receptor associated enzymes such as kinases, phosphatases, cyclases and g-proteins or their associated factors, as well as transcription factors, DNA and RNA binding proteins and specific histones or histone modification enzymes. Calmodulin-independent adenylate cyclase, calmodulin-binding transcription activator, calcium/calmodulin-dependent protein kinase type 1, Calcium/calmodulin-dependent 3',5'-cyclic nucleotide phosphodiesterase showed significantly increased observation frequency (Fig. 10\&11). 
Table 7. The summary of STRING analysis of the fetal serum enriched proteins with respect to a random sampling of the human Genome for Gene Symbols showed the top 400 proteins with the most significant Chi Square $(\chi 2)$ value (See Fig.11). The Gene Symbols from unbiased Table IV and biased SQL Queries V were combined for analysis by the STRING algorithm that showed strong enrichment and protein-protein interactions in the fetal specific factors.

\begin{tabular}{|l|l|}
\hline Network Stats & \\
\hline Number of nodes: & 292 \\
\hline Number of edges: & 461 \\
\hline Average node degree: & 3.16 \\
\hline Avg. local clustering coefficient: & 0.447 \\
\hline Expected number of edges: & 331 \\
\hline PPI enrichment p-value: & $9.60 \mathrm{E}-12$ \\
\hline $\begin{array}{l}\text { Your network has significantly more } \\
\text { interactions than expected (what does that } \\
\text { mean?) }\end{array}$ & \\
\hline Functional enrichments in your network & \\
\hline
\end{tabular}

\begin{tabular}{|l|l|}
\hline Biological Process (GO) & \\
\hline Pathway ID & pathway description \\
\hline GO:0051346 & negative regulation of hydrolase activity \\
\hline GO:0072376 & protein activation cascade \\
\hline GO:0010466 & negative regulation of peptidase activity \\
\hline GO:2000257 & regulation of protein activation cascade \\
\hline GO:0045861 & negative regulation of proteolysis \\
\hline GO:0010951 & negative regulation of endopeptidase activity \\
\hline GO:0010605 & negative regulation of macromolecule metabolic process \\
\hline GO:0030449 & regulation of complement activation \\
\hline GO:0043086 & negative regulation of catalytic activity \\
\hline GO:0051248 & negative regulation of protein metabolic process \\
\hline GO:0044092 & negative regulation of molecular function \\
\hline GO:0031324 & negative regulation of cellular metabolic process \\
\hline GO:0002920 & regulation of humoral immune response \\
\hline GO:0009892 & negative regulation of metabolic process \\
\hline GO:0051336 & regulation of hydrolase activity \\
\hline GO:0006953 & acute-phase response \\
\hline GO:0052547 & regulation of peptidase activity \\
\hline GO:0006956 & complement activation \\
\hline GO:0032269 & negative regulation of cellular protein metabolic process \\
\hline GO:0002526 & acute inflammatory response \\
\hline GO:0070613 & regulation of protein processing \\
\hline GO:0030162 & regulation of proteolysis \\
\hline GO:0006959 & humoral immune response \\
\hline
\end{tabular}




\begin{tabular}{|l|l|}
\hline GO:0052548 & regulation of endopeptidase activity \\
\hline GO:0002673 & regulation of acute inflammatory response \\
\hline GO:0072378 & blood coagulation, fibrin clot formation \\
\hline GO:0006957 & complement activation, alternative pathway \\
\hline GO:0030212 & hyaluronan metabolic process \\
\hline GO:0044710 & single-organism metabolic process \\
\hline GO:0048585 & negative regulation of response to stimulus \\
\hline GO:0050994 & regulation of lipid catabolic process \\
\hline GO:1903034 & regulation of response to wounding \\
\hline GO:0006958 & complement activation, classical pathway \\
\hline GO:0006103 & 2-oxoglutarate metabolic process \\
\hline GO:0051004 & regulation of lipoprotein lipase activity \\
\hline GO:0034377 & plasma lipoprotein particle assembly \\
\hline GO:0048523 & negative regulation of cellular process \\
\hline GO:0071827 & plasma lipoprotein particle organization \\
\hline GO:0090207 & regulation of triglyceride metabolic process \\
\hline GO:0002455 & $\begin{array}{l}\text { humoral immune response mediated by circulating } \\
\text { immunoglobulin }\end{array}$ \\
\hline GO:2001234 & negative regulation of apoptotic signaling pathway \\
\hline GO:0016584 & nucleosome positioning \\
\hline (less ...) & \\
\hline
\end{tabular}

\begin{tabular}{|l|l|}
\hline Molecular Function (GO) & \\
\hline Pathway ID & pathway description \\
\hline GO:0061134 & peptidase regulator activity \\
\hline GO:0030414 & peptidase inhibitor activity \\
\hline GO:0061135 & endopeptidase regulator activity \\
\hline GO:0004866 & endopeptidase inhibitor activity \\
\hline GO:0004857 & enzyme inhibitor activity \\
\hline GO:0030234 & enzyme regulator activity \\
\hline (less ...) & \\
\hline
\end{tabular}

\begin{tabular}{|l|l|}
\hline Cellular Component (GO) & \\
\hline Pathway ID & pathway description \\
\hline GO:0072562 & blood microparticle \\
\hline GO:0005615 & extracellular space \\
\hline GO:0044421 & extracellular region part \\
\hline GO:0034364 & high-density lipoprotein particle \\
\hline GO:0031982 & vesicle \\
\hline GO:0031988 & membrane-bounded vesicle \\
\hline GO:0070062 & extracellular exosome \\
\hline GO:0005576 & extracellular region \\
\hline GO:0060205 & cytoplasmic membrane-bounded vesicle lumen \\
\hline
\end{tabular}




\begin{tabular}{|l|l|}
\hline GO:0071682 & endocytic vesicle lumen \\
\hline GO:0043227 & membrane-bounded organelle \\
\hline GO:0043226 & organelle \\
\hline GO:0034366 & spherical high-density lipoprotein particle \\
\hline GO:0031012 & extracellular matrix \\
\hline GO:0030496 & midbody \\
\hline (less ...) & \\
\hline
\end{tabular}




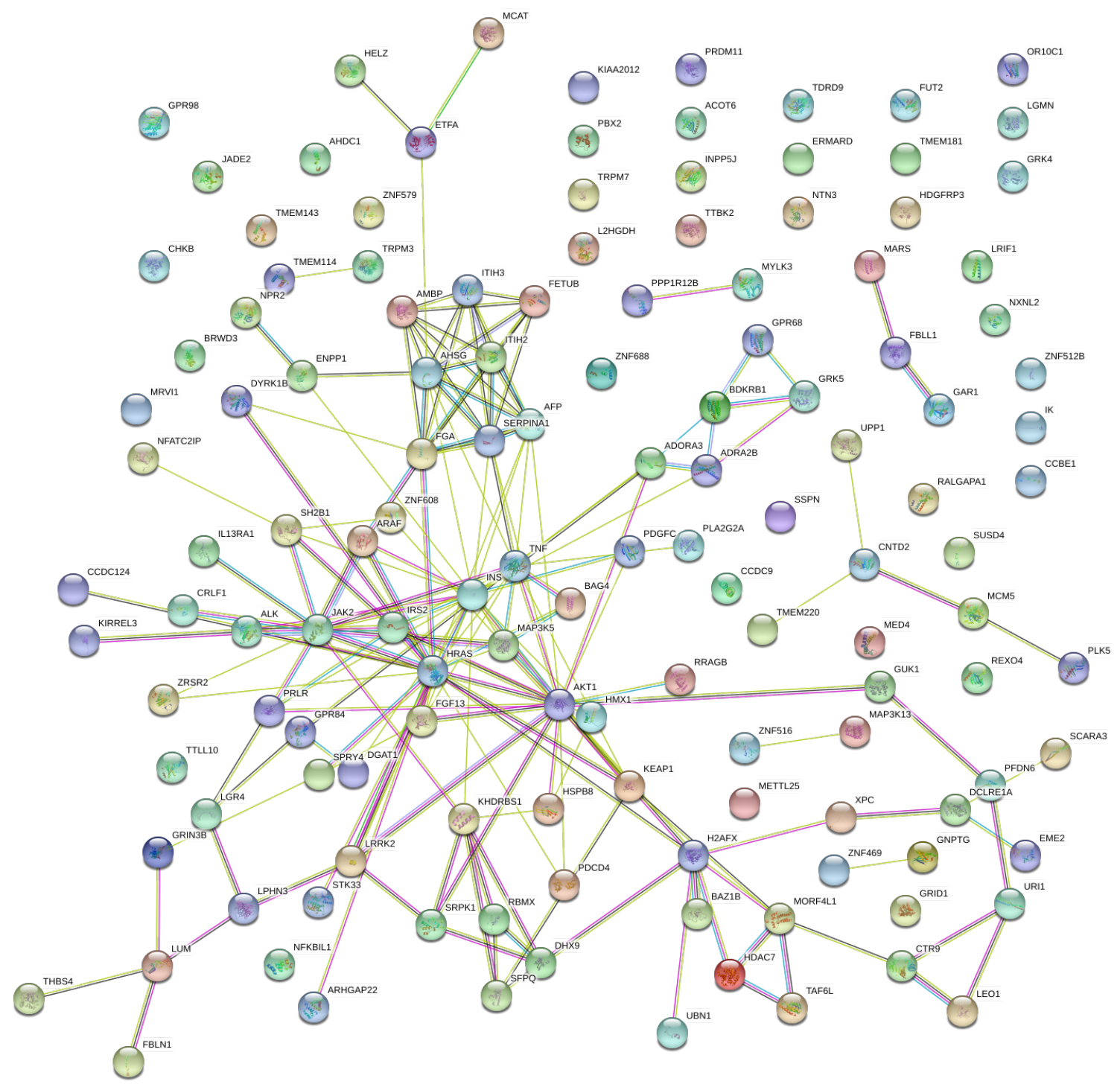

Figure 10. The Fetal serum STRING network where Chi Square $\chi 2 \geq 15$ from fully tryptic peptides. The network shown is where fetal serum observations exceeded those of adult serum by tryptic peptide frequency difference with $\chi 2$ value greater than 15 at degrees of freedom of $1(p<0.0001)$. 


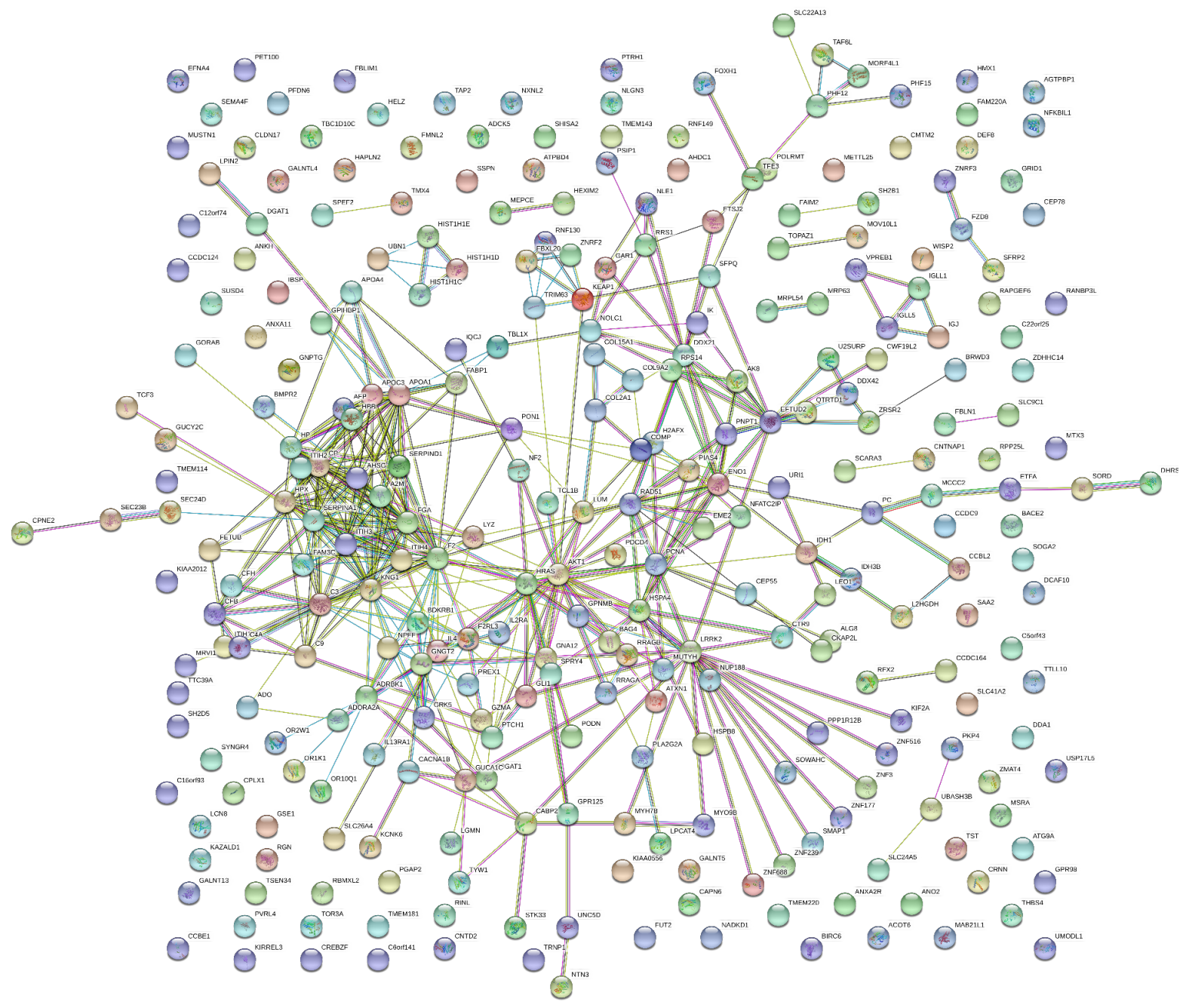

Figure 11. The STRING network shows the top 400 proteins with the most significant chisquare value in the fetal serum. Many AKT/HRAS proliferation pathways as well as AFP and Insulin like growth factors were observed. 


\subsection{ANOVA quantification of alpha feto protein (AFP)}

AFP was observed to be specific to the fetal serum and was markedly increased in the observation frequency compared to adult serum. Two independent computations returned similar results with the same protein AFP implicated. Exemplary MS/MS spectra were observed from Alpha feto protein (Fig. 12). Analysis of $\log 10$ transformed precursor intensity from MS/MS spectra correlated by X!TANDEM showed significant increased in Alpha-feto protein in all three of the fetal serum replicates both with and without phosphorylation (Table 8). Some peptides were found to be specific to AFP and highly observed in fetal serum. Variations of $\log 10$ transformed precursor intensity of peptides in AFP indicated that different peptides were observed in fetal versus adult serum but they are all specific to AFP, which was shown by the normality distribution (Fig. 13). The peptides LGEYYLQNAFLVAYTK, KAPQLTSPELMALTR, FLGDRDFNQLSSR, and QKPQITEEQLETVVADFSGLLEK were examples of sequences found to be unique to AFP and not Albumin (searched against BLAST), and they were only observed in fetal serum with enriched amounts compared to other sequences (Table 9 \& Fig. 14). 
Table 8. The mean and standard deviation of the Log10 precursor intensity values for treatments between adult versus fetal serum. Alpha-feto protein was highly enriched in FBS over the partition chromatography extraction (See appendix Table 10).

\begin{tabular}{|c|c|c|c|c|}
\hline & $\begin{array}{c}\text { Mean } \\
\text { Intensity }\end{array}$ & $\begin{array}{l}\text { Standard } \\
\text { deviation }\end{array}$ & $\begin{array}{c}\text { AFP } \\
\text { Counts }\end{array}$ & Treatment Name \\
\hline 1 & 5.478582 & 0.58540897 & 30 & ABS-NaCl Extraction \\
\hline 2 & 5.210961 & 0.45857083 & 20 & ABS- NaCl Extraction PSTY \\
\hline 3 & 6.066390 & 0.80549511 & 90 & ABS- $\mathrm{NaCl}$ Extraction \\
\hline 4 & 6.123193 & 0.72567329 & 44 & ABS- NaCl Extraction PSTY \\
\hline 5 & 5.450042 & 0.54669255 & 40 & ABS- $\mathrm{NaCl}$ Extraction \\
\hline 6 & 5.393417 & 0.54968106 & 14 & ABS- NaCl Extraction PSTY \\
\hline 7 & NA & NA & NA & ABS-ACN Extraction \\
\hline 8 & 4.756725 & 0.22025096 & 2 & ABS-ACN Extraction PSTY \\
\hline 9 & 4.875267 & 0.55411930 & 9 & ABS- ACN Extraction \\
\hline 10 & 4.942789 & 0.41958090 & 7 & ABS- ACN Extraction PSTY \\
\hline 11 & 4.591639 & 0.38176752 & 4 & ABS- ACN Extraction \\
\hline 12 & 4.813441 & 0.74986619 & 5 & ABS- ACN Extraction PSTY \\
\hline 13 & 5.323178 & 0.45386238 & 105 & FBS-NaCl Extraction \\
\hline 14 & 5.310902 & 0.43212468 & 48 & FBS- NaCl Extraction PSTY \\
\hline 15 & 5.294939 & 0.57956018 & 873 & FBS- $\mathrm{NaCl}$ Extraction \\
\hline 16 & 5.359196 & 0.55721166 & 344 & FBS- NaCl Extraction PSTY \\
\hline 17 & 5.027520 & 0.41713324 & 307 & FBS-NaCl Extraction \\
\hline 18 & 5.028439 & 0.44348405 & 153 & FBS- NaCl Extraction PSTY \\
\hline 19 & 5.307961 & NA & 1 & FBS-ACN Extraction \\
\hline 20 & 4.715307 & 0.11598031 & 2 & FBS-ACN Extraction PSTY \\
\hline 21 & 4.250918 & 0.26384156 & 6 & FBS-ACN Extraction \\
\hline 22 & 4.410122 & 0.36034454 & 18 & FBS-ACN Extraction PSYT \\
\hline 23 & 4.637643 & 0.24639235 & 4 & FBS-ACN Extraction \\
\hline 24 & 5.005919 & 0.09273483 & 2 & FBS-ACN Extraction PSTY \\
\hline
\end{tabular}


Table 9. Peptide sequences specific to AFP. FLGDRDFNQLSSR, LGEYYLQNAFLVAYTK, QKPQITEEQLETVVADFSGLLEK, and KAPQLTSPELMALTR were examples of peptides that were specific to AFP but not albumin with enriched amounts (searched against BLAST) and found in fetal serum only.

\begin{tabular}{|c|c|c|}
\hline Peptide Sequences & Intensity Values & Counts \\
\hline AAPASIPPFPVLEPVTSCK & 5.178533 & 15 \\
\hline AENATECFETK & 4.741233 & 2 \\
\hline AENATECFETKVTSITK & 5.174305 & 1 \\
\hline AFLVAYTKKAPQLTSPELMALTR & 5.12508 & 11 \\
\hline AITVTK & 5.030537 & 1 \\
\hline APQLTSPELMALTR & 5.163889 & 11 \\
\hline CCQSQEQEVCFTEEGPALISK & 5.261659 & 6 \\
\hline DFNQLSSR & 4.803041 & 10 \\
\hline DFNQLSSRDKDLSMARFTYEYSR & 5.229139 & 1 \\
\hline DKDLSMAR & 5.027066 & 32 \\
\hline DKDLSMARFTYEYSRR & 5.274222 & 1 \\
\hline DLCQVQGVPLQTMK & 4.958126 & 10 \\
\hline DLCQVQGVPLQTMKQQFLINLVK & 4.563741 & 1 \\
\hline DLSMARFTYEYSRRHTK & 4.643211 & 1 \\
\hline DVLTIIEKPTGSK & 5.168966 & 46 \\
\hline EIPEKYGLSDCCSR & 4.979192 & 3 \\
\hline EIPEKYGLSDCCSRTGEERHDCFLAHK & 5.007572 & 1 \\
\hline EKEIPEKYGLSDCCSR & 4.983226 & 4 \\
\hline EKEIPEKYGLSDCCSRTGEER & 4.824199 & 2 \\
\hline ELFINR & 5.035353 & 1 \\
\hline ELFINRYIYEIAR & 4.903483 & 11 \\
\hline ELRESSLLNQHICAVMGKFGPRTFR & 5.687433 & 1 \\
\hline ELRESSLLNQHICAVMGKFGPRTFRAITVTKVSQK & 4.472155 & 1 \\
\hline ESSLLNQHICAVMGK & 5.554158 & 10 \\
\hline ESSLLNQHICAVMGKFGPRTFR & 6.135839 & 1 \\
\hline FGPRTFR & 4.474459 & 1 \\
\hline FIFHKDLCQVQGVPLQTMK & 5.403825 & 1 \\
\hline FIFHKDLCQVQGVPLQTMKQQFLINLVK & 5.105651 & 1 \\
\hline FLGDRDFNQLSSR & 5.531424 & 156 \\
\hline FLGDRDFNQLSSRDKDLSMAR & 4.230859 & 1 \\
\hline FPKANFTEIQK & 5.307961 & 1 \\
\hline FTYEYSR & 5.239719 & 57 \\
\hline FTYEYSRR & 5.095873 & 7 \\
\hline GNVLECLQDGER & 5.066557 & 33 \\
\hline GYQELLEK & 5.173775 & 92 \\
\hline HDCFLAHKK & 4.860238 & 8 \\
\hline HPVLYAPTILSVANQYNK & 5.073591 & 8 \\
\hline HTKLAVPIILR & 5.127088 & 19 \\
\hline IIPHCCKAENATECFETKVTSITK & 5.833767 & 1 \\
\hline KAAPASIPPFPVLEPVTSCK & 5.206178 & 8 \\
\hline
\end{tabular}




\begin{tabular}{|c|c|c|}
\hline KAAPASIPPFPVLEPVTSCKSYK & 5.370925 & 1 \\
\hline KAAPASIPPFPVLEPVTSCKSYKENR & 5.552489 & 2 \\
\hline KAPQLTSPELMALTR & 5.292359 & 181 \\
\hline KAPQLTSPELMALTRK & 5.547794 & 13 \\
\hline KMANAGAICCHLSEDKQLACGEGVADLIIGHLCIR & 5.431735 & 2 \\
\hline LAVPIILR & 5.215772 & 77 \\
\hline LAVPIILRVAK & 5.423892 & 2 \\
\hline LGEYYLQNAFLVAYTK & 5.056435 & 186 \\
\hline LGEYYLQNAFLVAYTKK & 5.229229 & 6 \\
\hline LPTTLELGHCIIHAENDDKPEGLSPNVNR & 4.572126 & 3 \\
\hline LVMDVAHIHEECCK & 4.94861 & 4 \\
\hline LVMDVAHIHEECCKGNVLECLQDGER & 5.369604 & 2 \\
\hline MKWVVSFFLLFLLNFSDSR & 4.637449 & 1 \\
\hline MKWVVSFFLLFLLNFSDSRTMHK & 4.657245 & 1 \\
\hline QKPQITEEQLETVVADFSGLLEK & 5.428821 & 153 \\
\hline QLACGEGVADLIIGHLCIR & 5.252301 & 2 \\
\hline QPAGCLENQVSAFLEEICR & 4.637113 & 5 \\
\hline QPAGCLENQVSAFLEEICREK & 5.563586 & 3 \\
\hline QQFLINLVK & 5.542871 & 39 \\
\hline RHPVLYAPTILSVANQYNK & 5.240158 & 36 \\
\hline RHPVLYAPTILSVANQYNKIIPHCCK & 4.727681 & 1 \\
\hline RHTKLAVPIILR & 4.038676 & 2 \\
\hline RPCFSSLVVDETYVPPPFSDDK & 4.614878 & 2 \\
\hline RSCGLFQK & 4.990376 & 14 \\
\hline SCGLFQK & 4.814539 & 17 \\
\hline SYKENRELFINR & 5.237495 & 13 \\
\hline TFRAITVTKVSQKFPK & 4.77845 & 4 \\
\hline TGEERHDCFLAHK & 4.473828 & 12 \\
\hline TGEERHDCFLAHKK & 4.823098 & 33 \\
\hline TRAALGV & 4.90512 & 38 \\
\hline VAKGYQELLEK & 5.046219 & 33 \\
\hline VMSYICSQQDILSR & 5.203705 & 20 \\
\hline VMSYICSQQDILSRQIAECCK & 5.309928 & 1 \\
\hline VSQKFPK & 4.880662 & 70 \\
\hline VTSITKELR & 4.787943 & 4 \\
\hline VTSITKELRESSLLNQHICAVMGK & 4.828695 & 2 \\
\hline VTSITKELRESSLLNQHICAVMGKFGPR & 5.010108 & 1 \\
\hline YGLSDCCSR & 4.891239 & 22 \\
\hline YIQESQALAK & 5.82608 & 52 \\
\hline YIQESQALAKR & 4.607971 & 3 \\
\hline YIYEIAR & 5.544451 & 248 \\
\hline YIYEIARR & 5.46179 & 59 \\
\hline YLYEIAR & 5.64936 & 129 \\
\hline YLYEIARR & 5.451315 & 51 \\
\hline
\end{tabular}




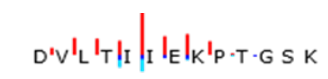

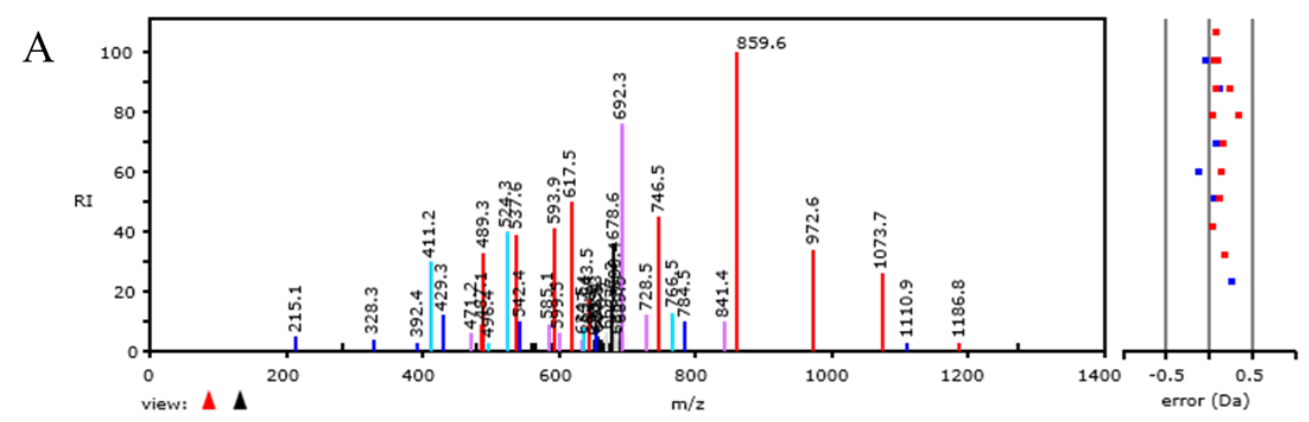

$S Y I_{K} I_{E \cdot N \cdot R \cdot E \cdot L \cdot F \cdot I} N \cdot R$
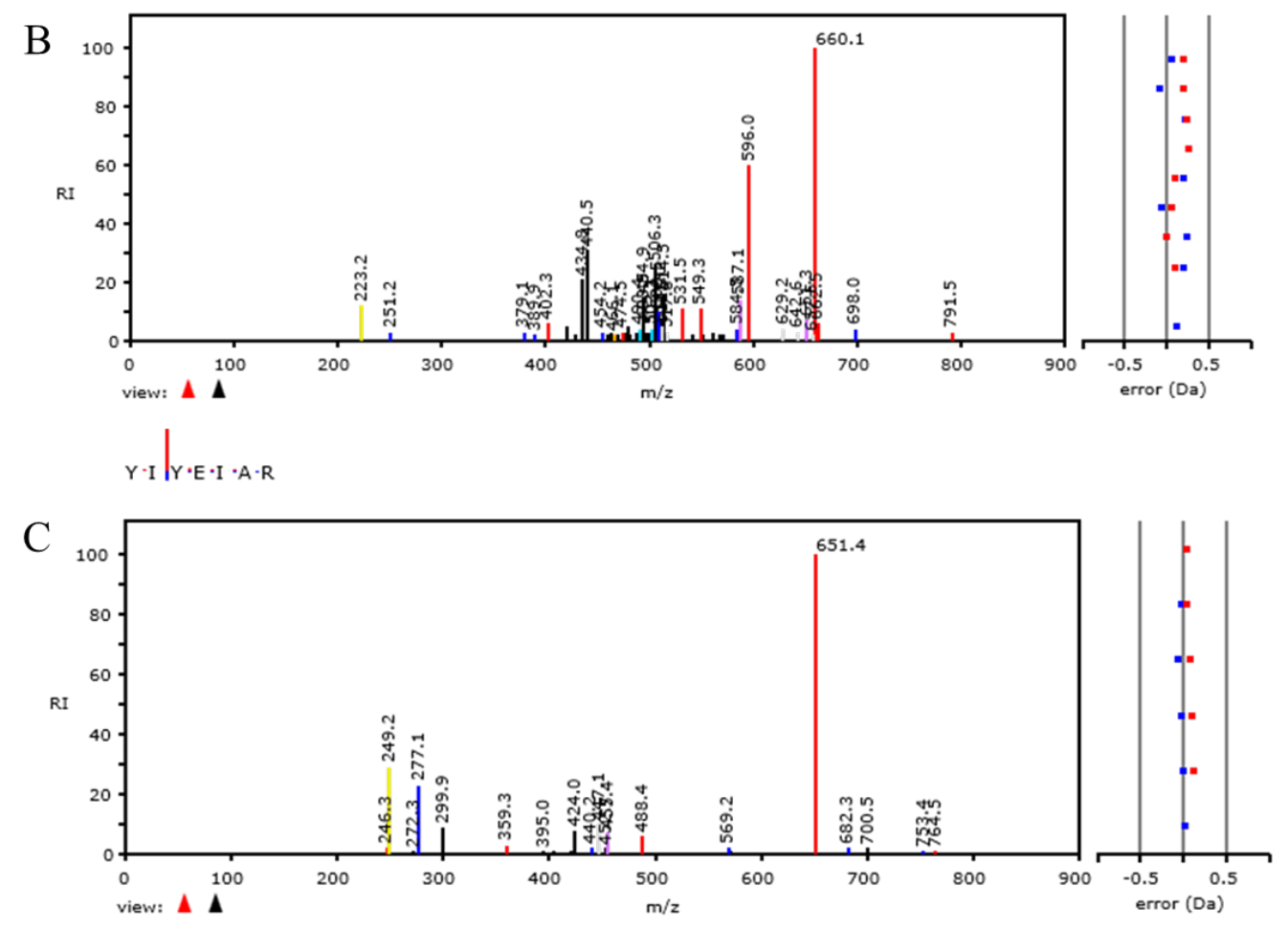

Figure 12. Example MS/MS spectra from alpha feto protein that was specific to fetal serum from the X!TANDEM algorithm. Panels: A, the peptide DVLTIIEKPTGSK; B, the peptide SYKENRELFINR; $C$, the peptide YIYEIAR. 

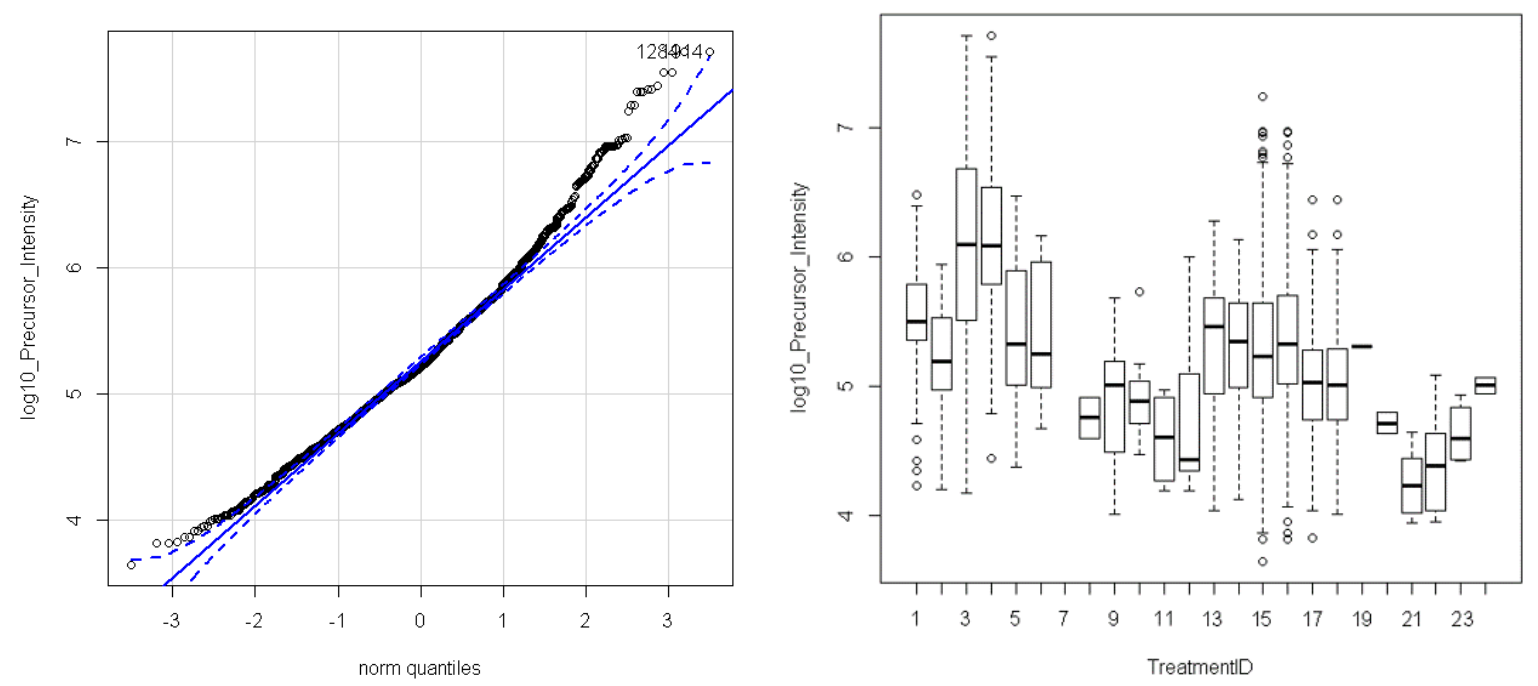

Figure 13. AFP in fetal and adult bovine serum between treatments and replicates. Treatments and replicates from salt partition chromatography and organic extraction with and without the consideration of phosphorylation of AFP were shown here. Panels: $A$, the quantile $Q-Q$ plot showing the normality of the log10 transformed intensity values; $B$, the box plot showing the average $\log 10$ intensity and variation in $\log 10$ for the adult versus fetal serum replicates.

ANOVA analysis showed a probability of $\sim 2 \mathrm{e}-16$ that the AFP between fetal versus adult serum samples were the statistically significant:

Response: $\log 10 \_$Precursor_Intensity

Sum Sq Df F value $\operatorname{Pr}(>$ F $)$

Peptide $\quad 138.92827 .2359<2.2 \mathrm{e}-16 * * *$

TreatmentID $\quad 133.02 \quad 2127.0545<2.2 \mathrm{e}-16 * * *$

Peptide:TreatmentID 60.05 $1751.46550 .0001405 * * *$

Residuals $\quad 432.681848$ 
A

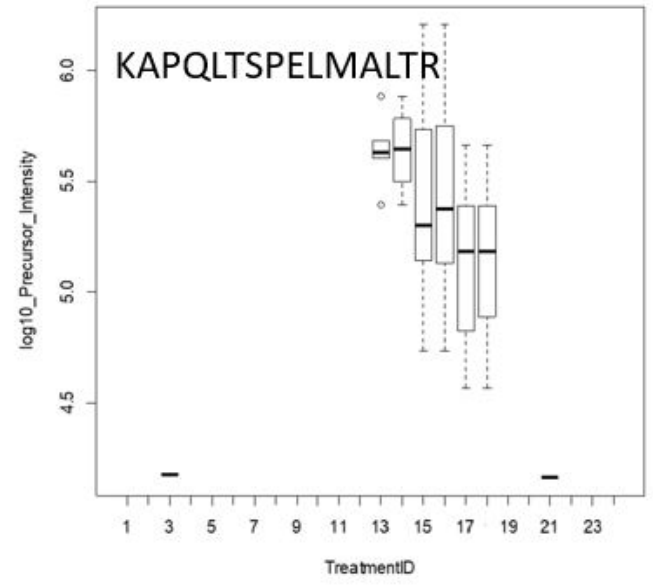

B

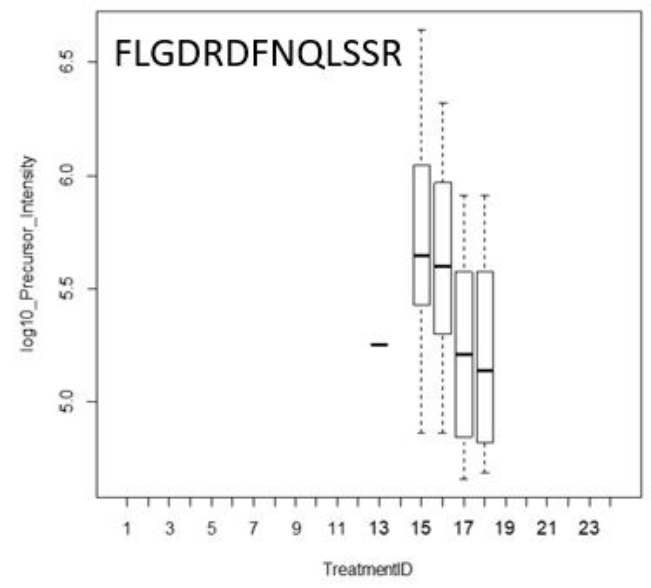

$\mathrm{C}$

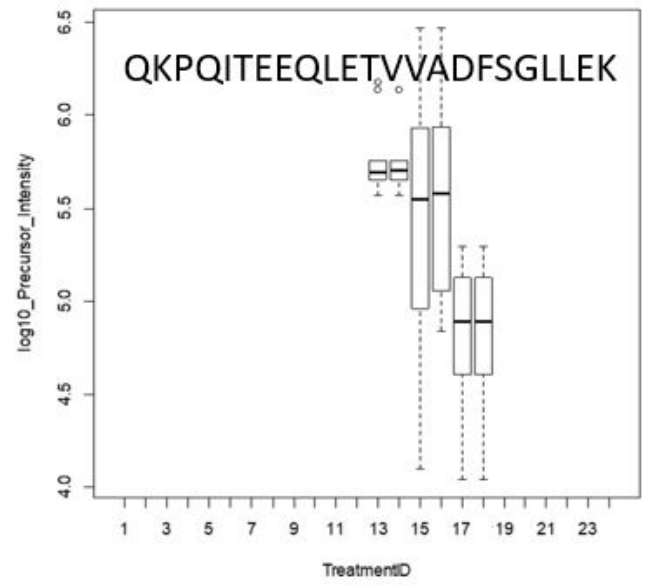

D

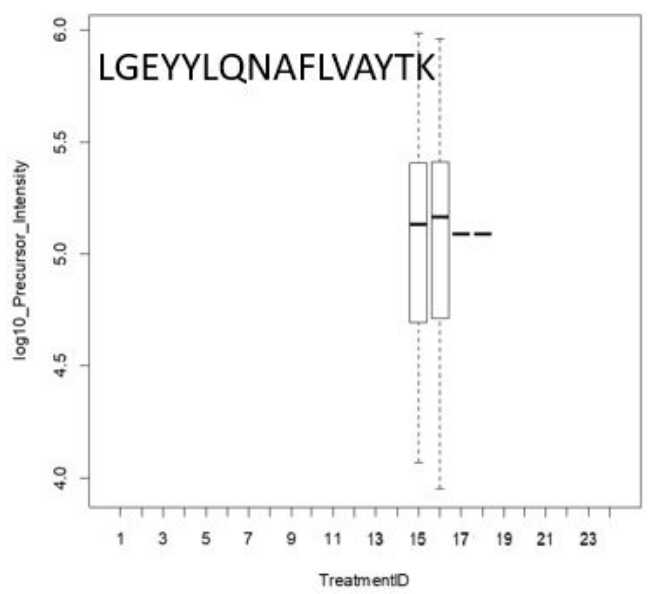

Figure 14. Some peptides were found to be specific to AFP and highly observed in fetal serum. The four peptides shown above (Panels A, B, C, and D) were found to be unique to AFP but not Albumin, which were only found in fetal serum. These peptides from AFP were only observed from partition chromatography (See Table 8). Panels: A, the peptide KAPQLSPELMALTR; B, the peptide FLGDRDFNQLSSR; C, QKPQITEEQLETVVADFSGLLEK; D, the peptide LGEYYLQNAFLVAYTK.

ID\# from 1-12: ABS treatments; ID\# from 13-24: FBS treatments (See Table 8) 


\subsection{Insulin in FBS and Addition of Insulin in ABS cell culture}

Insulin was another example of a protein found with increased observation frequency in FBS.

Exemplary MS/MS spectra were observed from Insulin (Fig. 15). The variations of INS peptides

in fetal versus adult serum indicated that different peptides were observed (Fig. 16). Addition of insulin to Raw cell macrophages in ABS cell culture resulted in rounded cells similar to FBS controls. Different amounts of insulin from $0.2 \mu \mathrm{g}, 2 \mu \mathrm{g}$, and $20 \mu \mathrm{g}$ added to ABS cell culture were compared with $0 \mu \mathrm{g}$ of insulin in ABS culture and FBS culture as controls. The addition of $2 \mu \mathrm{g}$ of insulin seemed to have the optimal results to the cultured cells in ABS where $0.2 \mu \mathrm{g}$ of insulin did not seem to have any effect and $20 \mu \mathrm{g}$ of insulin seemed to be too saturated (overdose) so the cells started to die. (Fig. 17\&18) 


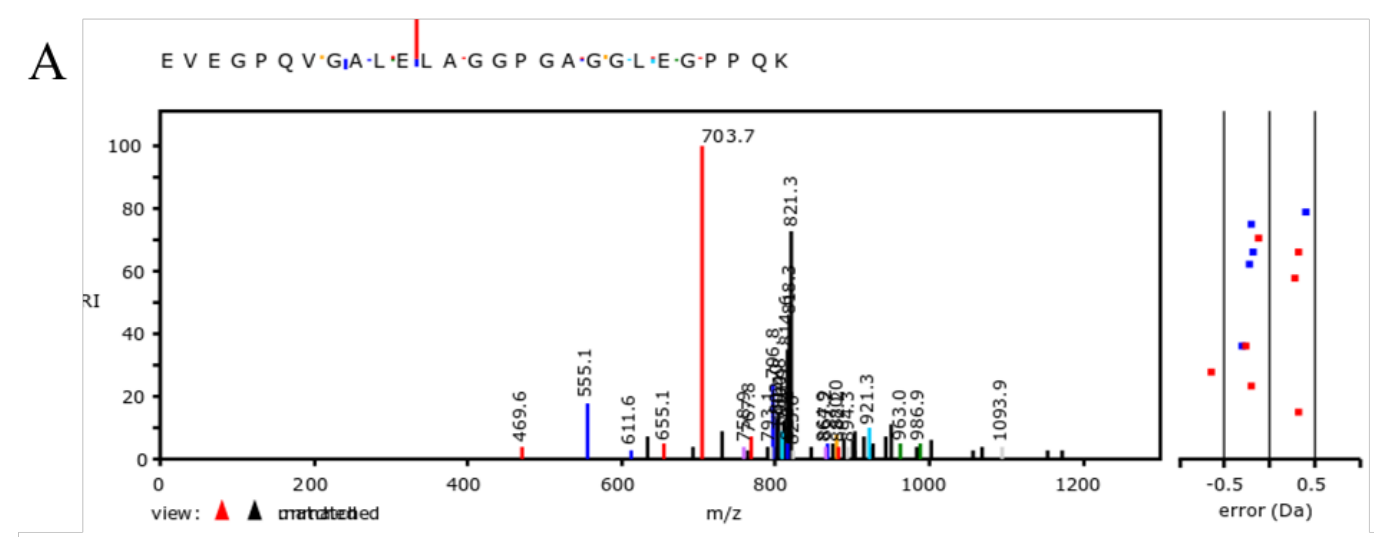

B
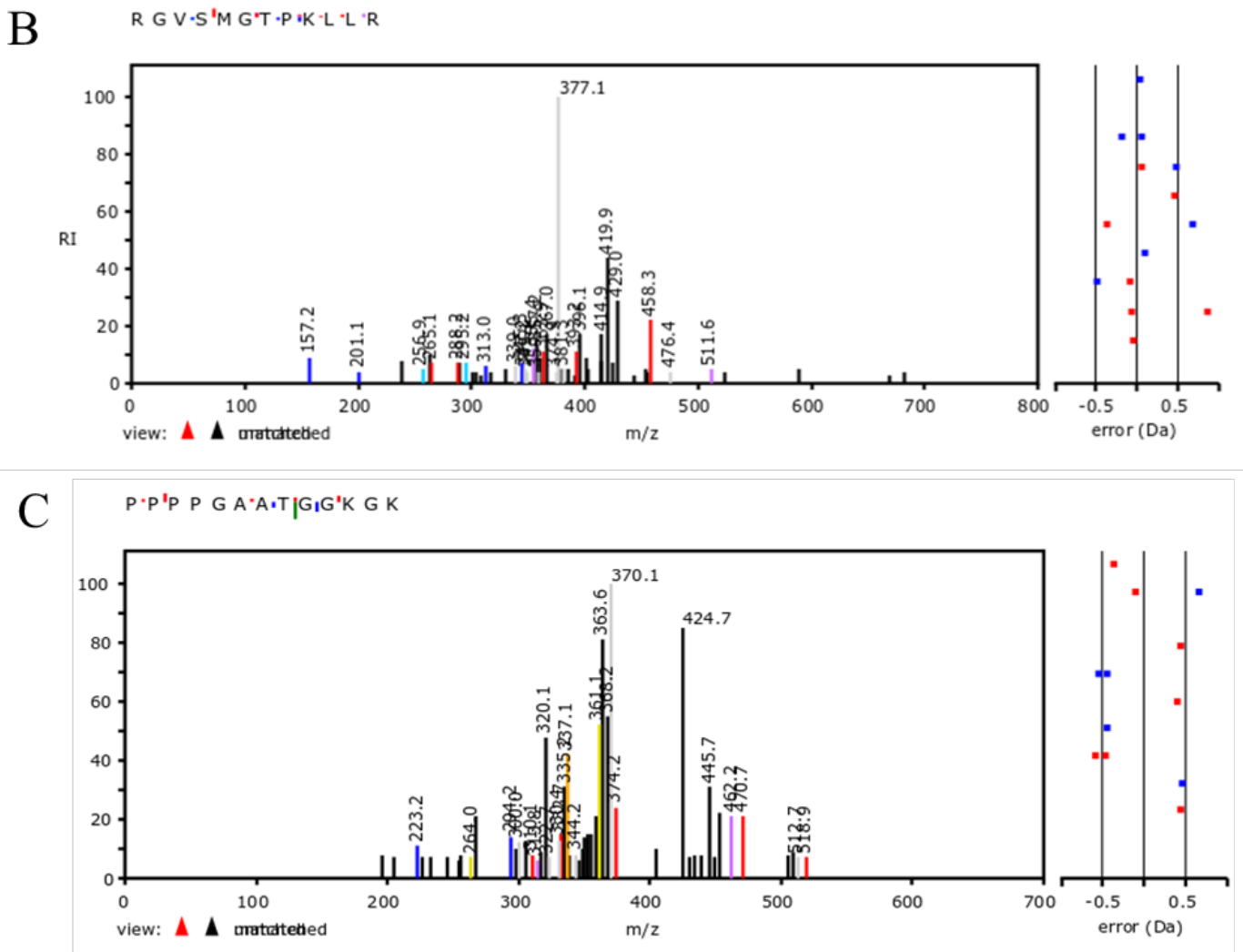

Figure 15. Example MS/MS spectra from high abundance insulin that was specific to fetal serum from X!TANDEM algorithm. Panels: A, the peptide EVEGPQVGALEKLAGGPPGAGGLEGPPQK; B, the peptide RGVSMGTPKLLR; C, the peptide PPPPGAATGGKGK. 

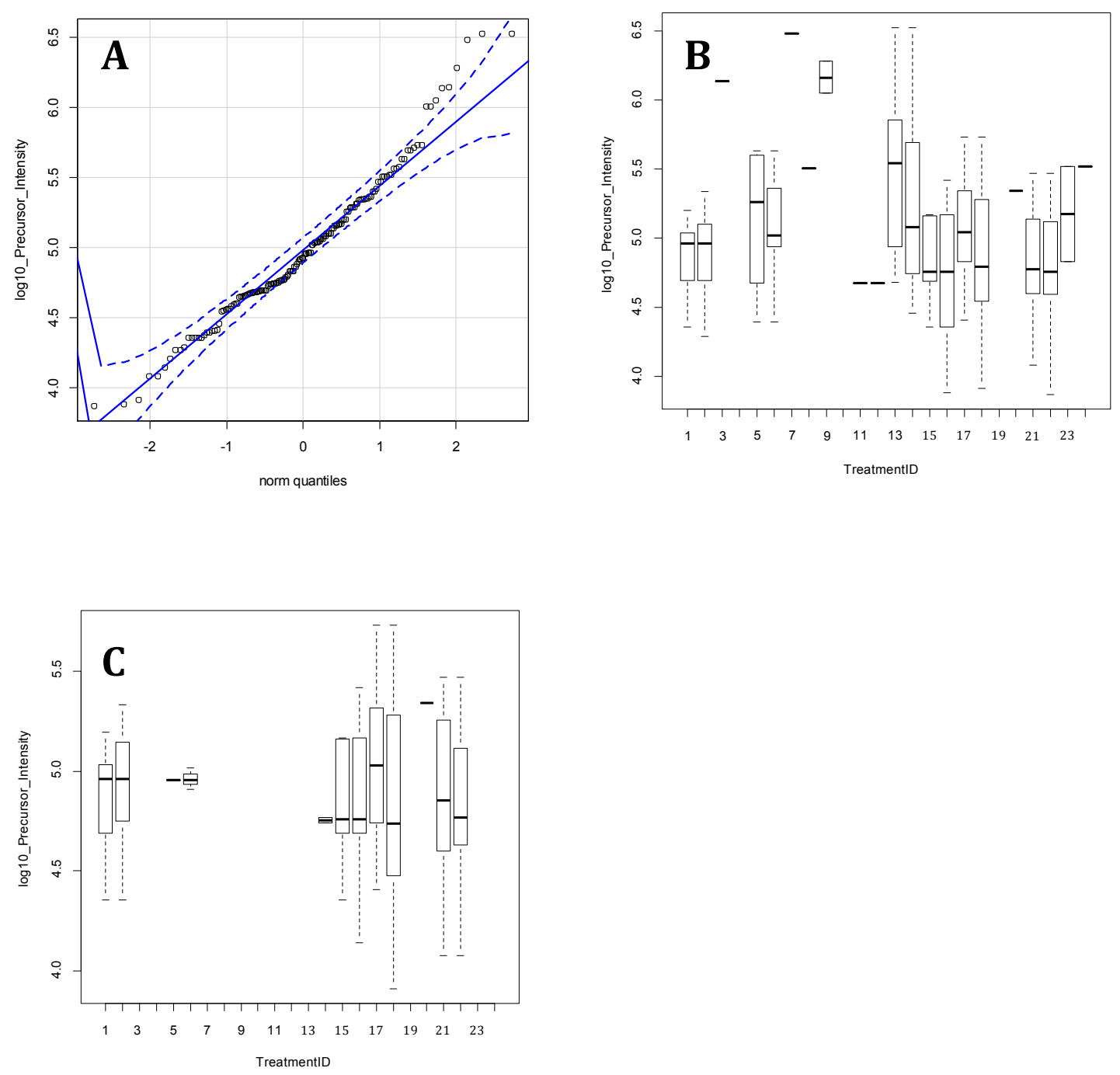

Figure 16. The variation in INS peptides in the fetal versus adult serum samples. Panels: A, the QQ plot showing the normality of the log10 transformed intensity values; $B$, all of the peptides from insulin (INS); $C$, the peptide MGPGRAR from insulin. The box plot showing the average $\log 10$ intensity and variation in $\log 10$ and $99 \%$ confidence interval is shown for the adult versus fetal serum replicates ANOVA analysis show a significant effect of treatment and peptides both with a value of $\sim 2 \mathrm{e}-16$. 


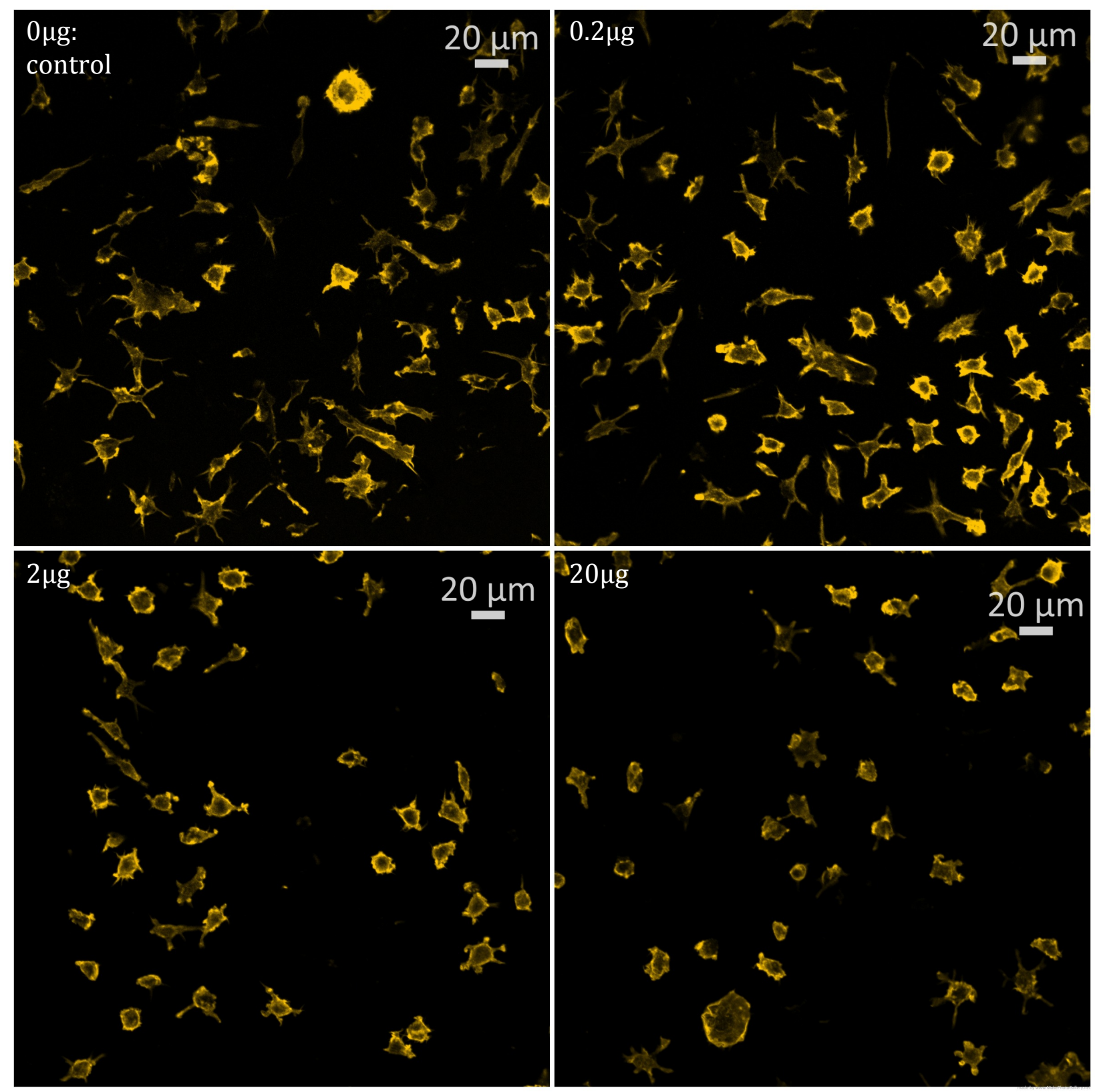

Figure 17. Raw cells cultured in 5\% ABS and stained with rhodamine phalloidin. The images were taken under a $20 \mathrm{X}$ magnification confocal microscope. Addition of $0 \mu \mathrm{g}, 0.2 \mu \mathrm{g}$, $2 \mu \mathrm{g}$, and $20 \mu \mathrm{g}$ of insulin to Raw cell 264.7 in ABS cell culture showed different cell morphologies. Different amounts of INS were compared to the control (no addition of INS), where $2 \mu \mathrm{g}$ of INS gave the similar results to FBS, $0.2 \mu \mathrm{g}$ of INS did not seem to have any results to the cell and $20 \mu \mathrm{g}$ of INS seemed to be saturated. 


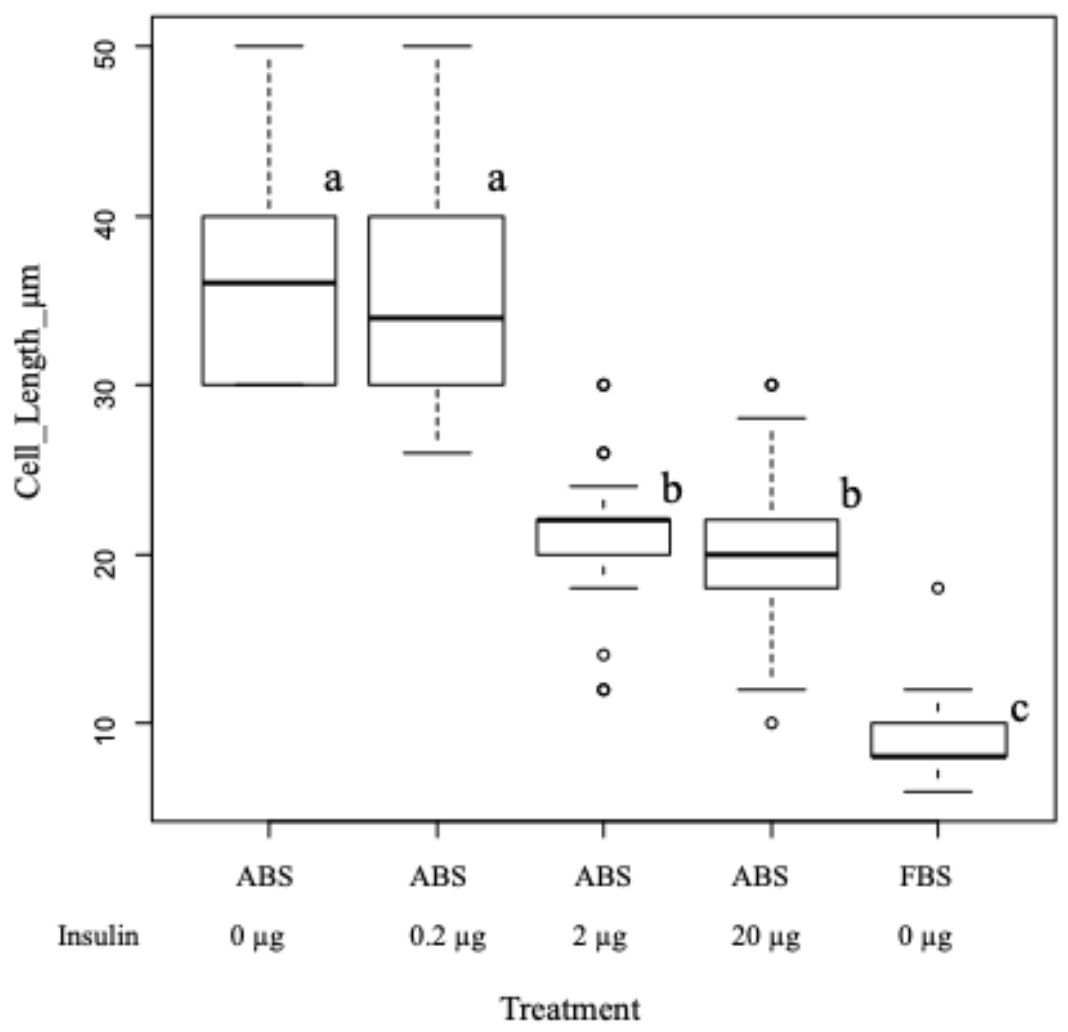

Figure 18. ANOAVA analysis shows the means of cell length between the levels of insulin addition to the ABS cell culture. Ten cells were measured from 3 spots of each treatment. The longest axis of the cell was measured.

> Summary(AnovaModel.1)

Df Sum Sq Mean Sq F value $\operatorname{Pr}(>\mathrm{F})$

Treatment $4 \quad 16064 \quad 4016 \quad 157.3<2 \mathrm{e}-16$ ***

Residuals $1453703 \quad 26$

Signif. codes: $0^{\prime * * * '} 0.001^{\prime * *} 0.011^{\prime *} 0.05$ '.' 0.1 ' ' 1

$>$ with(Dataset, numSummary(Cell_Length_um, groups=Treatment,

+ statistics=c("mean", "sd"))) mean sd data:n

ABS $\quad 36.400000 \quad 5.834499 \quad 30$

ABS_0.2_ug_Insulin $35.533333 \quad 7.04044130$

ABS_2_ug_Insulin $\quad 21.133333 \quad 4.125057 \quad 30$

ABS_20_ug_Insulin $\quad 20.200000 \quad 4.708027 \quad 30$

FBS

$\begin{array}{lll}8.933333 & 2.211776 & 30\end{array}$ 


\subsection{DISCUSSION}

The aim and objective of this study was to identify proteins and peptides specific to fetal versus adult serum by random and independent sampling of peptides from digested proteins (proteomics) or endogenous peptides (peptidomics) using a LC-ESI-MS/MS with a linear quadrupole ion trap to reveal the factors that may account for proliferative phenotype observed. There was near perfect (99\%) agreement on the proteins of bovine serum between the independent proteomic and peptidomic methods clearly and unambiguously demonstrated that the type I error of protein identification was low. However, there was large variation in the observation frequency and/or intensity of the peptides and proteins identified between fetal versus adult serum. Here for the first time all of the factors that differ between fetal versus adult serum are revealed.

\subsection{Agreement between independent methods}

Multiple independent lines of evidence including the effect of fetal versus adult serum on cells, the results of LC-ESI-MS/MS with both the X!TANDEM and SEQUEST algorithm (computed independently with and without phosphorylation), Chi square analysis of observation frequency [82], and previously observed structural and functional relationships from STRING analysis [78], all agreed that there were significant statistical and biological differences in the proteins of fetal versus adult serum. However, the source of the many cellular proteins observed in sera is not clear and at least some of them can be accounted for from red blood cells or white blood cells that may occur during sampling. 


\subsection{Release of cellular proteins from blood cells}

Many unexpected cellular proteins have been observed in serum of plasma by liquid

chromatography and tandem mass spectrometry by multiple groups in agreement [76], [83]-[85].

At present it is not clear if the many receptors observed in serum were cleaved from the cell

surfaces by proteases. Neither it is clear if the cellular proteins, other than those from blood cell

lysis, were secreted in solution, released in membrane bound vesicles like exosomes, were bound

to circulating nucleic acids [4], or otherwise released from cells. It remains possible that some of

the cellular factors observed were released from white blood cells like platelets or immune cells

and it will be important to rule out cells as a source of error in the serum or plasma proteome.

Some, but not all, the proteins that are known to be derived from platelets, monocytes,

macrophages, neutrophils, or granulocytes were observed in the serum. The fraction of all known

white or red blood cells proteins observed, and the even smaller subset that showed significantly

greater observation frequency in fetal serum, were not consistent with contamination from white,

or red blood cells as the largest source of the differences between fetal versus adult serum.

However, the observation that only a small fraction of all known white blood cells proteins were

observed and did not show significantly greater observation frequency in fetal serum, are not

consistent with contamination from white blood as the source of the fetal serum specific proteins.

White blood cells are known to secrete phospholipase A2 [86] that was also observed in serum

and plasma by LC-ESI-MS/MS in human and bovine samples. The observed hemoglobin

confirms that some red blood cell lysis occurred but it is difficult to account for the transcription

factor, histones and DNA binding proteins observed from enucleated red blood cells. The platelet

proteome is known to possess at least $\sim 1,100$ proteins [87] and platelet derived factors have

effects similar to fetal serum on cell cultures [29]. Platelet lysates are known to permit the 
expansion of cultured cell lines in a manner similar to fetal serum [13]. Some platelet derived factors such as platelet associated factor 4 (chemokine (C-X-C motif) ligand 4) observed in fetal serum have been associated with the biology of cancer [88].

\subsection{Quaternary amine chromatography versus organic extraction}

There was previously observed good agreement between the proteins that resulted from partition chromatography and endogenous peptides extracted from serum in single step extractions analyzed by micro chromatography [3]. Subsequently the use of step wise salt elution of partition chromatography resins followed by micro electrospray identified 4,396 distinct proteins by X!TANDEM [39]. Step wise organic fractionation with micro electrospray previously identified 3,463 protein from serum [38] and the combination with nano-spray identified some 14,000 proteins by X!TANDEM from the aggregation of hundreds of LC-ESI-MS/MS experiments [4]. Here the use of partition chromatography and organic extraction together by nano LC-ESI-MS/MS results in more than 12,000 proteins identified with multiple peptides by X!TANDEM that shows good agreement with the number of proteins reported from the HuPO (Human Proteome Organization) plasma proteome consortium [65]. Taken together the results indicate that more than 12,000 proteins can be reliably monitored by step-wise quaternary amine pre-fractionation prior to digestion.

\subsection{Fetal proteins}

The specific identification of the alpha feto protein [89] and fetal hemoglobin in the fetal serum seems to indicate that the LC-ESI-MS/MS system was capable of faithfully identifying the proteins that differ between fetal and adult serum [90]. Alpha feto protein (AFP) stands out as an 
example of a protein that was markedly different between adult versus fetal serum that is strongly suspected of directly mediating effects on cell growth: AFP is known to stimulate proliferation and inhibit apoptosis [91], [92], binds to a DNA-binding zinc finger transcription factor of the nuclear receptors and may be an important regulator of embryonic development [93].

The example of AFP also showed that the proteins were stable and did not degrade easily during the extraction over partition chromatography and organic extraction. This was indicated by looking at the accession protein counts that there was only a few of the AFP observed in the endogenous peptides extraction. (Table 8).

\subsection{Cellular and multi cellular growth pathways}

Unbiased chi square analysis of protein frequencies between fetal versus adult serum showed proto oncogenes from the cellular growth pathway such as AKT and HRAS were observed in the fetal serum consistent with a role for the pathway in the rapid growth of developing cells. The AKT/HRAS pathway is connected to many of the receptor and receptor enzyme proteins discovered specific to fetal serum. Increased frequency of adenylate cyclase, calmodulin-binding transcription activator, calcium/calmodulin-dependent protein kinase type 1, Calcium/calmodulin-dependent 3',5'-cyclic nucleotide phosphodiesterase links the PI3K, AKT, HRAS proliferation pathways to the cyclic AMP (cAMP) responsive element binding CREB/ATF bZIP transcription factor. 


\subsection{Potential Transforming factors from sera}

The specific increase in certain peptide hormones, growth factors or platelet derived proteins might be the source of the transformative effects of the fetal serum or platelet lysates. Peptide hormones and other potent ligands such as growth factor or interleukins observed present in relatively low levels present the greatest challenge to detection by LC-ESI-MS/MS. Formerly, insulin like growth factor II was barely detectable [41], [42], but after step wise fractionation together with nano scale LC-ESI-MS/MS insulin, insulin like growth factor II, insulin binding protein, and insulinoma-associated protein were all observed tens or hundreds of times and by both X!TANDEM and SEQUEST. A large variety of soluble protein or peptide factors that may contribute to the capacity of fetal serum to drive cell growth indefinitely were observed such as platelet-derived growth factor. The interleukins were undetectable in previous studies using single step protein or peptides extractions with micro electrospray ionization. However, interleukin-16 isoform X1 (IL16), interleukin-17D IL were strongly detected here with multiple step-wise fractionation and nano LC-ESI-MS/MS. Since fetal serum or platelet derived factors may be used to expand cultured cells, the specific increase in some growth factor proteins, including in platelet derived growth factors, was consistent with the transformative effects of the fetal serum. The apparent increase in growth factors, cytokines, chemokines, interleukin, or tumor necrosis factors may be consistent with the existence of factors in the fetal serum that drive the immortal replication of RAW 264.7 and other cells lines [12] and may permit the perfection of synthetic cell media that will prevent the contamination of secreted cellular proteins from culture media components in cell culture models of cancer [28], [29]. 


\subsection{Receptors and receptor signaling associated cellular and nuclear factors}

G protein receptors and receptor kinases as well as receptor associated enzymes, monomeric $\mathrm{G}$ proteins were observed in serum and might still play a role as co-receptors via protein-protein interactions outside of the cell [94]. Peptides mapping to overlapping tryptic peptides and sequences observed to multiple unique GPCR 98 variant that did not contain the transmembrane or cytosolic region may indicate the extracellular region of the receptor was shed from the cell surface by proteolytic activity and so the soluble receptor might not be functional in the conventional sense. While receptor fragments might be shed from the cell surface by proteolytic activity this pathway cannot explain the presence of intracellular receptor associated signaling factors. Cellular signaling proteins have been observed by many groups in human serum and plasma, and here are also observed in bovine serum and cannot be released by proteolytic action alone. It has suggested that secretion, or exosomes, may be responsible for the presence of apparently high concentrations of unexpected cellular proteins and nucleic acids in blood serum or plasma [85], [95].

\subsection{DNA and RNA binding proteins}

H2A Histone Family Member X (H2AFX) is associated with the Nijmegen Breakage Syndrome and Ataxia-Telangiectasia and the proliferation of cells in cancer [96]. Proteins such as bromodomains, PHD and Zinc finger domains [42] are known to bind DNA and/or RNA molecules that may influence the maintenance of the chromosomes and gene expression [97], [98]. 
The nuclear receptor for alpha-feto protein is a zinc finger DNA binding factor [99]. Cell free DNA exists in serum or plasma at $\mathrm{ng} / \mathrm{ml}$ concentrations [95], [100] and may remain bound to proteins such as histones, zinc fingers and transcription factors. The enriched presence of the CREB transcription factor links the MAPK and CAMK with AKT/HRAS growth pathway. It seems unlikely that such nuclear factors should be released by reticulocytes or enucleated red blood cells directly into a blood and so the source of these nucleic acid binding proteins in plasma is unclear. 


\subsection{CONCLUSION}

The overwhelming agreement between the entirely independent methods of protein fractionating by partition chromatography and digestion versus endogenous peptide extraction using organic solvents indicates that the level of type I error for protein identification by LC-ESI-MS/MS with a linear quadrupole ion trap is low. It appears that some of the proteins or peptides in blood might be cleaved from the surface of, or released from, white blood or red blood cells potentially as an artifact of collection. Fetal serum also contained high levels of alfa-feto protein, and fetal albumin as well as insulin, platelet derived and transforming growth factors that were consistent with the capacity to support indefinite cell proliferation. Unexpectedly, fetal serum also contained proteins associated with the AKT/HRAS growth pathways including cellular receptors, receptor associated enzymes and other signal transduction factors as well as transcription factors and DNA/RNA binding proteins were observed in fetal serum. The source of the apparently reproducible set of cellular proteins was not clear [101], but STRING analysis seems to indicate that the proteins may be participating in extracellular protein-protein or protein-nucleic acid interactions in circulation [85]. The combination of classical sample partition, random and independent sampling by LC-ESI-MS/MS with a sensitive, economical and robust linear ion trap, peptide identification from MS/MS spectra using SEQUEST or X!TANDEM with data filtering and storage in 64 bit SQL Server for statistical analysis with open source R was apparently sufficient to identify and compare some 12,000 different protein gene symbols from blood serum in a robust and inexpensive approach. It appeared that some as yet unknown fetal cells have released many proteins related to the AKT/HRAS growth pathway in the serum where their possible residual function(s), if any, were unclear. 


\section{APPENDICES}

Table A.1. Experimental treatment table. The data of all QA column extractions, organic extractions from ABS and FBS, and the data of all blank runs and column conditioning were collected by the Tandem Mass Spectrometry, and computed in the SQL server.

\begin{tabular}{|c|c|c|}
\hline Treatment & Count & TreatmentName \\
\hline 0 & & ProteinLibrary \\
\hline 1 & & BB_ABS_NaClExtraction_BOVINE_rep1 \\
\hline 2 & & BB_ABS_NaClExtraction_BOVINE_rep1_PSTY \\
\hline 3 & 64 & BB_ABS_NaClExtraction_BOVINE_rep2 \\
\hline 4 & & BB_ABS_NaClExtraction_BOVINE_rep2_PSTY \\
\hline 5 & 64 & BB_ABS_NaClExtraction_BOVINE_rep3 \\
\hline 6 & 64 & BB_ABS_NaClExtraction_BOVINE_rep3_PSTY \\
\hline 7 & 40 & BB_ABS_OrganicExtraction_BOVINE_rep1 \\
\hline 8 & 40 & BB_ABS_OrganicExtraction_BOVINE_rep1_PSTY \\
\hline 9 & 40 & BB_ABS_OrganicExtraction_BOVINE_REP2 \\
\hline 10 & 40 & BB_ABS_OrganicExtraction_BOVINE_REP2_PSTY \\
\hline 11 & 40 & BB_ABS_OrganicExtraction_BOVINE_rep3 \\
\hline 12 & 40 & BB_ABS_OrganicExtraction_BOVINE_rep3_PSTY \\
\hline 13 & 20 & BB_CTRL_BLANKS_BOVINE_REP1 \\
\hline 14 & 20 & BB_CTRL_Blanks_BOVINE_REP1_PSTY \\
\hline 15 & 20 & BB_CTRL_BLANKS_HUMAN_REP1 \\
\hline 16 & & BB_CTRL_BLANKS_HUMAN_REP1_PSTY \\
\hline 17 & 56 & BB_CTRL_CC_BOVINE_REP1 \\
\hline 18 & 56 & BB_CTRL_CC_BOVINE_REP1_PSTY \\
\hline 19 & 56 & BB_CTRL_CC_HUMAN_REP1 \\
\hline 20 & 42 & BB_CTRL_CC_HUMAN_REP1_PSTY \\
\hline 21 & 3500 & BB_CTRL_RNG_BOVINE_REP1 \\
\hline 22 & 3500 & BB_CTRL_RNG_BOVINE_REP1_PSTY \\
\hline 23 & 72 & BB_CTRL_TRP3_HUMAN_REP1 \\
\hline 24 & 54 & BB_CTRL_TRP3_HUMAN_REP1_PSTY \\
\hline 25 & 64 & BB_FBS_NaClExtraction_BOVINE_rep1 \\
\hline 26 & 64 & BB_FBS_NaClExtraction_BOVINE_rep1_PSTY \\
\hline 27 & 64 & BB_FBS_NaClExtraction_BOVINE_rep2 \\
\hline 28 & 64 & BB_FBS_NaClExtraction_BOVINE_rep2_PSTY \\
\hline 29 & 64 & BB_FBS_NaClExtraction_BOVINE_rep3 \\
\hline 30 & 64 & BB_FBS_NaClExtraction_BOVINE_rep3_PSTY \\
\hline 31 & 40 & BB_FBS_OrganicExtraction_BOVINE_rep1 \\
\hline 32 & 40 & BB_FBS_OrganicExtraction_BOVINE_rep1_PSTY \\
\hline 33 & 40 & BB_FBS_OrganicExtraction_BOVINE_REP2 \\
\hline 34 & 40 & BB_FBS_OrganicExtraction_BOVINE_REP2_PSTY \\
\hline 35 & 40 & BB_FBS_OrganicExtraction_BOVINE_rep3 \\
\hline 36 & 40 & BB_FBS_OrganicExtraction_BOVINE_rep3_PSTY \\
\hline
\end{tabular}


Table A.2. Precursor intensity of INS in $\log _{10}$ between treatments of ABS and FBS.

\begin{tabular}{|c|c|c|c|}
\hline & log10_Precursor_Intensity & Sd(mean) & Mean \\
\hline 1 & 4.853978 & 0.09069283 & 9 \\
\hline 2 & 4.884109 & 0.07600723 & 17 \\
\hline 3 & 6.137435 & NA & 1 \\
\hline 5 & 5.135398 & 0.29102713 & 4 \\
\hline 6 & 5.089139 & 0.15941548 & 7 \\
\hline 7 & 6.480922 & NA & 1 \\
\hline 8 & 5.505216 & NA & 1 \\
\hline 9 & 6.163147 & 0.11384392 & 2 \\
\hline 11 & 4.670567 & NA & 1 \\
\hline 12 & 4.670567 & NA & 1 \\
\hline 25 & 5.48388 & 0.22131844 & 8 \\
\hline 26 & 5.264823 & 0.18671255 & 13 \\
\hline 27 & 4.812131 & 0.12651844 & 6 \\
\hline 28 & 4.75955 & 0.16224421 & 10 \\
\hline 29 & 5.070476 & 0.12763632 & 10 \\
\hline 30 & 4.839104 & 0.10069634 & 21 \\
\hline 32 & 5.339887 & NA & 1 \\
\hline 33 & 4.850236 & 0.09479241 & 17 \\
\hline 34 & 4.804412 & 0.08244537 & 24 \\
\hline 35 & 5.173349 & 0.34666499 & 2 \\
\hline 36 & 5.520014 & NA & 1 \\
\hline
\end{tabular}




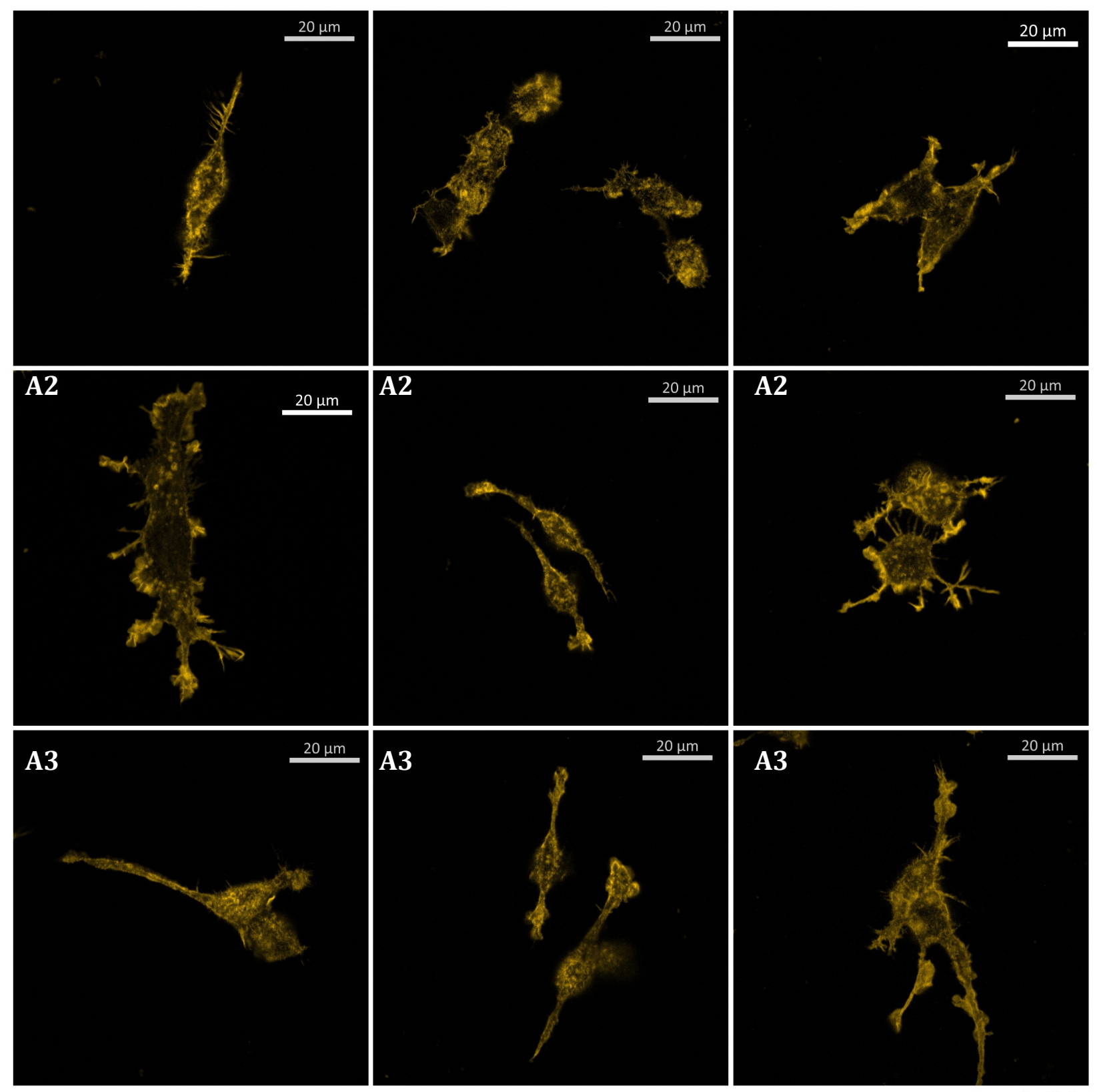

Figure B.1. The effect on the morphology of RAW cell 264.7 murine macrophages cultured in DMEM plus 5\% ABS and stained with rhodamine phallodin. The cells were cultured in three independent batches of ABS and observed to have dendritic shapes under a $63 \mathrm{X}$ magnification confocal microscope. Panels: A1, 3 different individual experiments from ABS batch 1; A2, 3 different individual experiments from ABS batch 2; A3, 3 different individual experiments from ABS batch 3. 


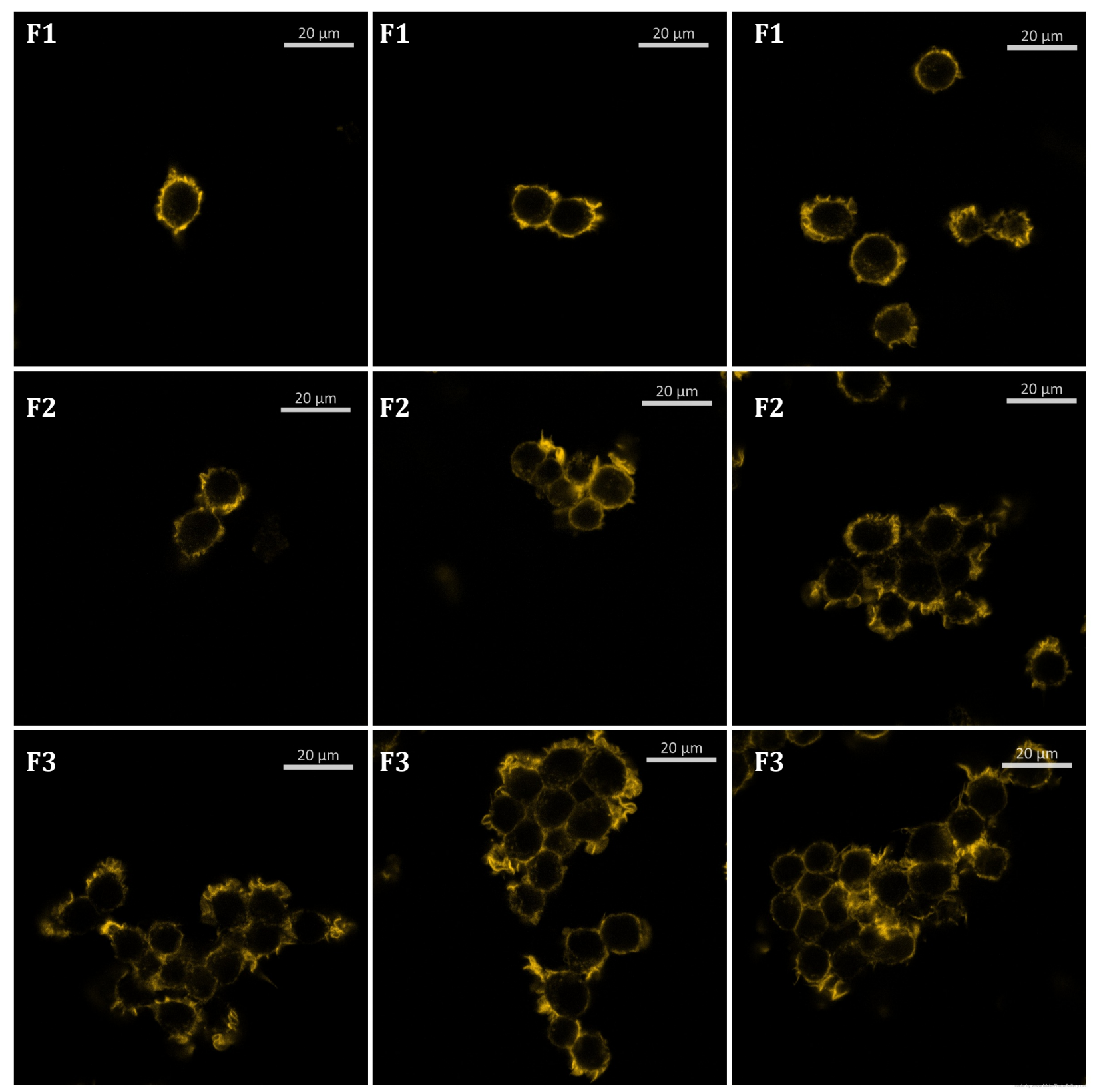

Figure B.2. The effect on the morphology of RAW cell 264.7 murine macrophages cultured in DMEM plus 5\% FBS and stained with rhodamine phallodin. The cells were cultured in three independent batches of FBS and observed to have rounded shapes under a $63 \mathrm{X}$ magnification confocal microscope. Panels: F1, 3 different individual experiments from FBS batch 1; F2, 3 different individual experiments from FBS batch 2; F3, 3 different individual experiments from FBS batch 3. 

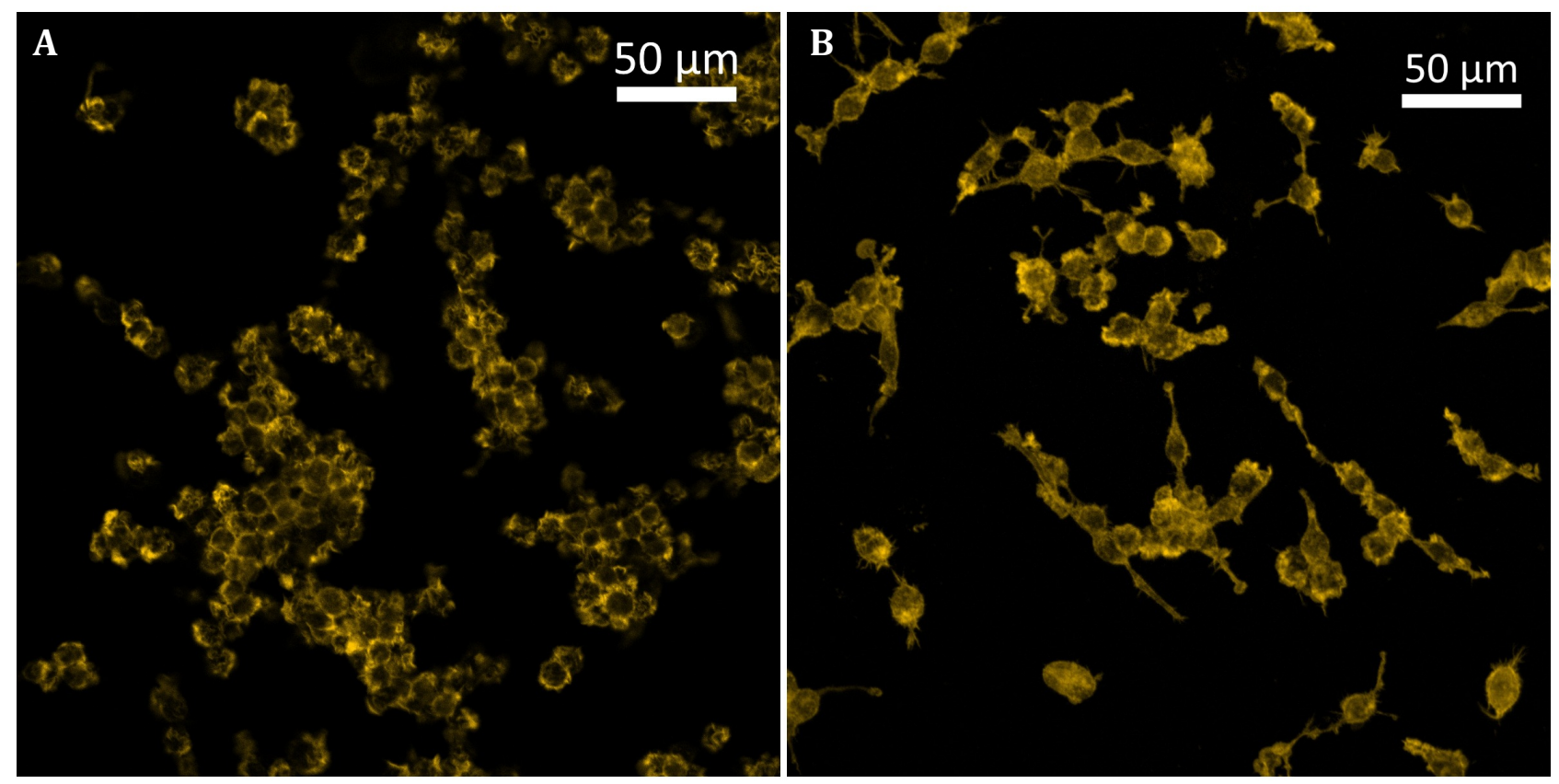

Figure B.3. The RAW cells cultured in the ABS/FBS were fixed with para-formaldehyde and stained with rhodamine phalloidin. The images were taken under a $20 \mathrm{X}$ magnification confocal microscope. Panels: A, cells grown in fetal serum that divided rapidly and piled onto each other; B, cells grown in adult serum that divided slowly and often died. 

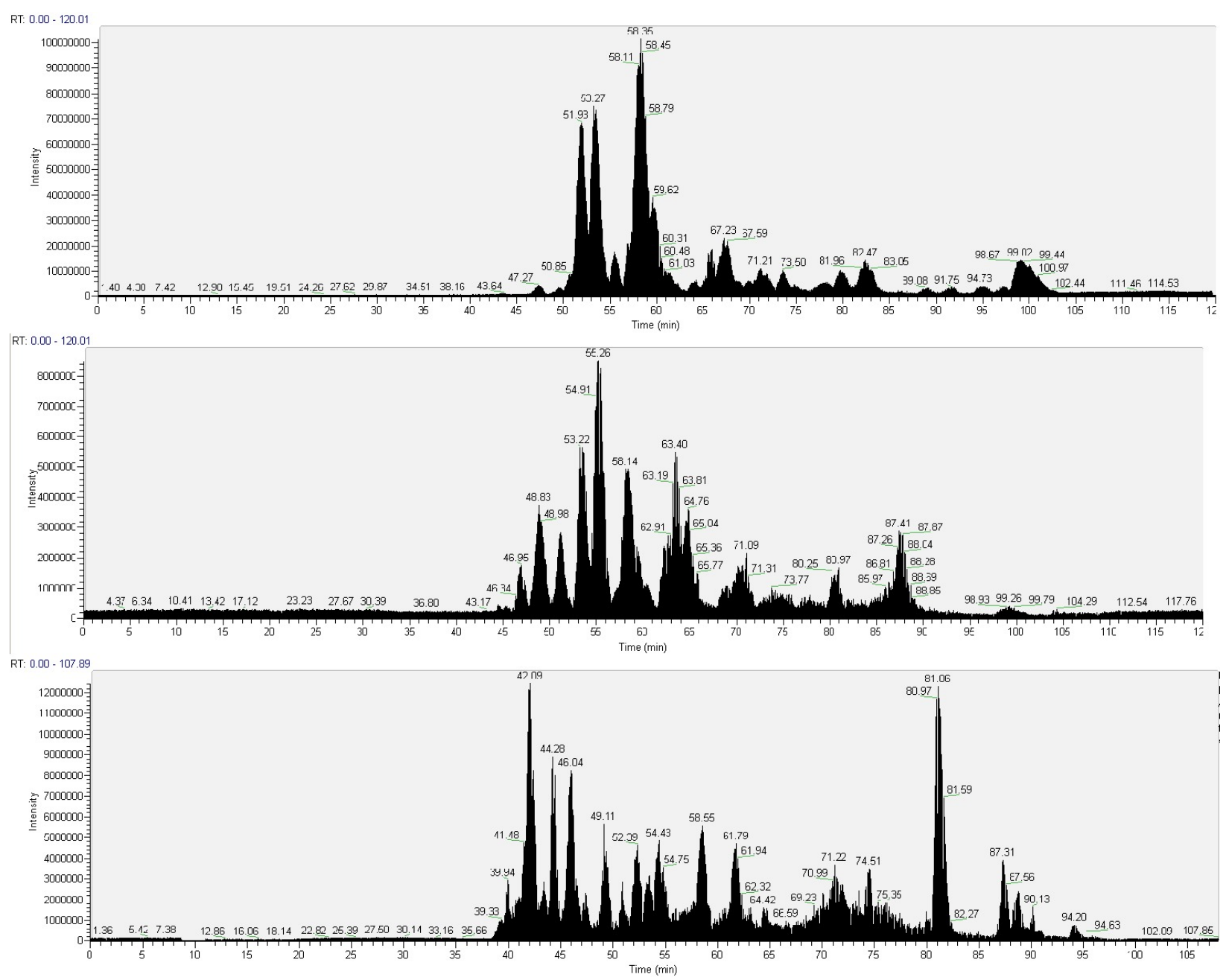

Figure B.4. Base-peak chromatograms of ABS sample collected over QA resin partition chromatography with $225 \mathrm{mM} \mathrm{NaCl}$ in tricine eluting buffer between 3 individual replicates. 

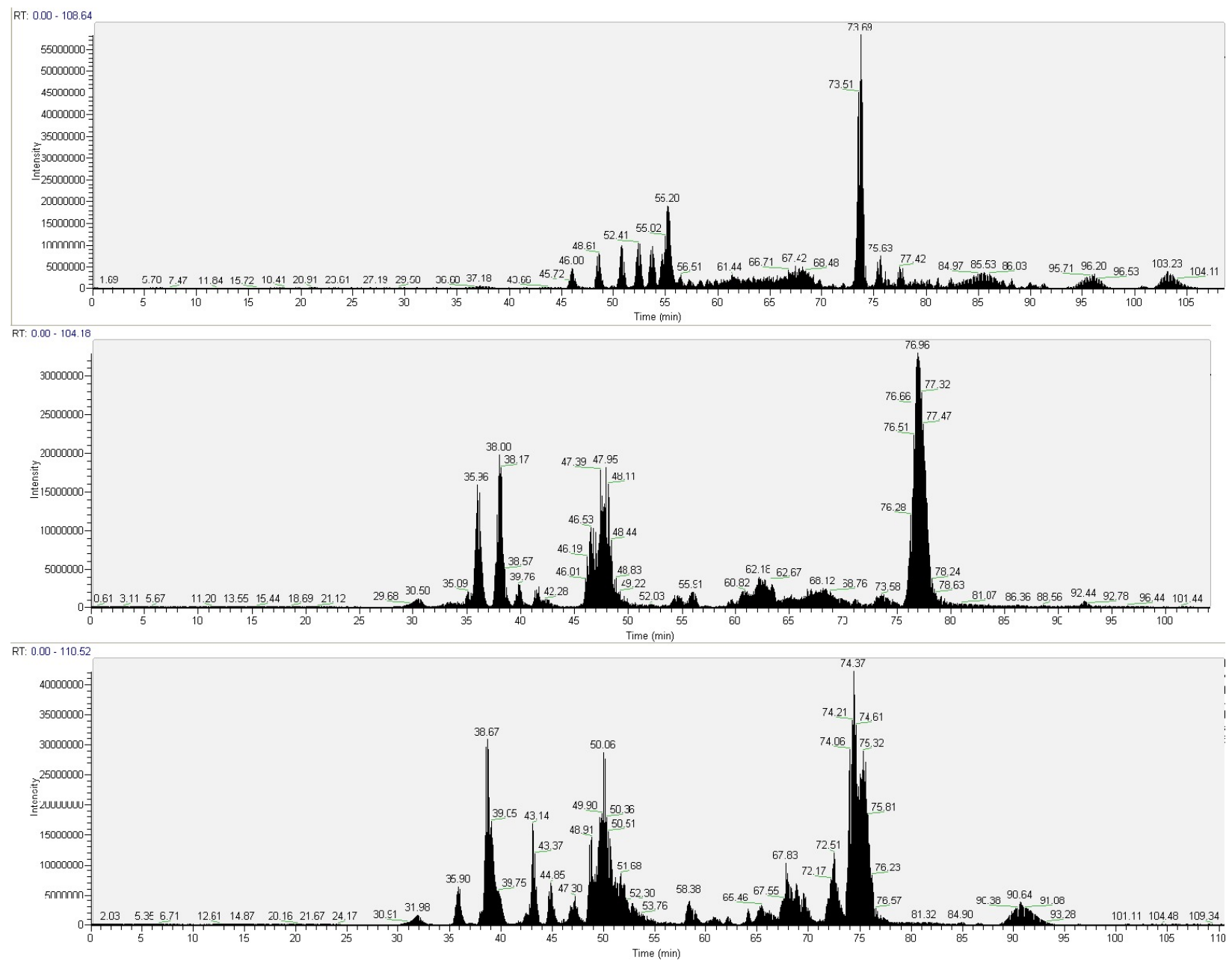

Figure B.5. Base-peak chromatograms of ABS sample collected over $40 \%$ acetonitrile organic extraction between 3 individual replicates. 


\section{REFERENCES}

[1] J. Adams, "The Proteome: Discovering the Structure and Function of Proteins," Nat. Educ., vol. 1, no. 3, p. 6, 2008.

[2] H. B. Vickery and C. L. A. Schmidt, "The history of the discovery of the amino acids," Chem. Rev., 1931.

[3] J. Marshall et al., "Human serum proteins preseparated by electrophoresis or chromatography followed by tandem mass spectrometry," J. Proteome Res., 2004.

[4] J. Dufresne et al., "The plasma peptidome.," Clin. Proteomics, vol. 15, p. 39, 2018.

[5] M. Johnson, "Fetal Bovine Serum," Mater. Methods, 2012.

[6] J. Fenn, M. Mann, C. Meng, S. Wong, and C. Whitehouse, "Electrospray ionization for mass spectrometry of large biomolecules," Science (80-. )., vol. 246, no. 4926, pp. 64-71, Oct. 1989.

[7] R. Craig and R. C. Beavis, "TANDEM: matching proteins with tandem mass spectra," Bioinformatics, vol. 20, no. 9, pp. 1466-1467, Jun. 2004.

[8] J. C. Schwartz, M. W. Senko, and J. E. . Syka, "A two-dimensional quadrupole ion trap mass spectrometer," J. Am. Soc. Mass Spectrom., vol. 13, no. 6, pp. 659-669, Jun. 2002.

[9] G. Gstraunthaler, "Alternatives to the use of fetal bovine serum: serum-free cell culture.," ALTEX, 2003.

[10] H. Lodish, B. Arnold, S. L. Zipursky, P. Matsudaira, D. Baltimore, and J. E. Darnell, "Growth of Animal Cells in Culture," in Molecular Cell Biology, 2000.

[11] J. E. Yu et al., "Potential use of adult bovine serum obtained during the slaughtering process as a biological reagent," Animal Cells Syst. (Seoul)., 2013.

[12] J. I. Jones, A. J. D’Ercole, C. Camacho-Hubner, and D. R. Clemmons, "Phosphorylation of insulin-like growth factor (IGF)-binding protein 1 in cell culture and in vivo: effects on affinity for IGF-I.," Proc. Natl. Acad. Sci., vol. 88, no. 17, pp. 7481-7485, Sep. 1991.

[13] L. Johansson, J. Klinth, O. Holmqvist, and S. Ohlson, "Platelet lysate: A replacement for fetal bovine serum in animal cell culture?," Cytotechnology, 2003.

[14] S. G. Ball, C. A. Shuttleworth, and C. M. Kielty, "Vascular endothelial growth factor can signal through platelet-derived growth factor receptors.," J. Cell Biol., vol. 177, no. 3, pp. 489-500, May 2007.

[15] T. J. Anderson, C. A. Lapp, M. A. Billman, and G. S. Schuster, "Effects of transforming growth factor-beta and platelet-derived growth factor on human gingival fibroblasts grown in serum-containing and serum-free medium.," J. Clin. Periodontol., vol. 25, no. 1, pp. 48-55, Jan. 1998.

[16] J. I. Heger et al., "Human serum alters cell culture behavior and improves spheroid formation in comparison to fetal bovine serum," Exp. Cell Res., 2018.

[17] S. Marino, J. G. Logan, D. Mellis, and M. Capulli, "Generation and culture of osteoclasts.," Bonekey Rep., vol. 3, p. 570, 2014.

[18] E. Bauman, P. L. Granja, and C. C. Barrias, "Fetal bovine serum-free culture of endothelial progenitor cells_-progress and challenges," Journal of Tissue Engineering and Regenerative Medicine. 2018.

[19] A. Honegger and R. E. Humbel, "Insulin-like growth factors I and II in fetal and adult bovine serum. Purification, primary structures, and immunological cross-reactivities," $J$. 
Biol. Chem., 1986.

[20] W. A. Ellis, E. F. Logan, and J. J. O’Brien, "Serum immunoglobulins in aborted and nonaborted bovine foetuses," Clin. Exp. Immunol., 1978.

[21] C. Y. Fang, C. C. Wu, C. L. Fang, W. Y. Chen, and C. L. Chen, "Long-term growth comparison studies of FBS and FBS alternatives in six head and neck cell lines," PLoS One, 2017.

[22] A. Kikuchi, H. Taira, T. Tsuruta, M. Hayashi, and K. Kataoka, "Adsorbed serum protein mediated adhesion and growth behavior of bovine aortic endothelial cells on polyamine graft copolymer surfaces," J. Biomater. Sci. Polym. Ed., 1996.

[23] K. O'Donoghue and N. M. Fisk, "Fetal stem cells," Best Practice and Research: Clinical Obstetrics and Gynaecology. 2004.

[24] R. Prywes, A. Dutta, J. A. Cromlish, and R. G. Roeder, "Phosphorylation of serum response factor, a factor that binds to the serum response element of the c-FOS enhancer.," Proc. Natl. Acad. Sci., 2006.

[25] J. M. MacSween, K. Rajaraman, R. Rajaraman, and R. A. Fox, "Macrophage migration inhibition factor (MIF): reducing the variables.," J. Immunol. Methods, vol. 52, no. 1, pp. 127-36, 1982.

[26] T. T. PUCK, S. J. CIECIURA, and A. ROBINSON, "Genetics of somatic mammalian cells. III. Long-term cultivation of euploid cells from human and animal subjects.," J. Exp. Med., 1958.

[27] D. Iyer et al., "Serum response factor MADS box serine -162 phosphorylation switches proliferation and myogenic gene programs," Proc. Natl. Acad. Sci., 2006.

[28] D. Kwon et al., "The effect of fetal bovine serum (FBS) on efficacy of cellular reprogramming for induced pluripotent stem cell (iPSC) generation," Cell Transplant., 2016.

[29] T. Burnouf, H. A. Goubran, T. M. Chen, K. L. Ou, M. El-Ekiaby, and M. Radosevic, "Blood-derived biomaterials and platelet growth factors in regenerative medicine," Blood Rev., 2013.

[30] C. Li, F. Wang, and L. Liu, "[Ultra-high performance liquid chromatography-mass spectrometry for analysis of newborn and fetal bovine serum components].," Nan Fang Yi Ke Da Xue Xue Bao, vol. 34, no. 5, pp. 751-3, May 2014.

[31] J. M. Castellano et al., "Human umbilical cord plasma proteins revitalize hippocampal function in aged mice," Nature, 2017.

[32] D. F. Hunt, J. R. Yates, J. Shabanowitz, S. Winston, and C. R. Hauer, "Protein sequencing by tandem mass spectrometry.," Proc. Natl. Acad. Sci. U. S. A., 1986.

[33] A. L. McCormack et al., "Direct Analysis and Identification of Proteins in Mixtures by LC/MS/MS and Database Searching at the Low-Femtomole Level," Anal. Chem., 1997.

[34] M. P. Washburn, D. Wolters, and J. R. Yates, "Large-scale analysis of the yeast proteome by multidimensional protein identification technology," Nat. Biotechnol., 2001.

[35] J. Link, " Direct analysis of large protein complexes using mass spectrometry.," Nat. Biotechnol., 1999.

[36] S. . F. Tsunoda, M.; Nonaka, "Determination of methylated arginines by columnswitching high-performance liquid chromatography -fluorescence detection," Analyst, vol. 130, no. 10, pp. 1410-1413, 2005.

[37] A. K. Florentinus, P. Bowden, G. Sardana, E. P. Diamandis, and J. G. Marshall, "Identification and quantification of peptides and proteins secreted from prostate epithelial 
cells by unbiased liquid chromatography tandem mass spectrometry using goodness of fit and analysis of variance," J. Proteomics, vol. 75, no. 4, pp. 1303-1317, Feb. 2012.

[38] J. Dufresne, A. Florentinus-Mefailoski, P. Bowden, and J. G. Marshall, "A method for the extraction of the endogenous tryptic peptides (peptidome) from human EDTA plasma," Anal. Biochem., vol. 549, pp. 188-196, May 2018.

[39] M. Tucholska et al., "Human serum proteins fractionated by preparative partition chromatography prior to LC-ESI-MS/MS," J. Proteome Res., 2009.

[40] G. Sardana, J. Marshall, and E. P. Diamandis, "Discovery of candidate tumor markers for prostate cancer via proteomic analysis of cell culture-conditioned medium.," Clin. Chem., vol. 53, no. 3, pp. 429-37, Mar. 2007.

[41] M. Tucholska et al., "Endogenous peptides from biophysical and biochemical fractionation of serum analyzed by matrix-assisted laser desorption/ionization and electrospray ionization hybrid quadrupole time-of-flight," Anal. Biochem., vol. 370, no. 2, pp. 228-245, Nov. 2007.

[42] M. Tucholska, A. Florentinus, D. Williams, and J. G. Marshall, “The endogenous peptides of normal human serum extracted from the acetonitrile-insoluble precipitate using modified aqueous buffer with analysis by LC-ESI-Paul ion trap and Qq-TOF," $J$. Proteomics, vol. 73, no. 6, pp. 1254-1269, Apr. 2010.

[43] X. Han, A. Aslanian, J. R. Yates, and III, "Mass spectrometry for proteomics.," Curr. Opin. Chem. Biol., vol. 12, no. 5, pp. 483-90, Oct. 2008.

[44] E. P. Diamandis, "Mass Spectrometry as a Diagnostic and a Cancer Biomarker Discovery Tool," Mol. Cell. Proteomics, 2004.

[45] M. Lu et al., "Proteomics and mass spectrometry for cancer biomarker discovery.," Biomark. Insights, vol. 2, pp. 347-60, Oct. 2007.

[46] J. Dufresne et al., "The plasma peptides of ovarian cancer," Clin. Proteomics, vol. 15, no. 1, p. 41, Dec. 2018.

[47] Y. V Karpievitch, A. D. Polpitiya, G. A. Anderson, R. D. Smith, and A. R. Dabney, "Liquid Chromatography Mass Spectrometry-Based Proteomics: Biological and Technological Aspects.," Ann. Appl. Stat., vol. 4, no. 4, pp. 1797-1823, 2010.

[48] W. M. A. Niessen and D. Falck, "Introduction to Mass Spectrometry, a Tutorial," 2015.

[49] L. Sleno and D. A. Volmer, "Ion activation methods for tandem mass spectrometry," Journal of Mass Spectrometry. 2004.

[50] "Finnigan ${ }^{\text {TM }}$ LTQ ${ }^{\text {TM }}$ Getting Started 97055-97012 Revision A," 2003.

[51] T. E. Angel et al., "Mass spectrometry-based proteomics: existing capabilities and future directions.," Chem. Soc. Rev., vol. 41, no. 10, pp. 3912-28, May 2012.

[52] P. Lössl, M. van de Waterbeemd, and A. J. Heck, "The diverse and expanding role of mass spectrometry in structural and molecular biology.," EMBO J., vol. 35, no. 24, pp. 2634-2657, 2016.

[53] G. Mitulović and K. Mechtler, "HPLC techniques for proteomics analysis - A short overview of latest developments," Briefings in Functional Genomics and Proteomics. 2006.

[54] C. T. Mant, Z. Jiang, B. E. Boyes, and R. S. Hodges, “An improved approach to hydrophilic interaction chromatography of peptides: Salt gradients in the presence of high isocratic acetonitrile concentrations," J. Chromatogr. A, 2013.

[55] O. Chertov et al., "Organic solvent extraction of proteins and peptides from serum as an effective sample preparation for detection and identification of biomarkers by mass 
spectrometry," Proteomics, 2004.

[56] J. B. Fenn, M. Mann, C. K. Meng, S. F. Wong, and C. M. Whitehouse, "Electrospray ionization-principles and practice," Mass Spectrom. Rev., vol. 9, no. 1, pp. 37-70, Jan. 1990.

[57] A. I. Nesvizhskii, A. Keller, E. Kolker, and R. Aebersold, "A statistical model for identifying proteins by tandem mass spectrometry.," Anal. Chem., 2003.

[58] J. C. Howard, A. Florentinus-Mefailoski, P. Bowden, W. Trimble, S. Grinstein, and J. G. Marshall, "OxLDL receptor chromatography from live human U937 cells identifies SYK(L) that regulates phagocytosis of oxLDL," Anal. Biochem., 2016.

[59] A. Florentinus-Mefailoski and J. G. Marshall, "Pyridoxamine-5-phosphate enzyme-linked immune mass spectrometric assay substrate for linear absolute quantification of alkaline phosphatase to the yoctomole range applied to prostate specific antigen," Anal. Chem., 2014.

[60] J. Dufresne, A. Florentinus-Mefailoski, J. Ajambo, A. Ferwa, P. Bowden, and J. Marshall, "Random and independent sampling of endogenous tryptic peptides from normal human EDTA plasma by liquid chromatography micro electrospray ionization and tandem mass spectrometry," Clin. Proteomics, vol. 14, no. 1, p. 41, Dec. 2017.

[61] J. Dufresne, A. Florentinus-Mefailoski, P.-H. Zhu, P. Bowden, and J. G. Marshall, "Reevaluation of the rabbit myosin protein standard used to create the empirical statistical model for decoy library searching," Anal. Biochem., vol. 560, pp. 39-49, Nov. 2018.

[62] P. Bowden, T. Thavarajah, P. Zhu, M. McDonell, H. Thiele, and J. G. Marshall, "Quantitative Statistical Analysis of Standard and Human Blood Proteins from Liquid Chromatography, Electrospray Ionization, and Tandem Mass Spectrometry," J. Proteome Res., vol. 11, no. 4, pp. 2032-2047, Apr. 2012.

[63] P. Zhu, P. Bowden, M. Tucholska, and J. G. Marshall, "Chi-square comparison of tryptic peptide-to-protein distributions of tandem mass spectrometry from blood with those of random expectation," Anal. Biochem., vol. 409, no. 2, pp. 189-194, Feb. 2011.

[64] P. Zhu, P. Bowden, M. Tucholska, D. Zhang, and J. G. Marshall, "Peptide-to-protein distribution versus a competition for significance to estimate error rate in blood protein identification," Anal. Biochem., vol. 411, no. 2, pp. 241-253, Apr. 2011.

[65] P. Bowden, R. Beavis, and J. Marshall, "Tandem mass spectrometry of human tryptic blood peptides calculated by a statistical algorithm and captured by a relational database with exploration by a general statistical analysis system.," J. Proteomics, vol. 73, no. 1, pp. 103-11, Nov. 2009.

[66] J. R. Yates, J. K. Eng, A. L. McCormack, and D. Schieltz, "Method to correlate tandem mass spectra of modified peptides to amino acid sequences in the protein database.," Anal. Chem., vol. 67, no. 8, pp. 1426-36, Apr. 1995.

[67] E. F. Codd, "A relational model of data for large shared data banks. 1970.," MD. Comput., vol. 15, no. 3, pp. 162-6.

[68] O. Uysal, T. Sevimli, M. Sevimli, S. Gunes, and A. Eker Sariboyaci, "Cell and Tissue Culture: The Base of Biotechnology," Omi. Technol. Bio-Engineering, pp. 391-429, Jan. 2018.

[69] A. R. Baydoun, Cell culture techniques. 2005.

[70] B. Taciak et al., "Evaluation of phenotypic and functional stability of RAW 264.7 cell line through serial passages," PLoS One, vol. 13, no. 6, p. e0198943, Jun. 2018.

[71] G. Melino, E. Candi, and P. M. Steinert, "Assays for Transglutaminases in Cell Death," 
Methods Enzymol., vol. 322, pp. 433-472, Jan. 2000.

[72] H. Frickmann, E. Schröpfer, and G. Dobler, "Actin assessment in addition to specific immuno-fluorescence staining to demonstrate rickettsial growth in cell culture.," Eur. $J$. Microbiol. Immunol. (Bp)., vol. 3, no. 3, pp. 198-203, Sep. 2013.

[73] A. J. Link and J. LaBaer, "Solution protein digest.," Cold Spring Harb. Protoc., vol. 2011, no. 2, p. pdb.prot5569, Feb. 2011.

[74] H. Schägger and G. von Jagow, "Tricine-sodium dodecyl sulfate-polyacrylamide gel electrophoresis for the separation of proteins in the range from 1 to $100 \mathrm{kDa}$," Anal. Biochem., vol. 166, no. 2, pp. 368-379, Nov. 1987.

[75] J. M. Chick et al., "A mass-tolerant database search identifies a large proportion of unassigned spectra in shotgun proteomics as modified peptides," Nat. Biotechnol., vol. 33, no. 7, pp. 743-749, Jul. 2015.

[76] P. Bowden, V. Pendrak, P. Zhu, and J. G. Marshall, "Meta sequence analysis of human blood peptides and their parent proteins.," J. Proteomics, vol. 73, no. 6, pp. 1163-75, Apr. 2010.

[77] A. K. Florentinus, A. Jankowski, V. Petrenko, P. Bowden, and J. G. Marshall, "The Fc receptor-cytoskeleton complex from human neutrophils," J. Proteomics, vol. 75, no. 2, pp. 450-468, Dec. 2011.

[78] C. von Mering et al., "STRING: known and predicted protein-protein associations, integrated and transferred across organisms," Nucleic Acids Res., vol. 33, no. Database issue, pp. D433-D437, Dec. 2004.

[79] S. Ghosh, S. Gepstein, J. J. Heikkila, and E. B. Dumbroff, "Use of a scanning densitometer or an ELISA plate reader for measurement of nanogram amounts of protein in crude extracts from biological tissues," Anal. Biochem., vol. 169, no. 2, pp. 227-233, Mar. 1988.

[80] T. Yao and Y. Asayama, "Animal-cell culture media: History, characteristics, and current issues," Reprod. Med. Biol., vol. 16, no. 2, pp. 99-117, Apr. 2017.

[81] B. Xin et al., "Critical role of Myc activation in mouse hepatocarcinogenesis induced by the activation of AKT and RAS pathways," Oncogene, vol. 36, no. 36, pp. 5087-5097, Sep. 2017.

[82] P. Zhu et al., "Comparison of protein expression lists from mass spectrometry of human blood fluids using exact peptide sequences versus BLAST," Clin. Proteomics, vol. 2, no. 3-4, pp. 185-203, Dec. 2006.

[83] J. N. Adkins et al., "Toward a human blood serum proteome: analysis by multidimensional separation coupled with mass spectrometry.," Mol. Cell. Proteomics, vol. 1, no. 12, pp. 947-55, Dec. 2002.

[84] G. S. Omenn et al., "Overview of the HUPO Plasma Proteome Project: Results from the pilot phase with 35 collaborating laboratories and multiple analytical groups, generating a core dataset of 3020 proteins and a publicly-available database," Proteomics, vol. 5, no. 13, pp. 3226-3245, Aug. 2005.

[85] J. Marshall, P. Bowden, J. C. Schmit, and F. Betsou, "Creation of a federated database of blood proteins: a powerful new tool for finding and characterizing biomarkers in serum," Clin. Proteomics, vol. 11, no. 1, p. 3, Dec. 2014.

[86] J. Marshall et al., "Involvement of Cytosolic Phospholipase $\mathrm{A}_{2}$ and Secretory Phospholipase $\mathrm{A}_{2}$ in Arachidonic Acid Release from Human Neutrophils," J. Immunol., vol. 164, no. 4, pp. 2084-2091, Feb. 2000. 
[87] L. Senzel, D. V Gnatenko, and W. F. Bahou, "The platelet proteome.," Curr. Opin. Hematol., vol. 16, no. 5, pp. 329-33, Sep. 2009.

[88] D. Cervi et al., "Platelet-associated PF-4 as a biomarker of early tumor growth," Blood, vol. 111, no. 3, pp. 1201-1207, Oct. 2007.

[89] L. R. Purves, M. Macnab, and I. Bersohn, "Serum alpha-feto-protein. I. Immunodiffusion and immuno-assay results in cases of primary cancer of the liver.," S. Afr. Med. J., vol. 42, no. 42, pp. 1138-41, Nov. 1968.

[90] A. Adinolfi, M. Adinolfi, and Lessof, "Alpha-feto-protein during development and in disease.," J. Med. Genet., vol. 12, no. 2, pp. 138-51, Jun. 1975.

[91] G. J. Mizejewski, "The alpha-fetoprotein third domain receptor binding fragment: in search of scavenger and associated receptor targets," J. Drug Target., vol. 23, no. 6, pp. 538-551, Jul. 2015.

[92] M. P. Laderoute and L. M. Pilarski, "The inhibition of apoptosis by alpha-fetoprotein (AFP) and the role of AFP receptors in anti-cellular senescence.," Anticancer Res., vol. 14 , no. 6B, pp. 2429-38.

[93] S. Wang, Z. Zou, X. Luo, Y. Mi, H. Chang, and D. Xing, "LRH1 enhances cell resistance to chemotherapy by transcriptionally activating MDC1 expression and attenuating DNA damage in human breast cancer," Oncogene, vol. 37, no. 24, pp. 3243-3259, Jun. 2018.

[94] M. J. Jimenez-Dalmaroni et al., "Soluble CD36 Ectodomain Binds Negatively Charged Diacylglycerol Ligands and Acts as a Co-Receptor for TLR2," PLoS One, vol. 4, no. 10, p. e7411, Oct. 2009.

[95] J. Aucamp, A. J. Bronkhorst, C. P. S. Badenhorst, and P. J. Pretorius, "The diverse origins of circulating cell-free DNA in the human body: a critical re-evaluation of the literature," Biol. Rev., vol. 93, no. 3, pp. 1649-1683, Aug. 2018.

[96] X. Liu et al., "Insulin-like growth factor-1 receptor knockdown enhances radiosensitivity via the HIF-1 $\alpha$ pathway and attenuates ATM/H2AX/53BP1 DNA repair activation in human lung squamous carcinoma cells," Oncol. Lett., vol. 16, no. 1, pp. 1332-1340, May 2018.

[97] F. M. J. Jacobs et al., “An evolutionary arms race between KRAB zinc-finger genes ZNF91/93 and SVA/L1 retrotransposons," Nature, vol. 516, no. 7530, pp. 242-245, Dec. 2014.

[98] M. Unoki, J. Okutsu, and Y. Nakamura, "Identification of a novel human gene, ZFP91, involved in acute myelogenous leukemia.," Int. J. Oncol., vol. 22, no. 6, pp. 1217-23, Jun. 2003.

[99] Z. Xie et al., "Zinc finger protein ZBTB20 is a key repressor of alpha-fetoprotein gene transcription in liver," Proc. Natl. Acad. Sci., vol. 105, no. 31, pp. 10859-10864, Aug. 2008.

[100] Y. M. D. Lo et al., "Maternal Plasma DNA Sequencing Reveals the Genome-Wide Genetic and Mutational Profile of the Fetus," Sci. Transl. Med., vol. 2, no. 61, pp. 61ra9161ra91, Dec. 2010.

[101] C. Théry, L. Zitvogel, and S. Amigorena, "Exosomes: composition, biogenesis and function," Nat. Rev. Immunol., vol. 2, no. 8, pp. 569-579, Aug. 2002. 